\title{
The Current State of Additive Manufacturing in Wind Energy Systems
}

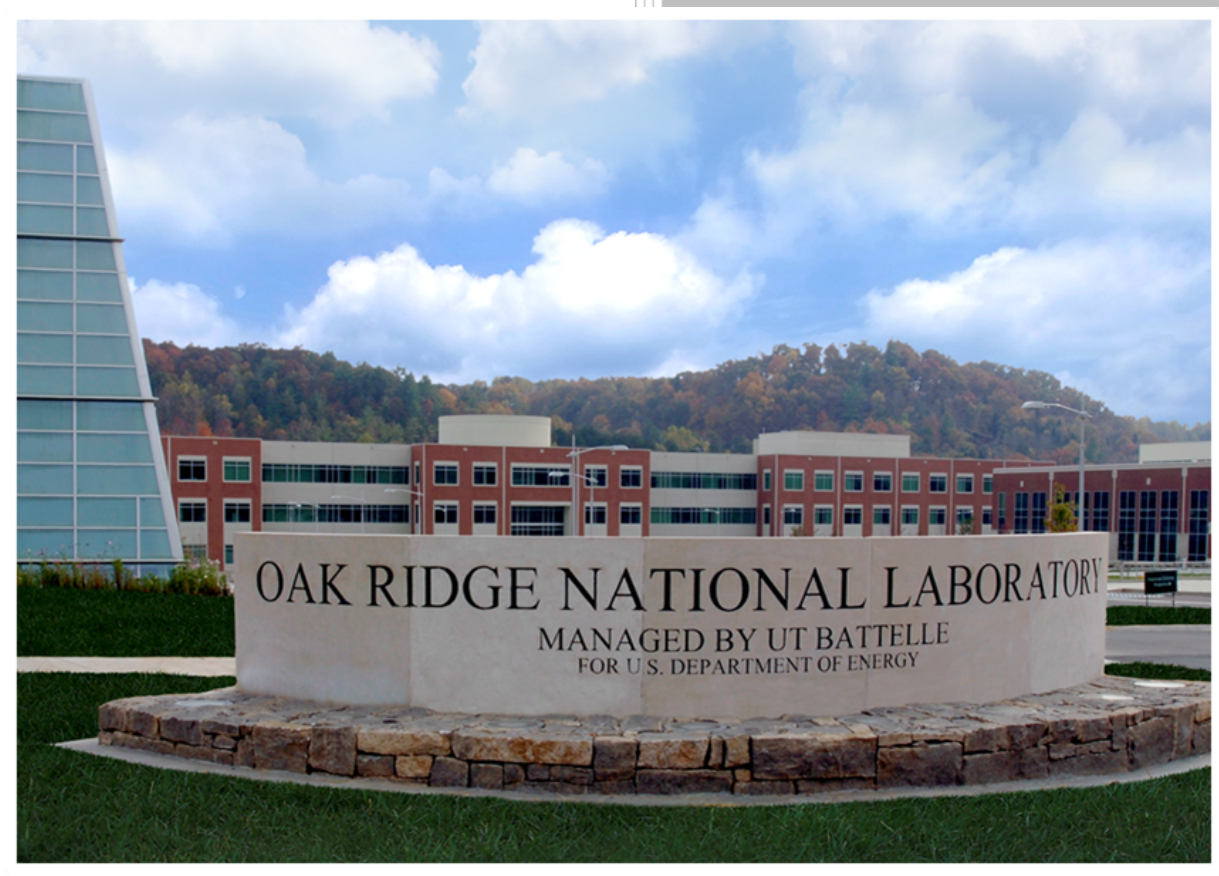

Brian Post

Bradley Richardson

Sierra Palmer

Lonnie Love

Dominic Lee

Parthiv Kurup

Timothy Remo

Dale Scott Jenne

Margaret Mann

Date: December 2017 


\title{
DOCUMENT AVAILABILITY
}

Reports produced after January 1, 1996, are generally available free via US Department of Energy (DOE) SciTech Connect.

Website http://www.osti.gov/scitech/

Reports produced before January 1, 1996, may be purchased by members of the public from the following source:

\author{
National Technical Information Service \\ 5285 Port Royal Road \\ Springfield, VA 22161 \\ Telephone 703-605-6000 (1-800-553-6847) \\ TDD 703-487-4639 \\ Fax 703-605-6900 \\ E-mail info@ntis.gov \\ Website http://www.ntis.gov/help/ordermethods.aspx
}

Reports are available to DOE employees, DOE contractors, Energy Technology Data Exchange representatives, and International Nuclear Information System representatives from the following source:

Office of Scientific and Technical Information

PO Box 62

Oak Ridge, TN 37831

Telephone 865-576-8401

Fax 865-576-5728

E-mail reports@osti.gov

Website http://www.osti.gov/contact.html

This report was prepared as an account of work sponsored by an
agency of the United States Government. Neither the United States
Government nor any agency thereof, nor any of their employees, makes
any warranty, express or implied, or assumes any legal liability or
responsibility for the accuracy, completeness, or usefulness of any
information, apparatus, product, or process disclosed, or represents that
its use would not infringe privately owned rights. Reference herein to
any specific commercial product, process, or service by trade name,
trademark, manufacturer, or otherwise, does not necessarily constitute
or imply its endorsement, recommendation, or favoring by the United
States Government or any agency thereof. The views and opinions of
authors expressed herein do not necessarily state or reflect those of the
United States Government or any agency thereof.


ORNL Wind Energy Technologies Program

The Current State of Additive Manufacturing in Wind Energy Systems

\author{
Author(s) \\ Brian Post (ORNL) \\ Bradley Richardson (ORNL) \\ Sierra Palmer (ORNL) \\ Lonnie Love (ORNL) \\ Dominic Lee (ORNL) \\ Parthiv Kurup (NREL) \\ Dale Scott Jenne (NREL) \\ Timothy Remo (NREL) \\ Margaret Mann (NREL)
}


December 2017

Prepared by

OAK RIDGE NATIONAL LABORATORY

Oak Ridge, TN 37831-6283

managed by

UT-BATTELLE, LLC

for the

US DEPARTMENT OF ENERGY

WIND ENERGY TECHNOLOGIES OFFICE

under contract DE-AC05-00OR22725 



\section{CONTENTS}

\section{CONTENTS}

Executive Summary

1. REVIEW OF ADDITIVE MANUFACTURING (AM) TECHNOLOGIES

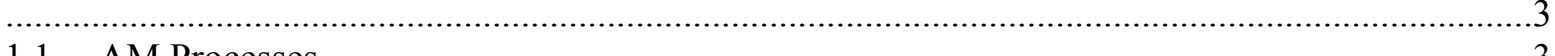

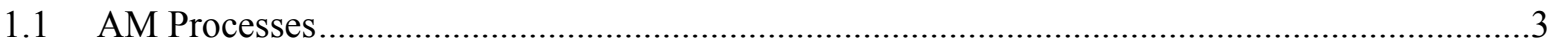

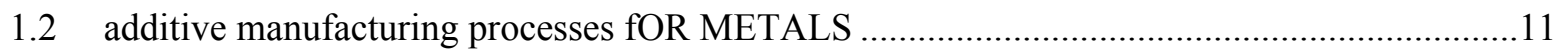

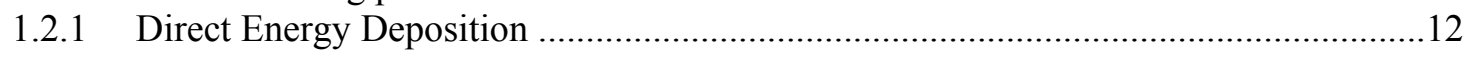

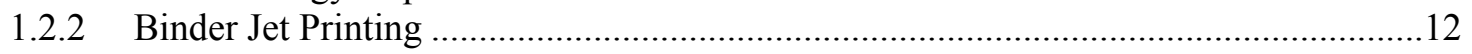

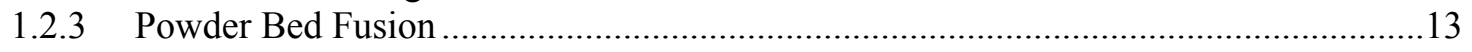

1.3 AM PROCESSES FOR POLYMER-BASED MANUFACTURING …...............................14

1.3.1 Vat Photopolymerization ................................................................................. 14

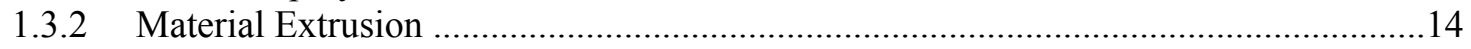

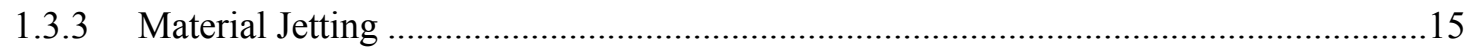

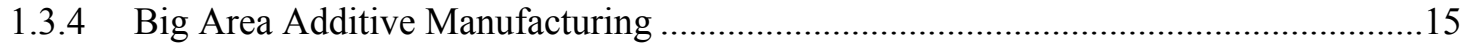

1.4 HISTORICAL AND CURRENT APPLICATIONS OF AM.............................................17

2. ECONOMICS OF ADDITIVE MANUFACTURING

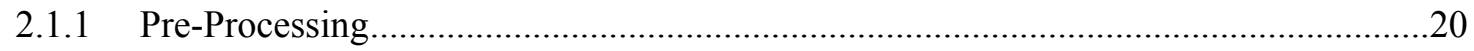

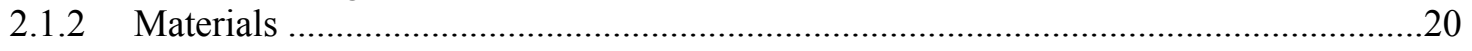

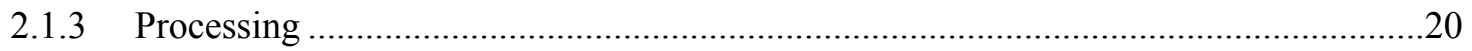

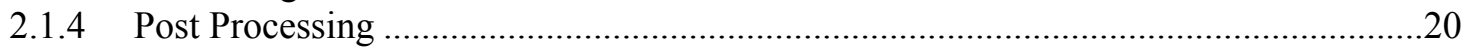

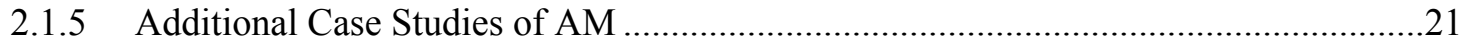

3. Potential APPLICATIONS OF CURRENT ADDITIVE MANUFACTURING SYsTEMS IN

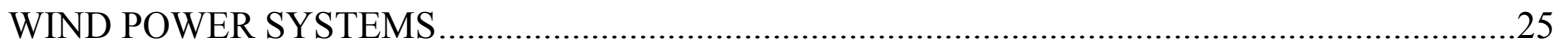

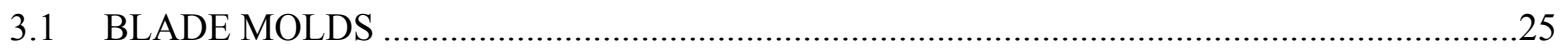

3.1.1 ORNL- TPI Scaled Wind Farm Technology (SWiFT) Facility Mold .........................26

3.1.2 Economics of Large-Scale AM Blade Mold Production ............................................28

3.1.3 Areas for Additional Economics and Supply Chain Analysis ....................................34

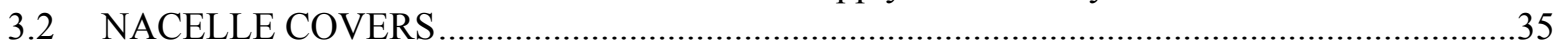

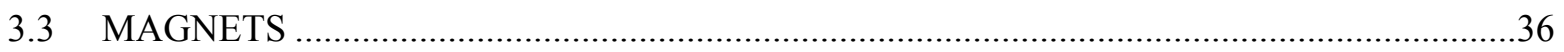

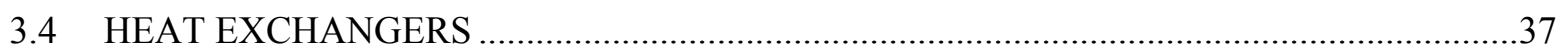

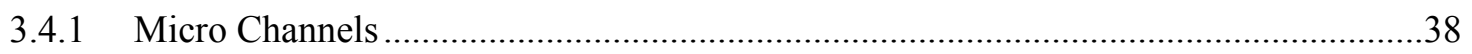

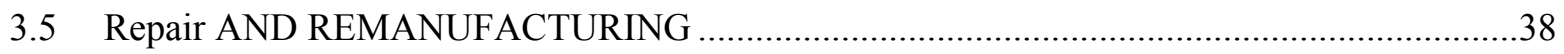

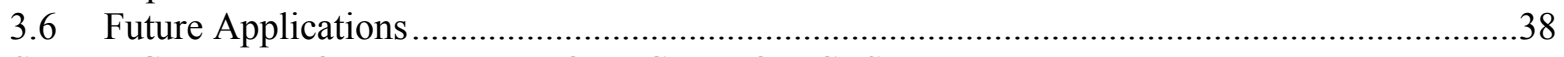

4. SYNERGY WITH OTHER WIND OFFICE PROJECTS

5. REFERENCES

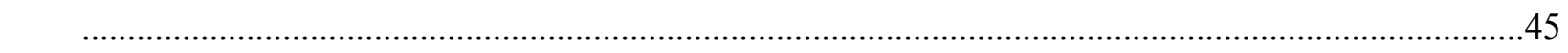

6. Appendix A. Data and Assumptions for AM Mold Cost Analysis ...........................50 


\section{ACRONYMS}

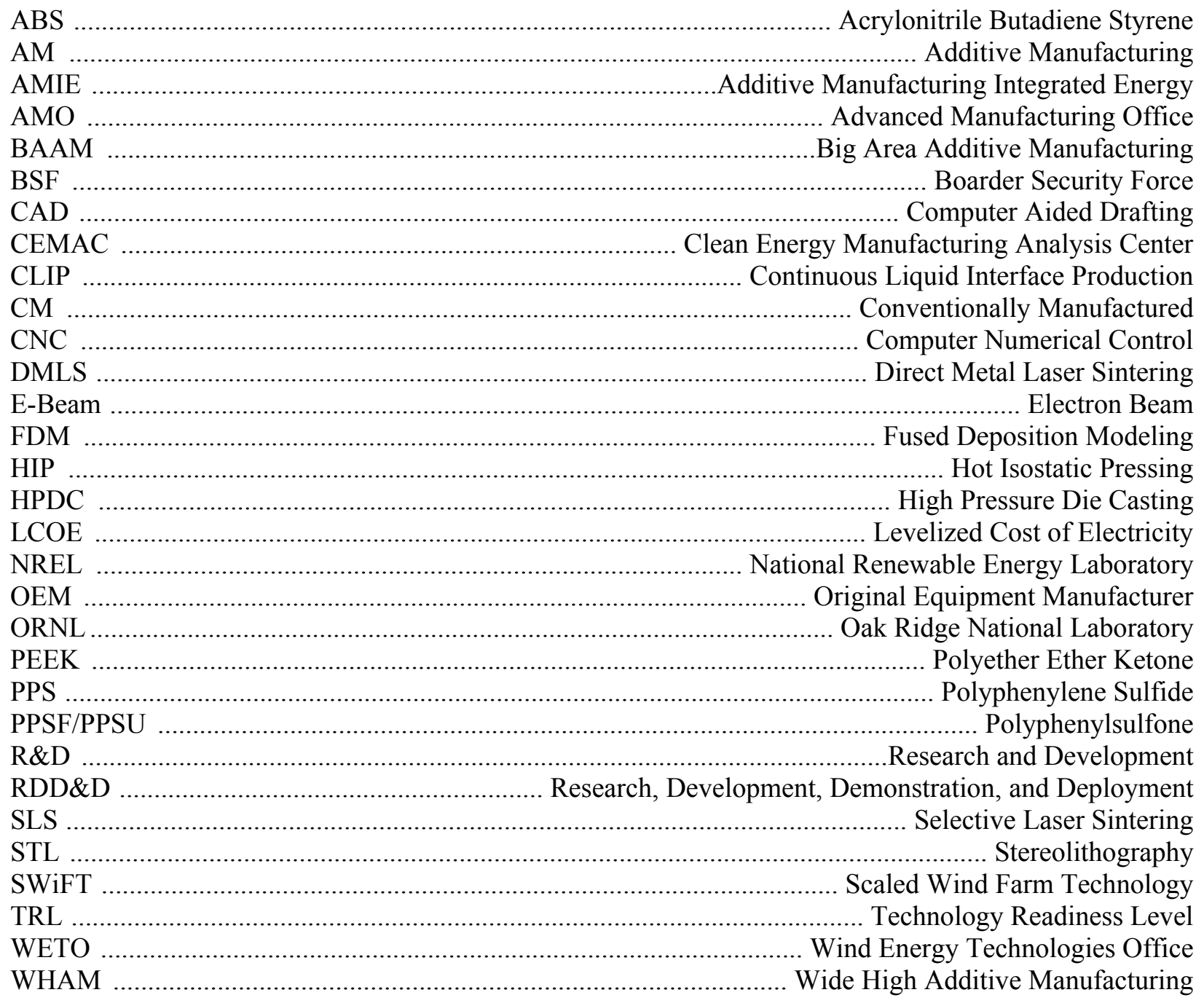




\section{EXECUTIVE SUMMARY}

Wind power is an inexhaustible form of energy that is being captured throughout the U.S. to power the engine of our economy. A robust, domestic wind industry promises to increase U.S. industry growth and competitiveness, strengthen U.S. energy security independence, and promote domestic manufacturing nationwide. As of 2016, 82GW of wind capacity had been installed, and wind power now provides more than $5.5 \%$ of the nation's electricity and supports more than 100,000 domestic jobs, including 500 manufacturing facilities in 43 States. To reach the U.S. Department of Energy's (DOE's) 2015 Wind Vision study scenario of wind power serving $35 \%$ of the nation's end-use demand by 2050 , significant advances are necessary in all areas of wind technologies and market. An area that can greatly impact the cost and rate of innovation in wind technologies is the use of advanced manufacturing, with one of the most promising areas being additive manufacturing (AM). Considering the tremendous promise offered by advanced manufacturing, it is the purpose of this report to identify the use of AM in the production and operation of wind energy systems. The report has been produced as a collaborative effort for the DOE Wind Energy Technology Office (WETO), between Oak Ridge National Laboratory (ORNL) and the National Renewable Energy Laboratory (NREL).

$\mathrm{AM}$, or 3D printing, is a fast-growing industry in which recent technological advances have expanded its use beyond rapid prototyping. AM encompasses techniques applicable across multiple material typesmost commonly polymers, metals, composites, and ceramics - that use computer-rendered designs to produce a near-net-shape part, layer by layer. There are many unique features that make AM a highly impactful manufacturing technology. These include:

- Reducing design-to-product life cycle;

- Directly printing raw materials into near-net-shape parts;

- Enhancing part properties through tailored materials and microstructure control;

- Ability to manufacture highly complexed shapes;

- Reducing the number of parts through clean-sheet designs;

- Integrating multiple parts into a single unit; and

- Incorporating multiple functionalities.

Advancements in AM techniques will continue to lower per-unit cost and enable advanced designs beyond the capabilities of current, conventionally manufactured components.

For the wind industry, current and research and development-level AM technologies have potential for considerable impact on the prototyping and manufacturing costs of wind energy tooling and components. In this study, several application areas for the use of AM for wind components that can be economically feasible, given the ongoing pace of AM technological advancements, are identified:

- Direct-print blade molds that have been studied in greater depth to understand the potential and costs;

- Functionalized nacelle covers;

- Permanent magnets; and

- Light-weight, high-efficiency heat exchangers.

In the future, AM technologies could enable on-site manufacturing of turbine parts as well as production of site-optimized components that are tailored to the unique wind and grid resources of a given location. With anticipated maturation of new technologies such as Macro 3-D Printing, high-capacity Wide High Additive Manufacturing, and Large-Scale Metal AM machines, it may someday be possible to affect a paradigm shift to directly print a variety of wind turbine components.

To further explore the efficacy of AM for wind energy systems, a more detailed analysis has been performed on AM wind turbine blade molds. Tooling, including molds, has been identified as a near-term application of AM that has been impacted by the present level of AM technology. The most impactful development in AM technology being the recent emergence of large-scale techniques such as Big Area 
Additive Manufacturing (BAAM). Since blade molds are expensive with long lead times for production and delivery, potential benefits in cost and time savings from AM are evident. Conventional manufacturing of wind turbine blade molds is a multi-step process where a plug in the shape of the blade is first subtractively manufactured from tooling resin and foam, which can take weeks to months to produce. Fiberglass layers that constitute the mold surface are then applied to the plug. Substantial lengths of heating wires that will provide the required temperatures for future blade production are manually embedded into the mold surface, which is finally attached to a steel frame that provides structural integrity. In totality, the production cost of one prototype mold or a small set of molds can often reach millions of dollars.

In contrast, direct printing of blade molds by AM eliminates the need for a plug. Therefore, AM provides upfront savings in production time, manufacturing costs, and transportation costs of the plug. Innovative design concepts such as the incorporation of partition channels into the mold structure can serve as structural support, which replace portions of the steel frame and provide a passage for hot air. This allows even heating of the mold without the cost of manually embedding the heating wires. A thin fiberglass layer is finally applied to the mold, and it gives the blade manufacturer a familiar surface material to work with. To validate this AM approach and acquire the design and manufacturing data for AM blade mold cost modeling and associated analyses, ORNL, working with TPI Composites Inc., has used BAAM to produce a set of 13-meter blade molds. Based on a Sandia National Laboratory (SNL) blade design, TPI will use the AM mold to produce a set of research blades that will be structurally evaluated at NREL and installed for flight test at SNL's Scaled Wind Farm Technology (SWiFT) facility in Lubbock, Texas. Details of this project, which is jointly sponsored by the WETO and the Advanced Manufacturing Office (AMO), will be reported as it progresses.

Using the Clean Energy Manufacturing Analysis Center (CEMAC) methodology, the economics of both 13-meter and 50-meter AM blade molds in a production environment were evaluated. The CEMAC cost model accounts for all manufacturing process. The model details the costs associated with materials, labor, energy, facilities, equipment, and maintenance costs of the toolset, as well as the selling, general, and administrative expenses (SG\&A). In this analysis, multiple toolset configurations were used to evaluate the most cost-effective scenario for AM blade molds for manufacturing. Looking at the short-term cases, the cost of blade molds manufactured with the SWiFT tool range from $\$ 422 \mathrm{k}$ to $\$ 1,058 \mathrm{k}$ per mold. Future cases show a possible reduction in manufacturing costs to $\$ 284 \mathrm{k}$ with improved manufacturing speeds and tool utilization. With these future scenarios, raw materials will become the largest cost drivers.

In summary, AM is a rapidly improving advanced manufacturing technology that can increase wind deployment by potentially lowering the cost through shorter design-to-product lifecycles and accelerated rate of innovation. Several wind applications have been identified as potential candidates for current AM techniques, with tooling blade molds being the most addressable area in the near-term. To assess the feasibility of the AM approach and acquire necessary data for AM cost modeling and associated analyses, a 13-meter AM blade mold was produced that will be used to manufacture a set of research blades to leverage the ongoing WETO Atmosphere-to-Electrons (A2e) Initiative. Analyses performed using the 50meter cost model developed in this study showed that addressing materials cost will be the major avenue for further cost reduction. Sensitivity to labor cost will continue to decrease as production tools continue to increase in size and speed in next generation toolsets. Proximity to blade manufacturing facilities and other innovation centers are becoming more relevant, especially with increasing turbine sizes. The current cost model can thus be refined and possibly be integrated into other tools like NREL's Wind-Plant Integrated System Design and Engineering Model (WISDEM). This integration will provide more in-depth assessments of the value propositions offered by AM regarding molds and other components on key metrics such as the Levelized Cost of Electricity (LCOE) and potential for increased electricity generation from a customized wind farm. 


\section{REVIEW OF ADDITIVE MANUFACTURING (AM) TECHNOLOGIES}

\subsection{AM PROCESSES}

AM is the official industry standard term (ASTM F2792) for all applications of the process of joining materials to make objects from $3 \mathrm{D}$ data. This terminology has been developed to contrast the traditional "subtractive" manufacturing processes where material is removed by cutting, grinding, or other methods to form the final part. AM processes usually consist of the deposition of layers of material in sequential order to form the final part. 3D printing, coined by MIT, was the term previously attributed to these processes and is widely adopted as the common name by the popular press. 3D printing is used interchangeably with additive manufacturing by industry professionals. Rapid prototyping has also been used, especially in the 1990s. The adoption of the AM terminology represents the maturation of the technology from prototyping, to form and fit, to end use part production.

Research in AM began in the late 1960s and culminated in the first commercialization of stereolithography (STL) in 1987 from 3D systems [1]. Although AM is not a novel concept, recent developments in AM technology have increased production rates and reduced costs, enabling increased adoption of AM and greatly increased component complexities [2]. From 2012 to 2015, the AM industry grew at a rate of $33.8 \%$ per year [3]. Some of the earliest adopters of AM were in the automotive industry [2], where rapid prototyping has dramatically reduced development time and cost. Moreover, the unique attributes of AM enable increased component complexity and the ability to reduce part count though cleansheet designs that can integrate several individual components into one component. Despite these possibilities and the recent improvements in AM production rates and costs, AM has yet to directly replace the manufacturing processes used in industries that are based on economies of scale. Irrespective of the specific production process or material used for the AM (e.g. polymers, metals and ceramics), the general process flow is as follows from Figure 1.

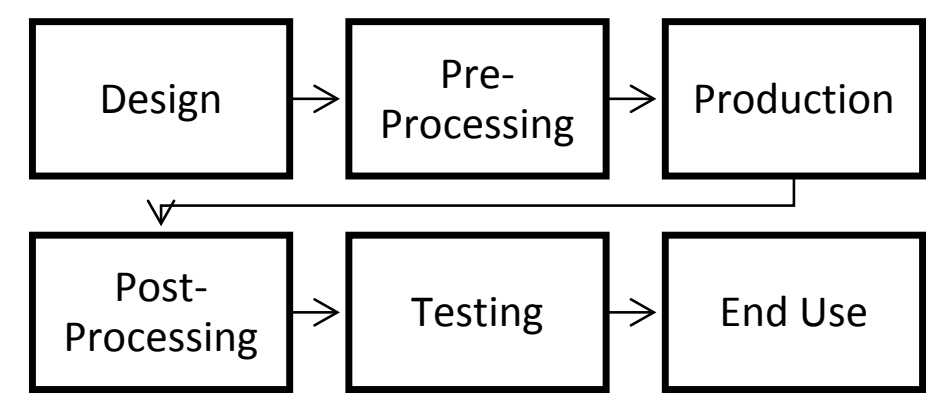

Figure 1: AM Process Flow

Each step of the process is driven by the end use case. Desired form, fit, and function drive the design, process and material selections, processing parameters, finishing processes, and tests required to certify the part for use in the intended application. While the production process is automated, operator interactions during the pre-processing and post-processing operations have significant impacts on the final part.

While the individual processes vary significantly in their materials and processing methodology, the framework and software is more or less universal. The industry accepted file format for AM is the STL, which was developed in the early 1980s. This format represents a computer-aided drafting (CAD) model's geometry by faceted surfaces as shown in Figure 2. 


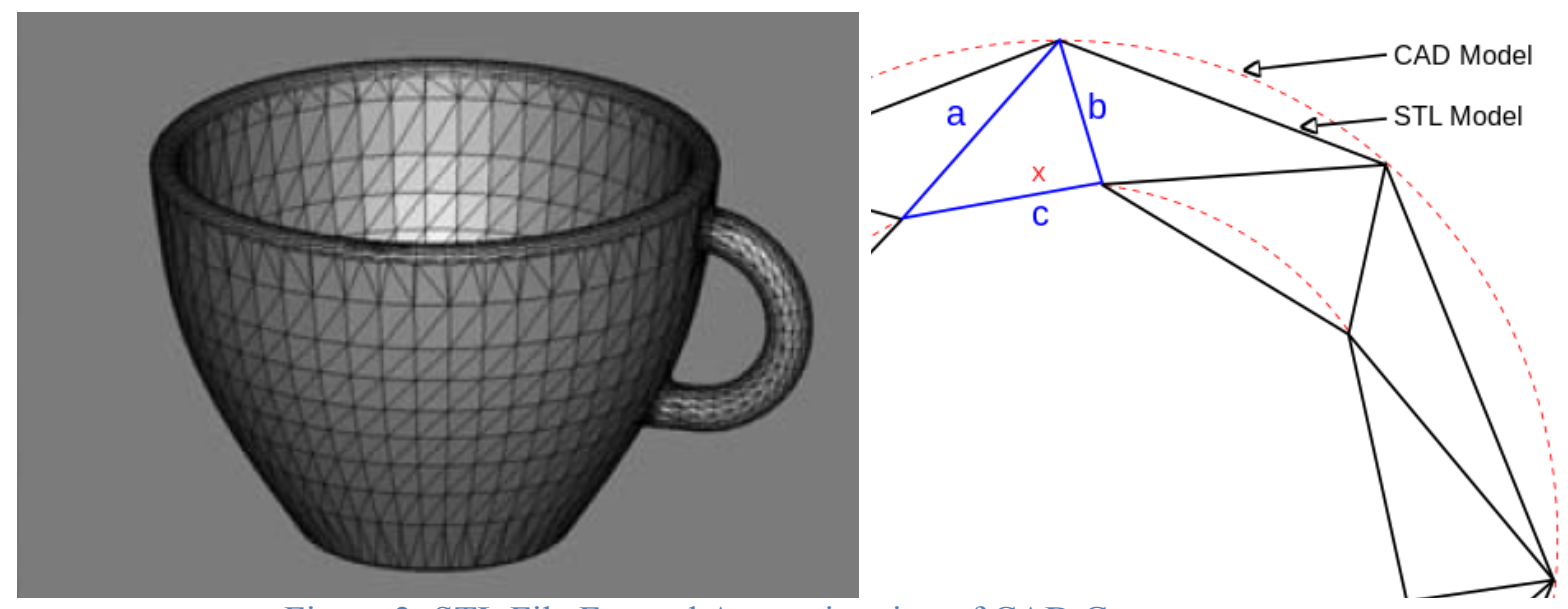

Figure 2: STL File Faceted Approximation of CAD Geometry

This approximation is virtually sliced and used to generate toolpaths for each layer of a part. Each layer is produced sequentially on top of the previous layers to form the finished part. The production process flow is shown in Figure 3.

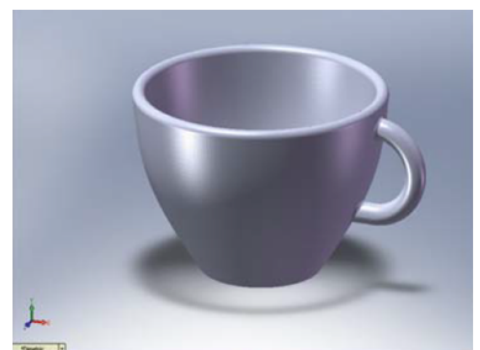

CAD Solid Model

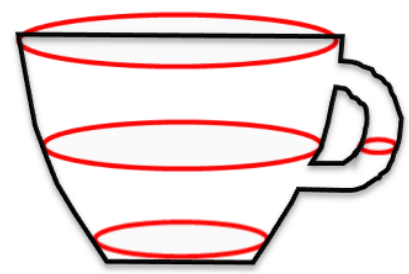

Layer-specific tool paths

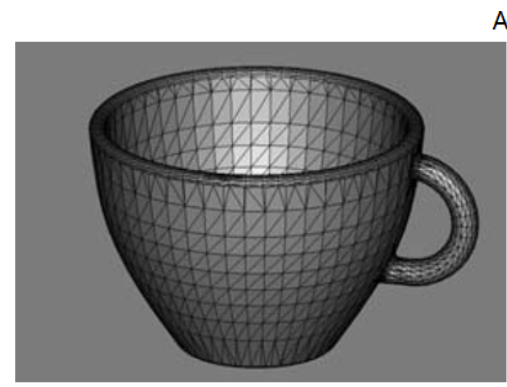

Faceted Model

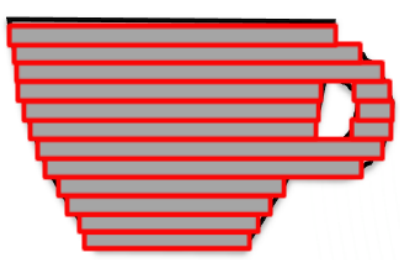

Build each layer on top of previous ones
Additive Manufacturing Technologies (2010)

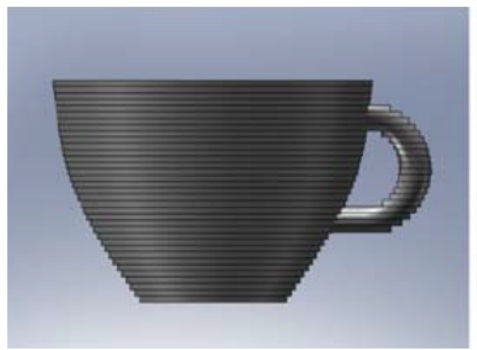

Virtually slice

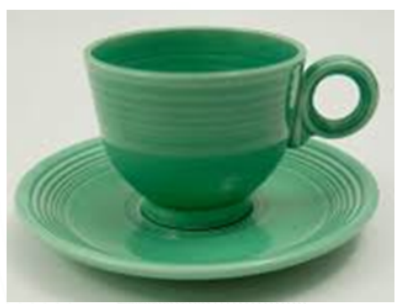

Finished Part

Figure 3: AM Production Flow

Support material is removed from locations with overhangs and finishing operations are performed to meet the specifications on surface quality or resolution. Often these finishing operations involve sanding, vapor distillation smoothing, or machining.

The benefits realized through AM are achieved through reduction in production waste, creating functional structures, and the production of parts where traditional manufacturing operations are either prohibitively expensive or require significant tooling for limited production runs.

The evolutionary rate of AM technologies and possibilities is accelerating as new developments and advances in AM occur daily. Therefore, this presented work illustrates a fraction of the options AM enables. These findings also illustrate areas in which research efforts could be directed, which may mature 
$\mathrm{AM}$ and accelerate the adoption of AM in the wind sector. Currently, AM processes need further research and refinement before large-scale implementation in new-component production. However, technology and process improvements are occurring rapidly in AM. This steadily reduces projected development times for widespread adoption of high-performance components and systems that AM processes cannot produce. Costs of AM also continue to decline, illustrating that there is potential for wide-scale deployment of AM in part production.

\subsubsection{Complexity and Quantity Considerations}

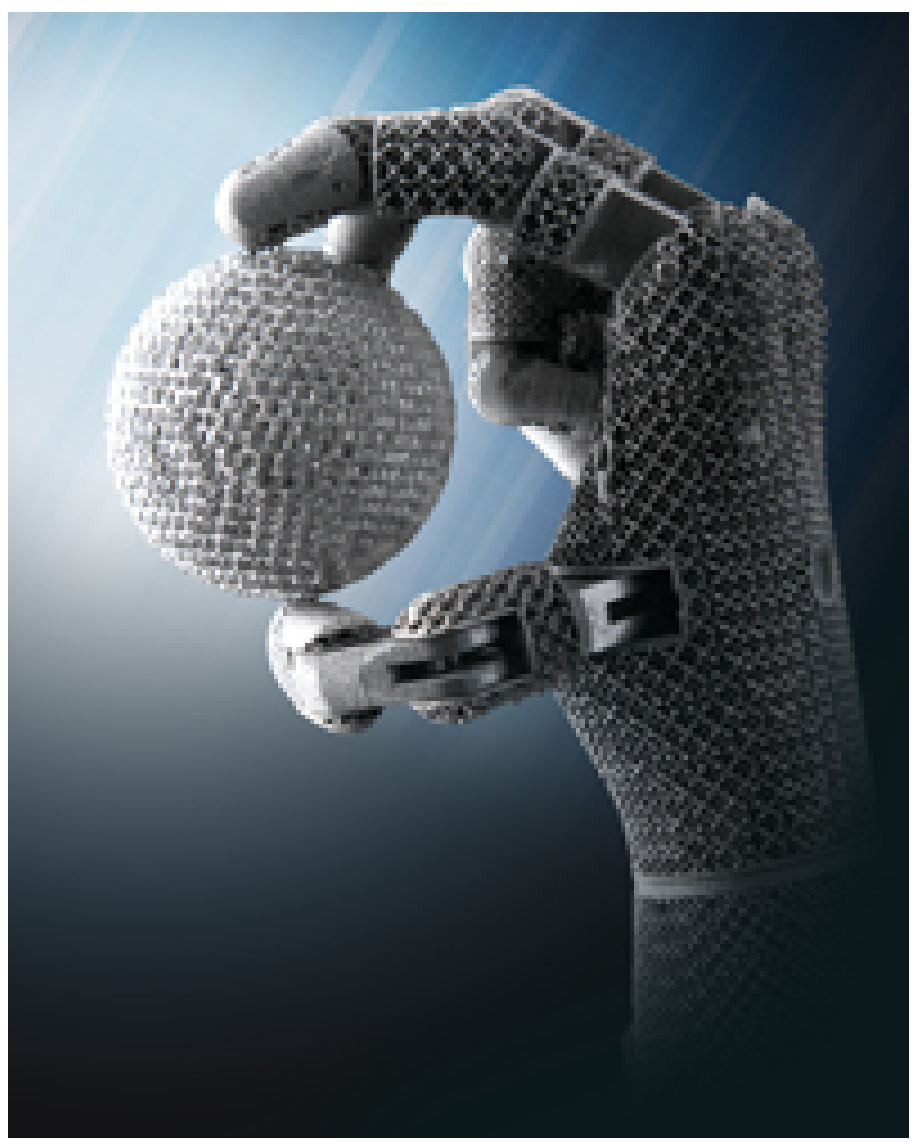

Figure 4: ORNL AM robotic hand

AM offers possibilities for accelerating mass reductions through complex geometries such as lattice structures (e.g., Figure 4), which have been created in laser and electron beam or e-beam manufacturing and have demonstrated improved tensile strength per unit of mass [69]. Recently, a simulation assessment of lattice structures for use in engine components was conducted by the University of Bath. The results illustrated the potential for integrating a lattice into the center section of a piston, as shown in Figure 5. The piston simulation prediction results suggest it may be possible to reduce piston mass by $9 \%$ [70] with little to no change in structural integrity. 


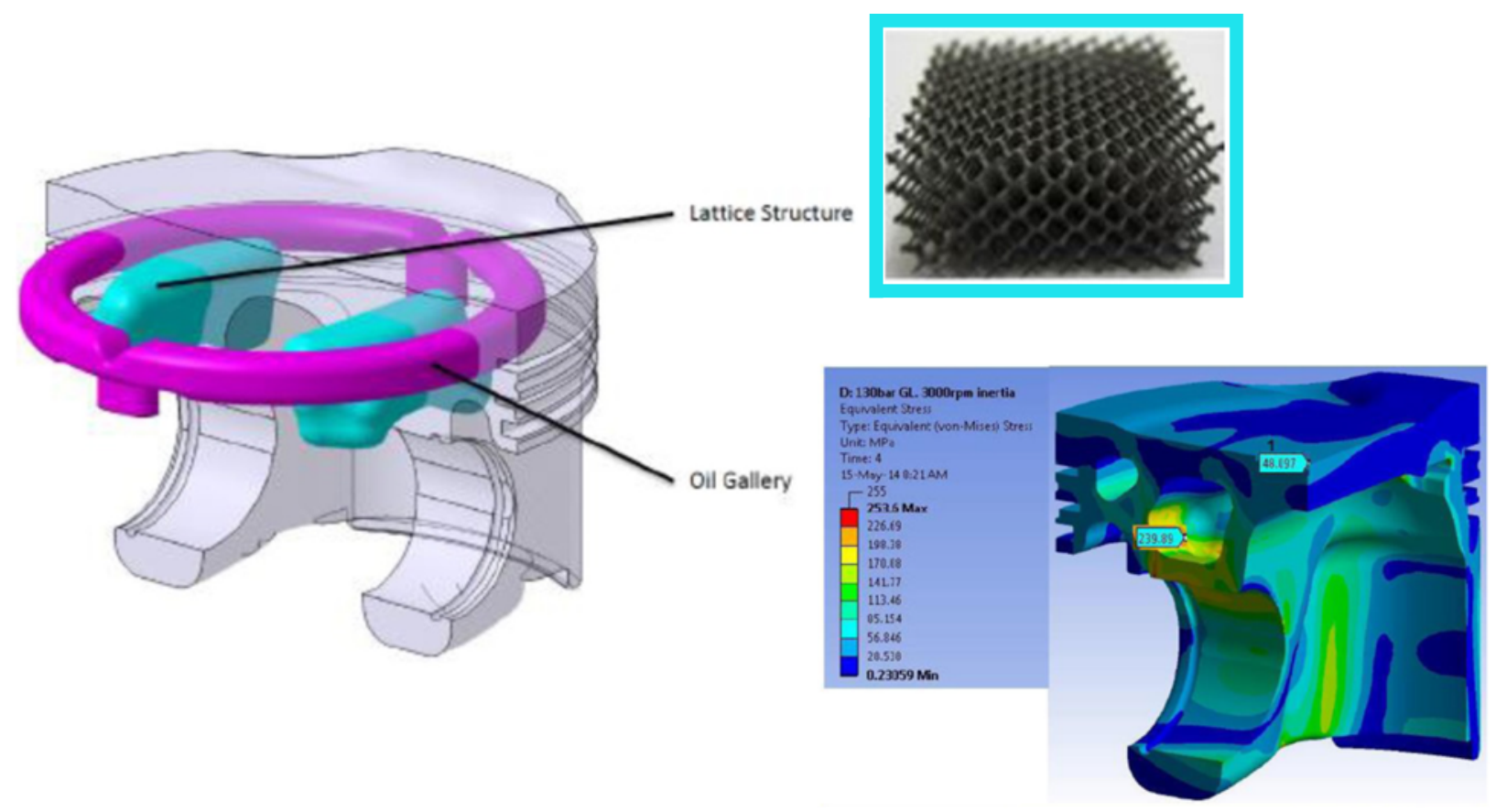

Figure 5: AM possibility for reducing piston weight through lattice integration. ${ }^{1}$

\subsubsection{Functional Assemblies}

Recently, an AM optimization and opportunity study of a Delphi-based diesel pump design was conducted by the AM consultant, Econolyst (now the Strategic Consulting Team at Stratasys), in association with Loughborough University [46]. The component investigated was a production part for a European midsize sedan diesel with a part lifetime of 186,000 miles. In Delphi's conventional cast product, several post-casting computer-numerically-controlled operations are needed for drilling holes and ensuring part tolerance accuracy. These add cost, time, and logistic complexity to the production. Additionally, Delphi needed subsequent processes to ensure leak prevention. In the clean-sheet AM approach, a majority of the secondary machining operations were eliminated. Furthermore, the fluid flow paths were reengineered using a topology optimization routine that could improve the pump efficiency, reduce internal flow losses and restrictions, and reduce overall losses. This approach is similar in concept to work by Cooper et al. [47] for a Formula 1 racecar's hydraulic transmission shifting valve. Their results show that clean-sheet AM design caused flow time reductions ranging from $100 \%$ to $250 \%$ when compared with conventional manufacturing approaches. The design and geometric freedom possible with AM enables these and other geometric-based opportunities in clean-sheet AM specific builds.

In the Delphi study, two materials - the powder form of cast aluminum (A380.0) and stainless steel (316L) - are studied using a selective laser melting process. The study not only analyzes the energy associated with CM versus AM parts, but also quantifies in-use and post-use energy, encompassing a cradleto-grave-based analysis. The resulting AM and CM designs are presented in Figure 6.

${ }^{1}$ Figure adapted from Reyes Belmonte et al. [106] 


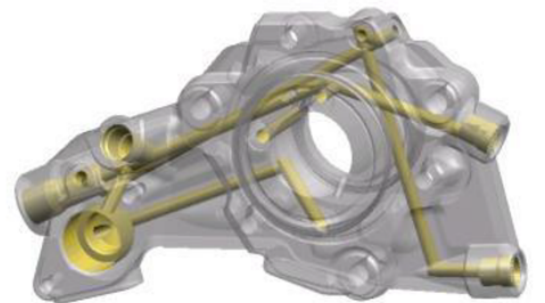

Conventionally manufactured part, which requires secondary machining for internal galleys

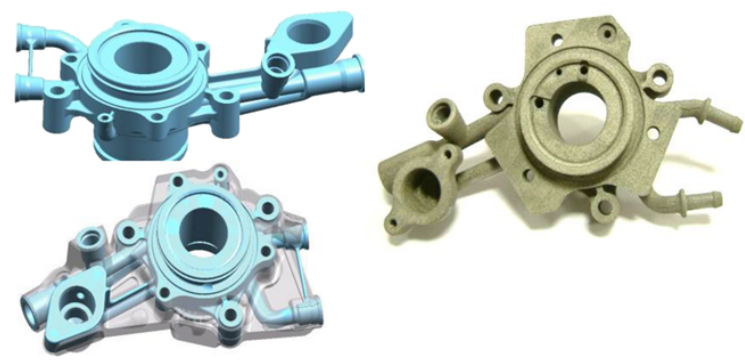

Re-designed parts for AM production using integrated internal galleys

Figure 6: Fuel pump used in Delphi Econolyst case study. ${ }^{2}$

Although the designs of the AM and the CM parts in Figure 6 are visually different, there is no geometric difference in fluid path connection or pump drive locations between the two parts. Beyond the opportunity for an improved flow path and reduced secondary machining operations, the AM part also had considerable weight savings compared with the conventional part, even though the AM part was made from a denser material (316 SS). These weight savings not only translate to in-use benefits, but they also are realized at the raw material transport and production stages because less material is required overall. Reduced component complexity may cause cost savings, which is a motivation for the manufacturer to implement this process, especially when savings are combined with vehicle weight and manufacturingenergy-intensity savings.

The Delphi study estimates that for the denser 316 SS component, which is approximately $1 \mathrm{~kg}$ in weight, savings could be realized in the total material weight (i.e., final part and production material) with the AM part. Likewise, if the AM part were made from $380 \mathrm{Al}$ (like the CM part), the total material weight savings could be nearly $2 \mathrm{~kg}$ for the AM part compared with the conventional gravity die cast part. Using these weight savings, the study estimates vehicle fuel savings resulting from the component-level weight savings by calculating the vehicle's energy use over its 186,000-mile lifetime. The results illustrate that the energy and $\mathrm{CO}_{2}$ benefits of $\mathrm{AM}$ are significant; the total energy and in-use portions of the findings are presented in Figure 7.

The results show that the energy savings potential of AM is significant, especially in the total energy and in-use portions. Moreover, the energy and $\mathrm{CO}_{2}$ savings during use in service can be very significant $-4 \times$ and $5 \times$ reductions, respectively. The findings highlight a large part of a component's energy consumption over an entire lifecycle is during the in-use phase. Note that the in-use energy savings calculated in this analysis are simply a function of the weight savings of the AM approach and are not based on any added functionality or part performance resulting from the redesign (it is assumed to be equal in performance and engine friction). Therefore, there is potential for additional energy benefits from improvements in component efficiency that could be realized by AM.

${ }^{2}$ Images are taken from Reeves. [103] 


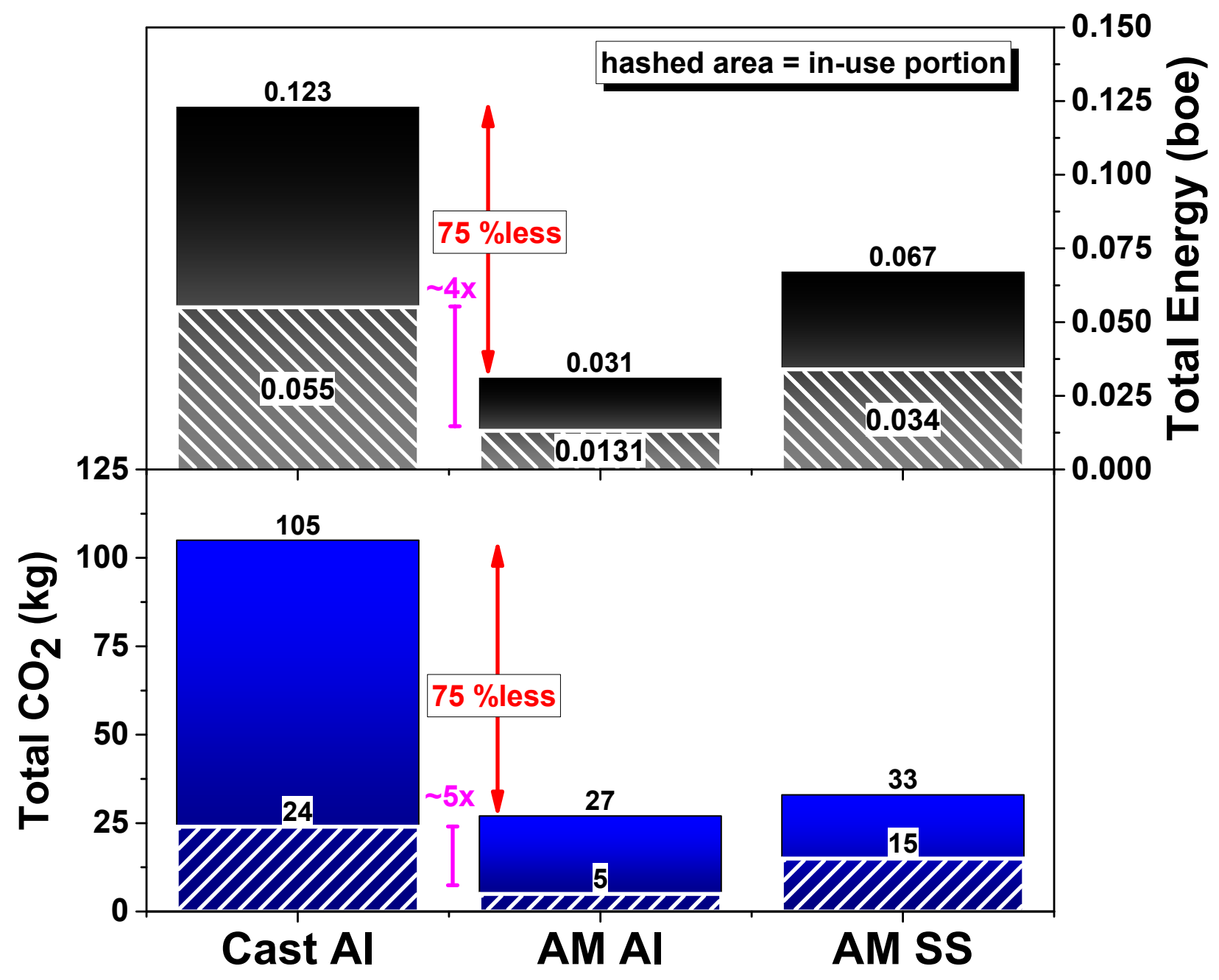

Figure 7: Life cycle analysis of Delphi diesel pump housing. ${ }^{3}$

In 2014, ORNL's Power Electronics and Electric Machines Group showcased a $30 \mathrm{~kW}$ power inverter that had three times the power density of a commercially available unit. The ORNL design used wide bandgap electrical components and used AM to redesign the inverter's heat sink so it could serve three functions: heat sink, structural member, and conductive busbar. The redesigned AM part enabled lower electrical losses by placing temperature-sensitive components closer to previously high-temperature areas, as seen in Figure 8 [50,51]. In addition, the heat sink design enabled the team to reengineer the capacitors used in the inverter by moving to a parallel array of smaller capacitors rather than fewer large "brick type" capacitors, further reducing the heat output (e.g. improving system efficiency). Using $50 \%$ AM parts, the group was able to achieve nearly $98 \%$ [52] system efficiency, with power density and specific power near 2020 DOE targets, as illustrated in Table 1.

${ }^{3}$ Produced using data from Benatmane. [46] 
Table 1: Prototype AM-produced inverters developed by power electronics researchers at ORNL. ${ }^{4}$

\begin{tabular}{c|cccccc} 
Inverter & Cooling & $\begin{array}{c}\text { Power level } \\
(\mathbf{k W})\end{array}$ & $\mathbf{W B G}$ & $\begin{array}{c}\text { Power density } \\
(\mathbf{k W} / \mathbf{L})\end{array}$ & $\begin{array}{c}\text { Specific power } \\
(\mathbf{k W} / \mathbf{k g})\end{array}$ & Efficiency \\
\hline $\mathbf{1}$ & Liquid & 10 & $\mathrm{SiC}$ & 13.3 & 11.3 & $99 \%$ \\
$\mathbf{2}$ & Air & 10 & $\mathrm{SiC}$ & 2.26 & & $98 \%$ \\
$\mathbf{2 0 2 0} *$ & Neutral & 55 & $\mathrm{SiC}$ & 13.4 & 14.1 & $\sim 97 \% \dagger$ \\
\hline
\end{tabular}

*Target inverter derived from figures in EV Everywhere Challenge Report and Electric Drive annual reports [51],[52]. $\dagger 97 \%$ is an average estimation of the efficiency needed by the inverter to meet the DOE 2020 target of $94 \%$ system efficiency (by taking the square root). System efficiency is a multiple of the inverter efficiency and motor efficiency.

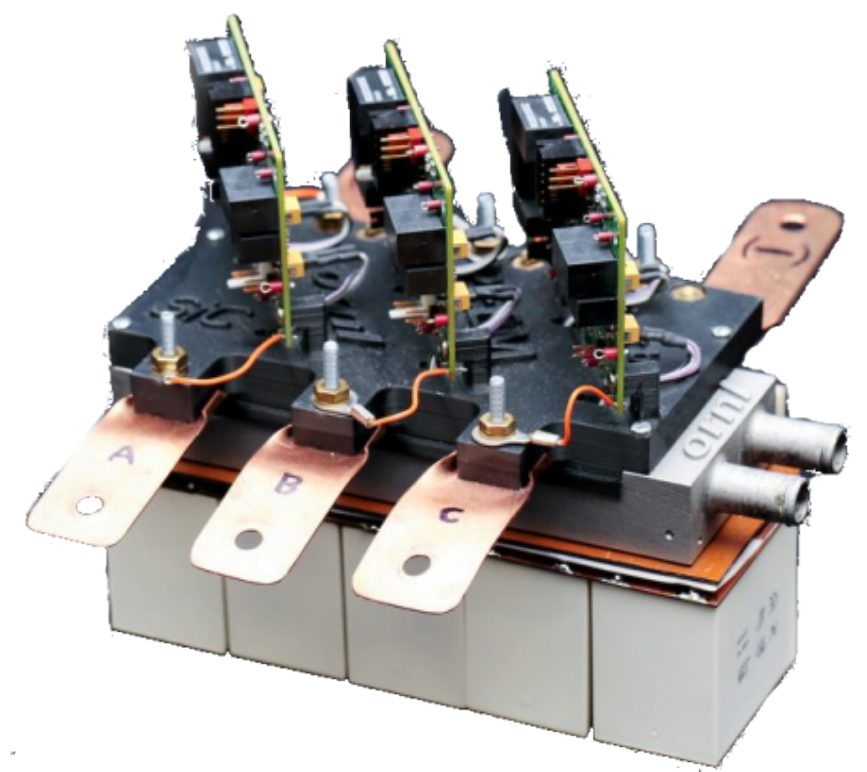

Figure 8: ORNL power inverter (Inverter 1) incorporating AM components for better packaging to improve power density. [51]

The team found the inverter's operating temperature range was between $100^{\circ} \mathrm{C}$ and $200^{\circ} \mathrm{C}$ when in use. Although this operating temperature range was acceptable, an even greater opportunity to improve performance exists. Specifically, Figure 8 illustrates that in the operating temperature range, the aluminum materials used in the heat sink for the prototype inverter design are less thermally conductive than CM materials, which caused inefficiency in the AM-produced inverter. Developing an aluminum alloy for the direct metal laser sintering (DMLS) process that can achieve higher thermal conductivities matching those of the CM Al 6061 alloy allowed for AM to increase the inverter's efficiency and reduce its size.

\subsubsection{Tailored Materials or Microstructure Control}

In-build property control has measurable benefits. Prior to assessing its applications, background on what AM has demonstrated possible is presented. Dehoff et al. [55] showed at ORNL's Manufacturing Demonstration Facility (MDF) that in an otherwise basic block part, preferential grain orientation during an AM build could be precisely managed through careful control of process parameters. Although it is not visible with the naked eye, neutron imaging of the part revealed that the material grains were specifically and purposefully oriented during the build to spell "DOE" within the part. The neutron image is illustrated

${ }^{4}$ Data compiled from [51],[52] 
in Figure 9, which provides further confirmation of the grain structure through electron backscatter diffraction along different lattice directions in Figure 10.

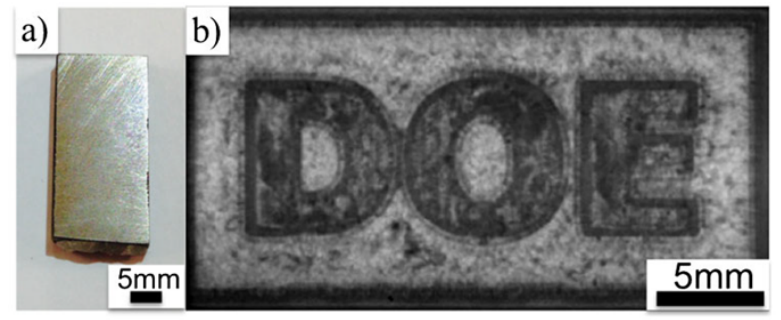

Figure 9: (a) Photograph and b) energy-selective neutron radiograph of a $5 \mathrm{~mm}$ thick slice of the 1 in thick Inconel 718 sample. ${ }^{5}$

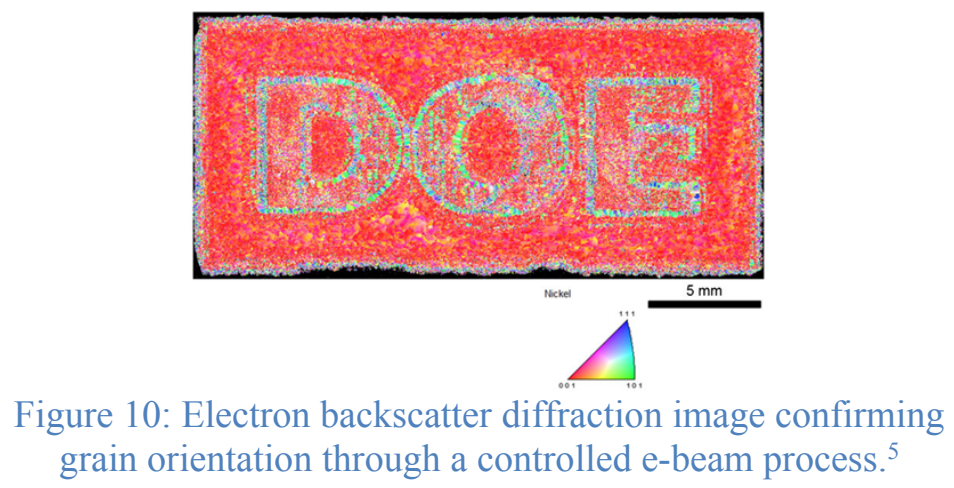

The use of AM to affect grain growth is not unique to Dehoff et al. [55]. Previous efforts in e-beam and laser melting AM demonstrated the ability of process parameters to affect grain growth in parts. Studies [56-58] show changing process parameters such as scan length, focus, and current can change the thermal gradient and solidification interface velocity. However, these findings were more oriented toward characterization of the process parameters, whereas the high-fidelity control presented in Dehoff et al. [55] is the first known public display of microstructure control during a print process that could localize the preferred orientation while using a different orientation for the bulk surface.

Scanning speed was an important parameter according to Dehoff et al.'s findings. The scanning velocity enabled direct changes in the melt pool during the part build of an ellipsoidal shape - similar to fusion welding $(\sim 0.5 \mathrm{~m} / \mathrm{s})$ to a linear melt pool $(>3.5 \mathrm{~m} / \mathrm{s})$. Large variations in gradient and solidification interface velocity that could be exploited for microstructure control were the results, which are presented in Table 2.

Table 2: Scan strategies by region of part. ${ }^{5}$

\begin{tabular}{c|cc} 
Scan strategy & Region & Grain growth \\
\hline $\mathbf{1}$ & Boundary of letters & Highly misoriented, equiaxed \\
$\mathbf{2}$ & Bulk & $<001>$ columnar \\
$\mathbf{3}$ & Interior of letters & Mixed mode, a combination of columnar, and equiaxed
\end{tabular}

5 Image from Dehoff et al. [55] 
Solidification maps, like the one in Figure 11, have been developed from analytical models for fusion welding, which serve as good approximate representations of the physical and thermal processes taking place during e-beam and laser AM.

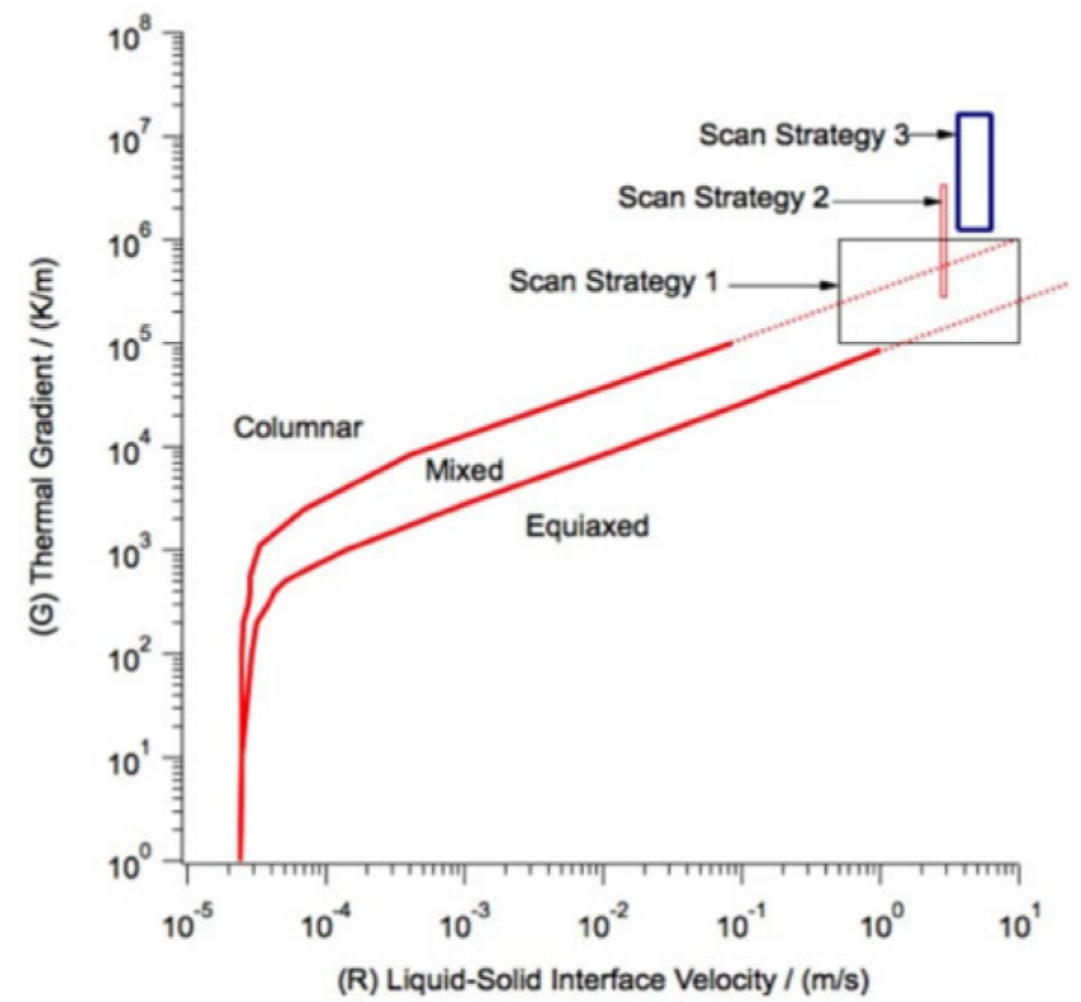

Figure 11: Process used to control grain orientation by manipulating the thermal gradient with the liquid-solid interface velocity relative to an analytical model for Inconel $718 .^{5}$

Once the relationships between AM process parameters for gradient and solidification interface velocity are understood, using AM to control the material properties is possible. The results of Dehoff et al. visually illustrate the power of AM, but they do not quantify the potential use and impact of this AMspecific ability. However, the research explains how parameters for e-beam or laser processes could be characterized to enable the integration of AM build parameters. The corresponding material properties could be integrated into a $\mathrm{CAD}$ processes for material and component optimization in the near future.

\subsection{ADDITIVE MANUFACTURING PROCESSES FOR METALS}

This report highlights three processes for AM fabrication of metals: directed energy deposition, binder jet, and powder-bed fusion. Although there are additional AM processes for metals that are not discussed, such as those based on contact rolling of thin metal sheets, most AM process for metals use metal powders. The powders are on the order of $50 \mu \mathrm{m}$ to $200 \mu \mathrm{m}$ in diameter, and the final builds achieve a surface finish roughness and geometric resolution similar to that of the powder diameter [4-6]. The powders are fabricated into final components either by using precise direction of thermal energy (directed energy deposition and powder-bed fusion) or by using a binding agent (binder jet) to bond powder particles together locally to form a solid. The thermal energy-based approaches physically melt the powder during the build, with little to no secondary processing. The binder jet process bonds powder together with a low melting-point media, and secondary post-processing removes the binding media and sinters the powder 
together. The following subsections detail specific attributes and uses of the different AM processes for metals.

\subsubsection{Direct Energy Deposition}

One of the earliest metal processes, directed energy deposition, is based on feeding a metal powder into the path of a laser, creating a melt pool. As illustrated by Figure 12, directed energy deposition moves the powder feed and laser together, selectively adding material layer by layer. The advantage of the process is that it can grow parts out of a plane, eliminating the need for a layered process, while a shielding gas enables shielding of the melt pool solidification from oxidation [7]. Furthermore, the process enables multiple simultaneous and individual material feeds, enabling in-build blending and modification of materials. The primary application for the technology is repairs and surface coatings. The specific capability to engineer material composition and property gradients locally in the build process holds extraordinary potential. The disadvantages of the process are the low deposition rate, poor surface finish, and lack of support material. Since the inception of this process, the technology has matured and is currently classified under several different names: laser powder forming, laser engineered net shaping, laser metal deposition, direct metal deposition, direct laser deposition, laser cladding, laser deposition welding, and powder fusion welding.

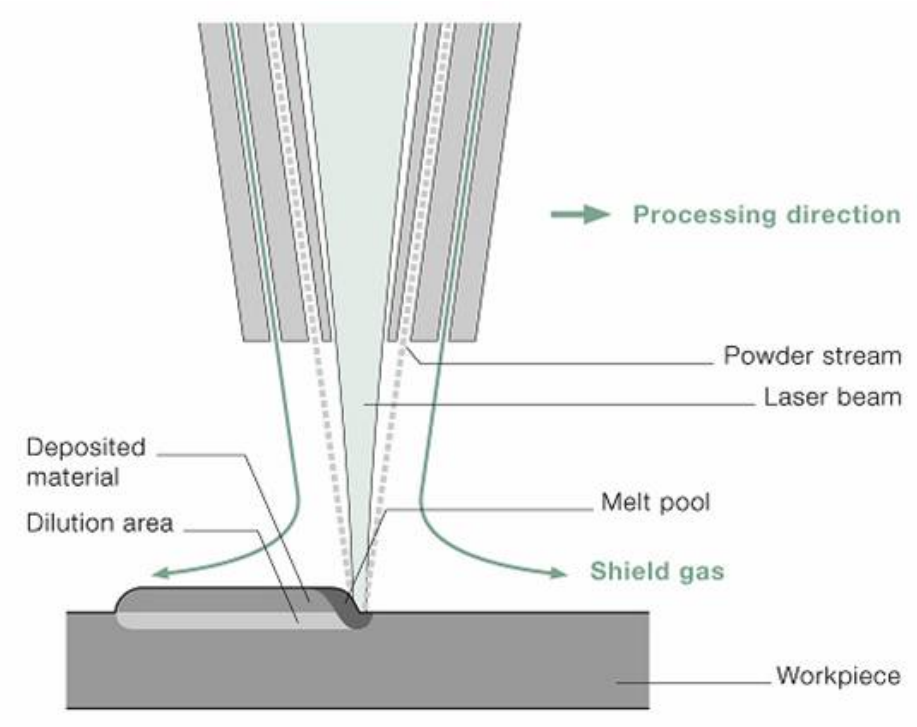

Figure 12: Schematic of direct energy deposition process. ${ }^{6}$

\subsubsection{Binder Jet Printing}

The AM process that currently seems to be the most adaptable to large-scale production is binder jet printing. This is illustrated by the availability of production line-scale printers. Production line-scale printers are capable of printing build volumes containing a single of multiple parts nearing $2 \mathrm{~m}^{3}$ in total volume with build rates nearing $1 / 2 \mathrm{~m}^{3} / \mathrm{hr}$ [8]. Binder jet printing is a powder bed process that uses an inkjet head to deposit a binder (eg, polyethylene glycol) to build objects from powdered media. The binder is quickly photo-catalytically cured, and the process repeats, building the component layer by layer. For parts with internal passages, uncured powder in each layer serves as the support for successive layers. When the

${ }^{6}$ This process is highlighted in the section. Image taken from LPW Technology. [100] 
part build is complete, the part is in a fragile "green" state and must be carefully removed from the powder bed. A secondary oven curing process is then used to partially sinter the part and to remove the binder. Although this process is well suited for large-scale production, the binder removal need results in relatively high part porosity (greater than 30\%) [6,9]. To increase final part density, a lower-melt-temperature material (eg, bronze) can be used to back-infiltrate the part during the sintering process. The result is a fully dense part is produced with composite materials[7].

The advantages of this process are the low residual stress during the manufacturing process; the capability to easily fuse high-temperature materials; and the ease of scaling it to larger-volume printing, as no vacuum is needed for production. The primary disadvantages are the fragile condition of the green part before sintering and the need for multiple steps [9-11], which ultimately add to the cost of final printed components. This process is well suited to metals, and it was originally developed for printing complex sand casting molds. Currently, sand molds created with binder jet printing are used by automotive original equipment manufacturers, like Ford Motor Company [2], to develop prototype engines. Sand molds created with binder jet printing are also used by startup companies with novel technologies, like MCE-5, which used the technique to develop its variable-compression engine [12,13]. Binder jet printing of sand cores reduces production time to hours and is very adaptable to design changes without retooling costs [12]. It has an inherent potential to increase vehicle fuel economy, as it can reduce design integration times by approximately 6 months, enabling further refinement and optimization during development [12].

\subsubsection{Powder Bed Fusion}

Although the binder jet process produces sand cores and could be the most scalable process for metals, the most common and mature metal AM process is powder bed fusion. Rather than using a binder to attach and later sinter metal powders, powder bed fusion uses an intense energy source, such as a laser or e-beam, to sinter or melt the powder. The earliest powder bed fusion systems used only lasers. A gimbaled mirror directs the energy from the source to the powder. The advantages of this process are that it transforms the powder, through the welding process, directly into the final part with a high degree of spatial resolution and a high-quality surface finish. However, the process is relatively slow compared to conventional techniques such as casting and can result in part builds that experience very high internal residual stress [7,14-16]. Residual stress issues associated with the process can localize at the base of the build, as the process initiates the first production layers on top of a build plate (eg, a steel plate). After the part is grown, it is heat treated to relieve the stress, and then the build plate is cut off.

E-beam melt technology is a more recent alternative energy source for powder bed fusion [7]. Rather than using a laser and gimbaled mirror, e-beam technology uses electromagnetic fields to guide a stream of electrons to melt the powder [7]. The advantage of this process is that it is possible to defocus the beam and rapidly preheat the powder bed close to melting temperature. The e-beam is moved rapidly so that numerous weld pools are generated almost simultaneously. This distribution of thermal input improves local thermal distribution, which increases the deposition rate and significantly reduces residual stress. Because of a low possibility of residual stress, there is little need to weld the part to the start plate. The disadvantage of the e-beam process is that the solid powder is lightly sintered together, which affects the surface finish and makes part removal more labor-intensive than in laser powder bed fusion [7].

Both laser and e-beam approaches to powder-based AM result in nearly complete densification of the finished build - unlike binder jet approaches. This reduces secondary processing handing considerations, time, and costs. Although there are advantages to both e-beam and laser-based powder bed processes, they require high-vacuum environments inside the build chamber, making scalability and production throughput cost a challenge. Recent patent expirations [17] have opened opportunities for new 
businesses to enter the technology space, which will increase competition between suppliers and potentially lead to further gains in the finish quality of prints.

\subsection{AM PROCESSES FOR POLYMER-BASED MANUFACTURING}

Four main technologies currently are used for AM with polymers. To date, polymer-based AM accounts for most of the AM market and offers the most attractive economics. For these reasons, AM of plastics is more mature in the market and is being used in-field for many applications, such as hearing aids, orthodontic aligners, and functional-use prototypes in aerospace and automotive applications [7]. This report assesses current research and future research opportunities regarding physical processes and improvements to polymer-based AM.

The adoption of polymers in AM and the automotive industry began as early as 1990 with Chrysler's investment in form/fit assessments with STL [18]. The opportunities provided by polymer-based AM have since evolved into an industry-wide reliance on AM during the prototyping. Future polymerspecific opportunities for AM are most likely to succeed in weight and cost reductions. Therefore, research in this area tends to be less technical and more application- or design-specific. For this reason, a detailed assessment of polymer-based AM is beyond the scope of this report, although that should not be interpreted as downplaying the opportunities AM offers to reduce energy consumption.

One area in which polymer-based AM has tremendous potential for market growth and could help to dramatically reduce fuel consumption for transportation, is in the rapid low-cost production of forms and molds for composites (eg, carbon fiber body panels or other structural parts). Low-cost rapid prototyping and production of molds represents a significant opportunity for AM, albeit in the production and manufacturing of products and not necessarily in improving the efficiency or the economics of their enduses. Therefore, AM processing of polymers is highlighted in the following sections through specific examples of their use by individual manufacturers.

\subsubsection{Vat Photopolymerization}

The metal AM process most similar to vat polymerization is binder jet printing because vat polymerization uses a photocatalytic curing process for polymers. However, rather than using curing to bind individual powder particles as in the binder jet process, vat polymerization physically builds the component from the polymer itself. The volume of material that can be produced in vat polymerization is dictated by the size of the vat. This process has only been demonstrated using acrylate photopolymer to date [7]. However, future developments in the polymer-based medium or media used in this process might not be limited to single material builds, and multi-material and graded material solutions could become possible.

\subsubsection{Material Extrusion}

One of the most popular types of polymer AM is based on the use of an extruder that melts a powder or wire and deposits material onto a substrate. This approach is commonly used in many desktop-size, consumer-level AM systems [3]. The extruder melts a thermoplastic wire and pushes the molten material through a fine orifice. The coordinated motion of a gantry system coupled with the material extrusion flow rate produces the final part. Once the part build is complete, the part is removed from the substrate. The metal-based AM process most similar to material extrusion is a system that uses an e-beam or laser as the energy source with a metal wire feedstock instead of a powder. 
Technologies are being developed for larger print volumes. A large print volume is considered to be at least 15 times the build volume of desktop-size, consumer-level AM system. For example, Cincinnati Incorporated partnered with ORNL to developed the Big Area Additive Manufacturing (BAAM) process in 2014 that improved the extrusion process from desktop-sized AM systems of 1-5 cubic inches per hour to more than 1,000 cubic inches per hour [19]. To achieve high print rates, material pellets are used, which also significantly lowers the material cost from $\$ 110-\$ 220 / \mathrm{lb}$ to $\$ 3-\$ 5 / \mathrm{lb}$. The pellets are used in combination with an optimized feed screw that reduces throttling of the pellet flow into the material. Due to its higher build rates and build sizes, BAAM's initial targeted applications are in the tooling industry, specifically where large, complex injection molds are needed to produce CM polymeric and metal parts at low cost.

\subsubsection{Material Jetting}

Material jetting is similar in its advantages and disadvantages to directed energy deposition. Typically, a photopolymer is jetted and cured in place. The process enables multi-material and graded material parts. However, as with vat polymerization, the photopolymers are suitable for prototypes but generally have poor mechanical properties and degrade in sunlight.

\subsubsection{Big Area Additive Manufacturing}

Conventional fused deposition modeling (FDM) is based on melting and extruding a filament of thermoplastic feedstock. Prior work shows that the peak flow rate is limited by the rate at which the filament can be melted (Monzon 2013). BAAM is an extrusion process that uses injection molding material for the feedstock and a single screw extruder for melting and metering the flow rate (see Figure 13) [113]. A gantry system, commercialized by Cincinnati Incorporated (see Figure 14), moves the extruder in x, y, and $\mathrm{z}$ directions to build the part. The extruder is capable of delivering $100 \mathrm{lbs} /$ hour of thermoplastic materials from pellet feedstock. The gantry system is capable of achieving $200 \mathrm{inch} / \mathrm{sec}$ peak velocities with 64.4 in $/ \mathrm{s}^{2}$ accelerations and position accuracy of $0.002 \mathrm{inch}$. As previously reported, the use of carbon fiber reinforcement in the thermoplastic resins increases the part strength and stiffness. [117]. Also, the use of carbon fiber increases thermal conductivity and reduces the coefficient of thermal expansion eliminating the need for a heated chamber to produce large parts (see Figure 13 and Figure 14) [114]. The elimination of the oven significantly decreases the energy intensity, which is defined as the manufacturing energy required per kilogram of product produced. As shown in Figure 16, conventional FDM systems with heated chambers have a $100 \mathrm{~kW}-\mathrm{hr} / \mathrm{kg}$ energy intensity. Desktop systems that have similar production rates have a $5.5 \mathrm{~kW}-\mathrm{hr} / \mathrm{kg}$ energy intensity suggesting that the oven accounts for $95 \%$ of the energy use in FDM production. BAAM further reduces the energy intensity to $1.1 \mathrm{~kW}-\mathrm{hr} / \mathrm{kg}$ by significantly increasing productivity from $1 \mathrm{ci} / \mathrm{hr}$ to $2,500 \mathrm{ci} / \mathrm{hr}$ and is manufactured at room temperature.

Therefore, the combination of lower energy intensity, higher productivity, and lower material cost suggests that there will be a significant production cost reduction with BAAM when compared to conventional FDM AM systems. As with conventional AM, there are four primary costs associated with manufacturing a part: pre-processing, material, processing, and post processing. The combination of significantly higher production rates with low cost feedstock changes the cost distribution of each of these elements. Pre-processing typically includes preparation of the file (slicing, support, and orientation) and preparation of the machine (loading material and filing). Material is generally slightly over the volume of the part and includes support material. Post processing includes removal of the part, support, recycling of any leftover materials, and final finishing (machining and polishing). 


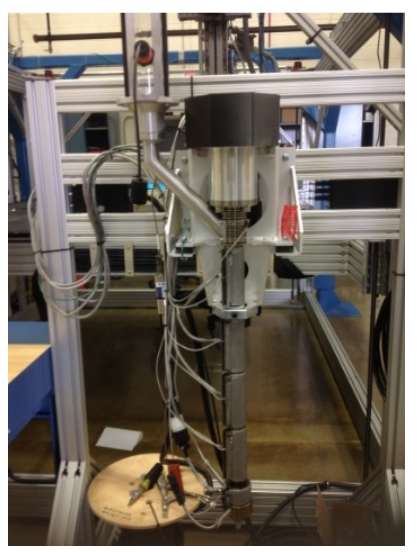

Figure 13: BAAM Extruder

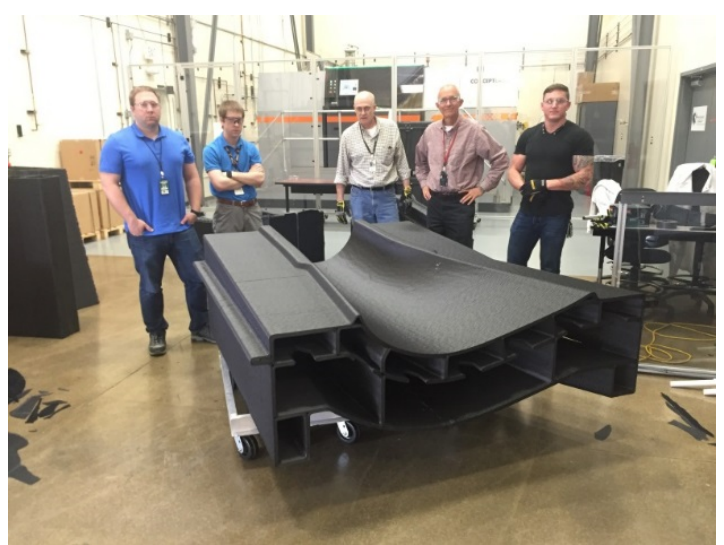

Figure 15: Section of a wind turbine mold

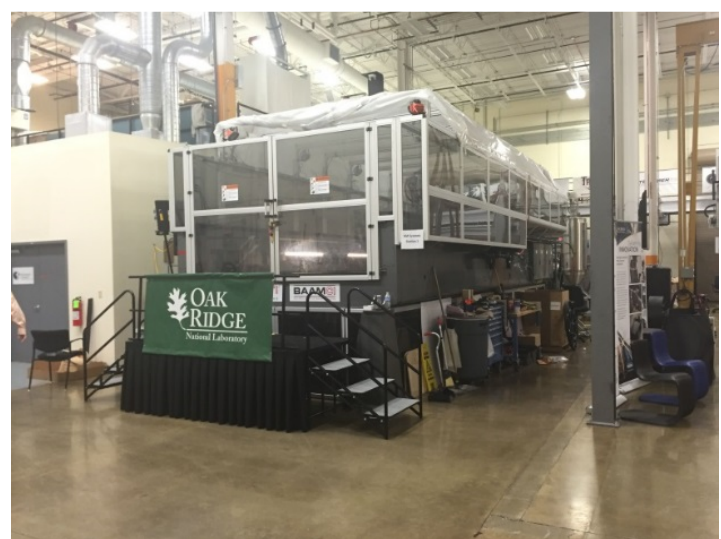

Figure 14: Cincinnati BAAM

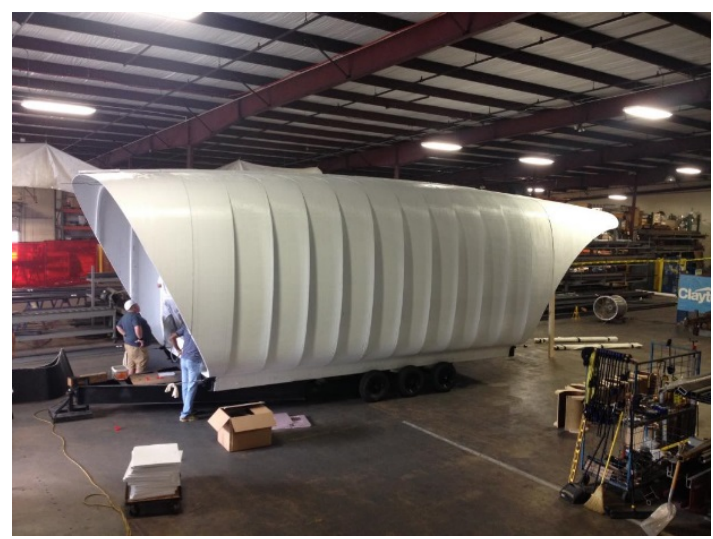

Figure 16: Printed prototype house

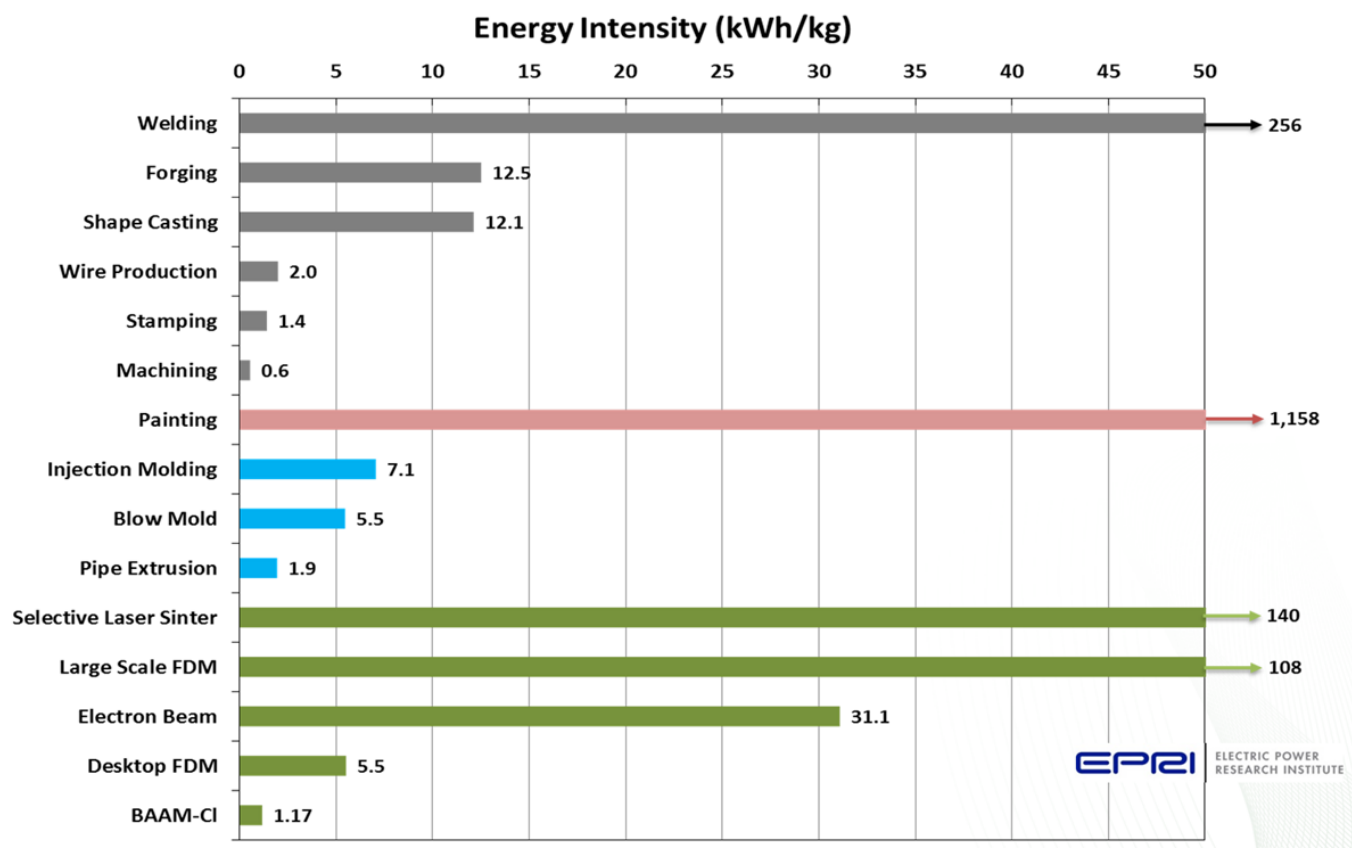

Figure 17: Energy intensity of manufacturing 


\subsection{HISTORICAL AND CURRENT APPLICATIONS OF AM}

The above highlighted AM processes illustrate that since its inception in the 1960s and its first significant adoption by industry in the $1980 \mathrm{~s}$, AM has been developing rapidly. The AM industry as a whole has grown at nearly $34 \%$ per year since 2010 , as it transitions from rapid prototyping to an extensive array of final end-use metal, ceramic, and composite parts [2,3]. Total revenue from AM is expected to reach $\$ 492$ million in 2015, with nearly $40 \%$ of it coming from selective laser sintering (SLS) of metals. The industry growth trajectory of SLS of metals is expected to continue and revenue is expected to surpass $\$ 900$ million by 2020 [3]. As with any emerging industry, growth rates remain high in select applications while barriers to entry for new players remain low. For example, dentistry is benefitting from advances in scanning tools, software, and AM. Currently, Align Technologies manufactures 17 million unique Invisalign ${ }^{\circledR}$ orthodontic aligners annually [19]. Each aligner is produced by thermoforming sheets of material over a unique mold made by AM. Examples of uses of AM in this and other industries highlight the adaptive nature of AM and illustrate how unconventional designs could be enabled through AM.

An industry more similar to wind energy production is the aerospace industry, which is rapidly deploying AM in production. Boeing has installed more than 20,000 production AM non-metallic parts in the field. This represents more than 300 unique designs on 10 different commercial and military aircraft, including the F/A-18 Super-Hornet. The F/S-18 Super-Hornet, "has approximately 150 parts in the forward fuselage area that have been produced through selective laser sintering [20]."

To date, the most aggressive demonstration of AM use in the aerospace industry is GE's commitment to additively manufacture 40,000 metal fuel injector nozzles for its new Leap engine. GE claims that the new fuel injector nozzle design will cost less to manufacture because CM fuel injector nozzles required 18 separately manufactured parts, but AM allows for nozzles to be manufactured as a single part. The new AM nozzles will also be $25 \%$ lighter and have design features that reduce carbon buildup, which makes them more energy efficient [21].

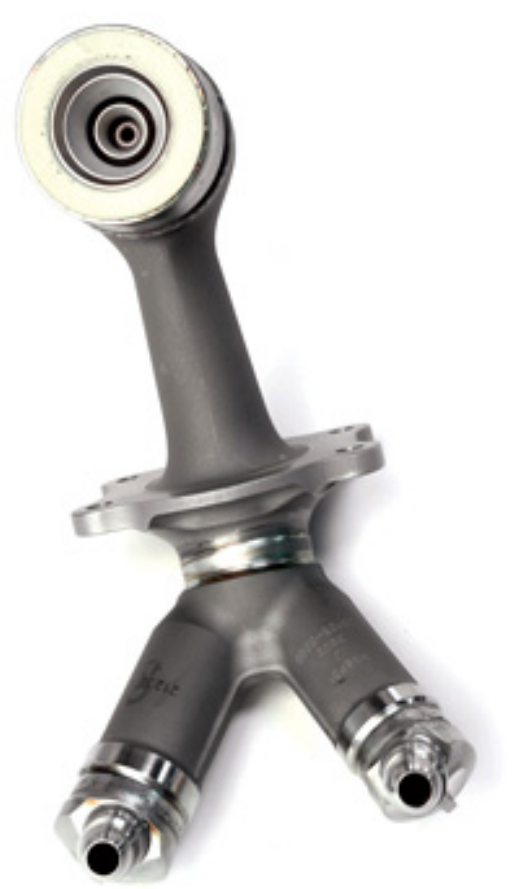

Figure 17: GE fuel injector nozzle. [21] 
These examples of AM in biomedicine and aerospace stem from AM's ability to provide easy customization, weight of part reductions and part count reductions. These examples illustrate how AM enables unconventional approaches and designs. They also map a path for AM-based design and production at scale of light- to heavy-duty manufacturers. While the above examples highlight AM implementation outside of transportation, the automotive industry contributes more to total AM revenue than either the aerospace or biomedical sectors (16\% vs. 14.8\% and 13.1\% respectively) (Figure 18) [3].

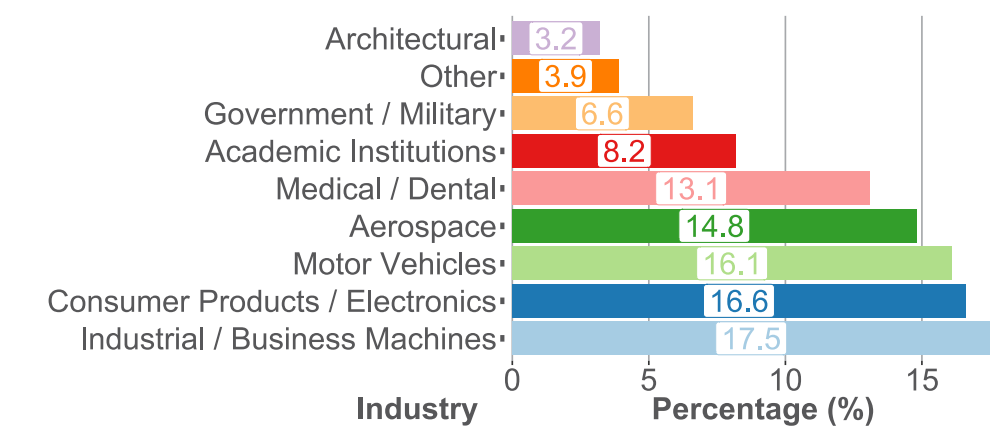

Figure 18: Revenue in select Industry as percentage of total revenue of AM manufacturers and service providers in $2014 .{ }^{7}$

Figure 18 shows that the automotive industry generates a significant portion of the revenue in the AM industry as a whole, but final-product use of AM is small (Figure 19). Figure 19 uses economic data from Thomas [22] at the National Institute of Standards and Technology and Sharon Ford [17] at the US Economic Trade Commission. Figure 18 and Figure 19 show there is very high growth potential for AM in many sectors.

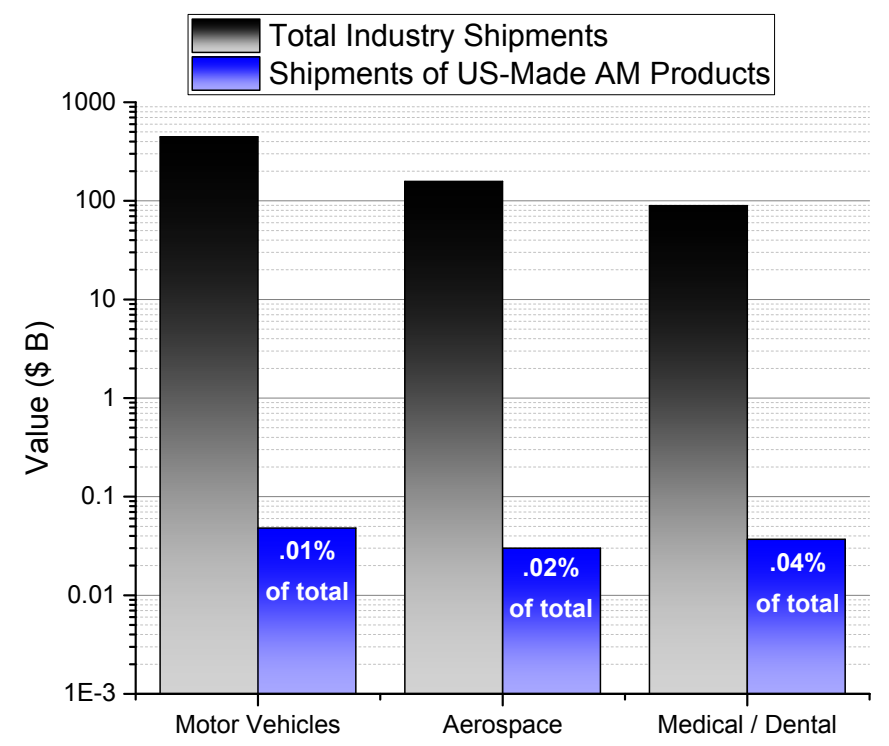

Figure 19: Economic assessment of global market shipments of goods, in billions of dollars, by select industries (black) and AM-specific market shipments by sector (blue). ${ }^{8}$

${ }^{7}$ Data from Wohlers 2015. [3]

${ }^{8}$ Note the use of a $\log$ y-axis scale. Data from Thomas [22] and Ford [17] 


\section{ECONOMICS OF ADDITIVE MANUFACTURING}

Many AM scenarios have been envisioned to improve the wind energy supply chain. An example is the flexibility to customize wind turbine and component designs for the wind resource at specific locations. AM even offers customization of multiple turbine, nacelle, blade, and tower designs of individual wind farms. AM could allow original equipment manufacturers (OEMs) and component designers to take advantage of advanced aerodynamic modeling, grid interface, and atmospheric data. Such customization could also result in more efficient operation of the entire plant, thus improving annual energy production and reducing the levelized cost of energy (LCOE). While materials would need to be transported to the manufacturing location, infrastructure constraints associated with large blades and towers could reduce transportation costs and potentially reduce the need for expensive site prep and crane operations. An additional opportunity for applying AM to the wind supply chain is in the R\&D phase. While there are a number of promising prospects, the potential for AM to revolutionize wind turbine manufacturing has largely been unexplored from market and economic perspectives.

One economic analysis is provided by Salmi (2012), which compares conventional high pressure die casting (HPDC) to SLS, an additive manufacturing process, when fabricating an aircraft component. Because the AM process did not have the inherent limitations of traditional casting and machining, the team was able to redesign a simpler component that still met the requirements of its use. The new design was $72 \%$ lighter than the original, meeting a fundamental objective of aircraft components. The conventional HPDC process had four primary cost elements: materials, tooling, machine cost, and labor for pre- and post-processing, while the AM SLS process had three primary cost elements: material, machine cost, and labor for pre- and post-processing. The fundamental differences between the two manufacturing approaches was the lack of tooling cost for the AM SLS process and the higher production rate of the conventional HPDC process (3.6 seconds per part for HPDC versus 13.5 hours for AM SLS). Salmi determined that the cost per part from the conventional HPDC process was $\$ 21.29+\$ 21,000 / \mathrm{N}$ where $\$ 21,000$ is the tooling cost and $\mathrm{N}$ is part count. The AM SLS process was estimated to have a fixed cost of $\$ 526.31$ per part. Therefore, if the production volume is less than 41 parts, AM SLS is the more economical manufacturing process. At a volume of 41 parts, tooling accounts for $97 \%$ of the manufacturing cost in HPDC but decreases as volume increases. For AM SLS, machine cost per part accounts for $90 \%$ of the total part cost and does not change with volume (see Table 3). Therefore, in this case, allocation of the cost of the machine over the number of parts, not material or labor, is the most expensive cost of AM. It should be noted, however, that in the case of this aircraft component, even in situations where less than 41 parts are required, AM provides the benefit of producing a part that is more suitable to its application, ie, lower weight. Additionally, the Salmi analysis does not take into account the likely use of the AM machine for other parts manufacturing following the run of the aircraft component. Therefore, the cost per part could be significantly less if the AM machine is operated by a shop that serves multiple customers or is used in-house for the manufacturing of multiple parts.

Table 3: SLS Additive Cost Breakdown

\begin{tabular}{|l|c|c|}
\hline & Cost & Percentage \\
\hline Pre-processing & $\$ 8.00$ & $1.5 \%$ \\
\hline Material & $\$ 25.81$ & $4.9 \%$ \\
\hline Processing & $\$ 472.50$ & $89.8 \%$ \\
\hline Post processing & $\$ 20.00$ & $3.8 \%$ \\
\hline
\end{tabular}

For all AM processes the manufacturing cost can be associated with several distinct process phases and consumables: pre-processing, materials, processing, and post processing. What follows is a discussion of each category and the relationship to total manufacturing cost. 


\subsubsection{Pre-Processing}

Pre-processing encompasses the design and setup phases of production. The design phase costs differ depending on the type of design. For example, reverse engineering a conventionally manufactured part for production with AM requires significant time investment to scan, fit, and modify the design to leverage the strengths and mitigate the weaknesses of the AM process. Reverse engineering can easily take more time than the manufacturing process itself, depending on the complexity of the component. In contrast simply varying the parameters of a design of a component previously designed for AM, e.g., changing loft sections in a blade mold or scaling the overall assembly, requires very little design effort. Therefore, labor costs are significantly reduced.

The design phase also generates trickle down effects that drastically affect the costs associated with the processing phase. For example, a design variant which reduces the material volume required by onethird, will reduce the material costs and processing time by one-third, resulting in a significant impact to overall cost. Other pre-processing costs associated with consumables of the AM process include build sheets, start plates, and energy costs associated with bringing the AM system up to temperature. Technician labor for slicing and machine setup is also included in pre-processing costs.

\subsubsection{Materials}

Material costs are the simplest to project and scale, as they vary more-or-less linearly with the volume of the printed component. The only exception is support material costs. Support material costs are dependent on the design of unsupported overhangs, which exceed a minimum support angle. The material costs associated with AM have been significantly exaggerated because of low production rates. For example, acrylonitrile butadiene styrene (ABS) used in commercial AM systems will often cost more than $\$ 100 / \mathrm{kg}$. In injection molding, ABS will typically cost less than $\$ 2.50 / \mathrm{kg}$. The primary driver of this disparity is the comparative production volumes and material sensitivities associated with the filaments used in AM, such as moisture content and variation in diameter. With increased AM across industries, material costs are expected to be normalized to those seen in conventional manufacturing.

\subsubsection{Processing}

Processing costs include capital expenditures on equipment, service, maintenance contracts, and energy costs associated with AM production. The investment in equipment and maintenance is often the largest cost in AM production. These costs for most industrial AM platforms are generally more than $\$ 30$ per hour of processing time and can often reach more than $\$ 100$ per hour. These costs include amortization of the equipment costs and application of labor, facility, and overhead costs.

\subsubsection{Post Processing}

Post processing costs are often overlooked when considering AM production. These costs include: support removal, post-curing, hot isostatic pressing (HIP), subtractive machining, polishing (or other methods of enhancing surface finish), coatings to improve durability, and qualification/certification of material properties. Qualification and certification of end use materials is traditionally done by building destructive test specimens concurrently with the part. The test specimens are characterized and used to form an upper and lower boundary of the part's performance. For applications where material costs are high, significant costs are often incurred with qualification. Conversely, tooling requirements are often low and 
require less stringent qualification procedures. Thus, the tooling market may have lower barriers to entry for AM processing.

\subsubsection{Additional Case Studies of AM}

Table 4 provides a survey of typical build volumes and rates for commercial AM systems. In terms of build rate, extrusion technologies (extrusion, jetting, and directed energy) are relatively straightforward to estimate since is it directly related to flow rate of the material. Estimates of production rates for powder bed and vat systems are slightly more complex. The layer time is a function of both fusion and the preparation of the bed (raking and possibly preheating the material). Therefore, the majority of industry quoted rates is measured in layer time rather than volumetric rate. In order to provide a rough order of magnitude comparison between technologies, we bound the volumetric rate by assuming between $2 \%$ and $20 \%$ of the layer volume is fused in powder bed systems.

Table 4: AM Volumes and Rates

\begin{tabular}{|l|c|c|c|}
\hline System & Technology & $\begin{array}{c}\text { Build Volume } \\
\text { (cm x cm x cm) }\end{array}$ & $\begin{array}{c}\text { Build Rate } \\
\text { (cm } \mathbf{3} / \mathbf{h r})\end{array}$ \\
\hline Arcam Q20 & Powder bed fusion & 35 dia $\times 38$ tall & 20 to 400 \\
\hline Concept Laser Xline 2000R & Powder bed fusion & $80 \times 40 \times 50$ & 10 to 100 \\
\hline SLM Solution 280 HL & Powder bed fusion & $28 \times 28 \times 35$ & 20 to 35 \\
\hline Stratasys 900 mc & Material Extrusion & $91 \times 61 \times 91$ & 10 to 80 \\
\hline ExOne mFlex & Binder jetting & $40 \times 25 \times 25$ & 12 to 260 \\
\hline Stratasys Connex 500 & Material jetting & $50 \times 40 \times 20$ & 50 to 500 \\
\hline Optomec MR-7 & Direct energy & $30 \times 30 \times 30$ & 20 \\
\hline 3D Systems ProX 950 & Vat polymerization & $150 \times 75 \times 55$ & 50 to 600 \\
\hline Fabrisonic SonicLayer 4000 & Sheet lamination & $100 \times 60 \times 60$ & 500 \\
\hline
\end{tabular}

The rates quoted in Table 4 only consider the manufacturing process. Pre- and post-processing also impact total production rate. In the case of e-beam powder bed systems, the unmelted material is lightly sintered and must be mechanically removed, broken down, and filtered prior to reuse. Laser powder bed systems do not preheat the powder to the level of the e-beam systems, so powder separation is easier. However, the resulting increased temperature gradients of laser powder bed systems result in higher residual stress, which requires welding the parts to the start plate and heat treatment prior to part removal. Binder jet systems generate "green parts" that require sintering in a furnace prior to use. Material extrusion, vat polymerization, and material jetting systems produce near-net shaped parts but require the removal of support material either mechanically or chemically prior to use. Sheet lamination processes are additive or subtractive systems that require machining processes to remove material in-situ to the process. The magnitude of post processing varies from process to process. However, in general, the additive process is the main cost element in AM and is not currently competitive with traditional manufacturing processes.

The Johnson Controls automotive division conducted a case study in conjunction with Senvol LLC that compared the economic feasibility of AM automotive part versus a $\mathrm{CM}$ part using injection molding [23]. Although the specific part type and purpose are not listed in the report, the part dimensions are $25 \mathrm{~cm}$ x $12 \mathrm{~cm} \times 5 \mathrm{~cm}$ with 8,500 parts produced annually. Note that the component is a reasonable size but has a small production volume relative to the industry. The results show that using AM rather than injection molding allowed the redesign of the component studied and a reduction in its weight. However, the study also found that using current AM approaches (2014) was much costlier than traditional injection molding as seen in

Table 5 ( $\$ 2.64$ for the injection molded part compared with $\$ 39.42$ for the AM part). 


\begin{tabular}{l|cc}
\multicolumn{3}{c}{ Table 5: Manufacturing cost comparison. } \\
Cost component & Injection molding & Additive manufacturing \\
\hline Unit purchase price & $\$ 1.99$ & \\
New tooling & $\$ 0.36$ & \\
Tooling maintenance & $\$ 0.14$ & \\
Excess operational cost & $\$ 0.15$ & $\$ 26.65$ \\
Material cost & & $\$ 1.69$ \\
AM annual service cost & & $\$ 0.01$ \\
Redesign cost & & $\$ 9.42$ \\
AM machine cost & & $\$ 1.50$ \\
Qualification cost & & $\$ 0.15$ \\
Labor cost & $\mathbf{\$ 2 . 6 4}$ & $\mathbf{\$ 3 9 . 4 2}$
\end{tabular}

Although the study by Simkin and Wang [23] found there was a significant per-part cost premium using AM, the analysis also investigated how the cost premium of AM could be reduced through improvements in AM technology. The first item they considered was material cost. Traditional 3D printer companies generate revenue in three ways: machines sales, maintenance agreements, and material. The typical material markup is over 100 times more expensive than the material used in commercial-grade machines. For example, ABS plastic typically costs less than $\$ 1$ per pound when purchased in pellet form but is approximately $\$ 100$ per pound when purchased for industrial printers. Recent trends show that traditional machine tool manufacturers (e.g., Cincinnati Incorporated or Renishaw) are introducing AM products that use low-cost commodity feedstocks. Therefore, it is anticipated that the material cost for this part could drop to under $\$ 0.30$ per unit.

The next contributors to cost that Simkin and Wang [23] considered were the AM machine cost and annual service contract. A conventional industry AM system costs approximately $\$ 350,000$ and has a $\$ 35,000$ per year service contract. This is another trend that is changing. In 2015, Carbon3D announced [24] a partnership with Ford Motor Company under which Carbon3D is considering leasing equipment to Ford for $\$ 35,000$ per year rather than selling the machines to Ford. In addition, Carbon3D has developed a new polymer AM technology (Continuous Liquid Interface Production or CLIP) that grows parts 25 to 100 times faster than traditional AM systems [24]. Considering these recent AM developments-low-cost feedstocks, machine leasing options, and CLIP - the cost analysis presented in

Table 5 could change dramatically. If these developments prove to be viable at scale, material costs could drop by two orders of magnitude (a \$26.30/part savings), and machine cost could be replaced with a leasing cost at $1 / 10^{\text {th }}$ the cost (a $\$ 8.48 /$ part saving). Just these two fundamental changes would drop the cost of the AM part shown in Table 5 from $\$ 39.42$ to $\$ 2.95$, making AM costs very competitive with traditional manufacturing costs. Figure 20 highlights the magnitude of AM cost savings that are realizable in the near term.

With a substantial reduction in material and machine costs afforded by developments like that proposed by Carbon3D, as seen in Figure 20, the cost of plastic components produced through AM could become more competitive with existing injected molded parts. Moreover, these processes tend to be economically advantageous to complexity or clean-sheet redesigns because they place less emphasis on unique materials or properties developed through end-use applications research.

${ }^{9}$ Data from Simkin and Wang [23] 


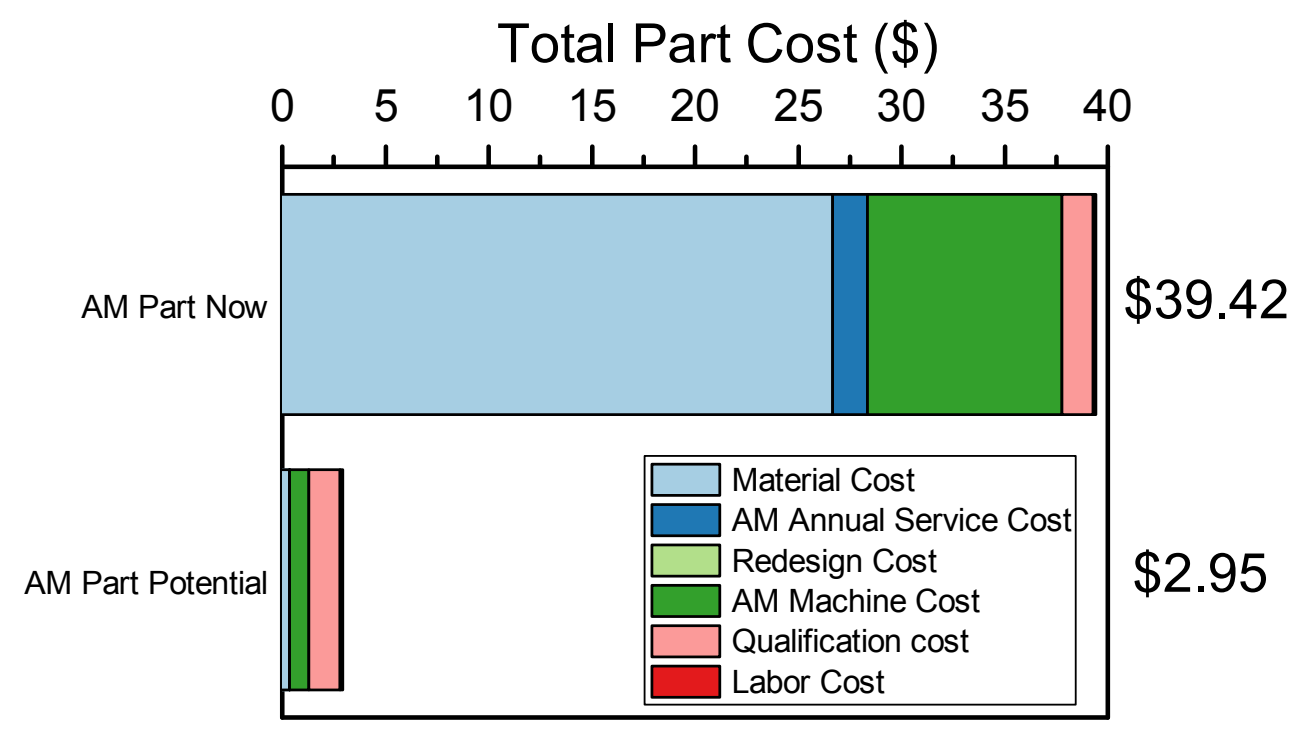

Figure 20: Total Part Cost of an AM produced component currently and proposed with potential cost savings. Source: Senvol, Inc, through ORNL.

Tooling is the foundation of many manufacturing industries. Tools or molds are used in the aerospace, automotive, and appliance industries to shape metal, plastic, and composite parts. For example, the automotive industry generally spends $\$ 200 \mathrm{M}$ on tooling for each car model. By 2018, tooling for the automotive industry is expected to exceed $\$ 15.2 \mathrm{~B}$ per year. More generally, tooling is also expensive $(\$ 10 \mathrm{~K}$ to $\$ 100 \mathrm{~K}$ per mold) and has long lead times (months to years). Part of these high costs can be attributed to manufacturing a small number of parts, including the production of one-off designs. The design time and allocation of capital costs required per part are increasingly high cost factors. Manufacturing small runs of components with complex designs and quick turnaround requirements is an area AM may target for early industry entry. As the technology matures, AM of molds, which fit the criteria of small runs, may have the potential to reduce $R \& D$ costs.

Because of weight concerns, the aerospace industry began to transition from aluminum to carbon fiber composites. The conventional approach for manufacturing composite structures is to layer the carbon fiber, core structure, and resin on a mold. The molds and composite materials are processed inside an autoclave to rapidly cure the resins and remove any air. The requirements for the molds are elevated operating temperatures (from $200^{\circ} \mathrm{C}$ to $375^{\circ} \mathrm{C}$ ), vacuum integrity ( 15 mbar over 60 minutes), and moderate pressures (100 psi) with tight dimensional tolerances (under 0.005 ” distortion). A conventional composite tool will cost more than $\$ 100 \mathrm{~K}$ and take several months to manufacture. ORNL recently partnered with Boeing, Ford, Techmer, and Boarder Security Force (BSF) to evaluate the feasibility and economics of using BAAM to produce composite tools. A variety of materials were evaluated including polyether ether ketone (PEEK), Ultem, Apollo, polyphenylene sulfide (PPS), and polyphenylsulfone (PPSF/PPSU). The final material of choice, based on performance and cost, was PPS loaded with $50 \%$ carbon fiber. The material cost was approximately $\$ 8 / \mathrm{lb}$. As an example, a modeled sample tool weighed approximately $65 \mathrm{lbs}$ and took 2 hours to print. Pre-processing time (setting up the machine and slicing the model) was approximately 2 hours. The mold was grown approximately 0.100 " oversized and machined using a Thermwood router to the final size. It took approximately 2 hours to transfer the mold to the router and another 5 hours to machine. Assuming labor rates of $\$ 50 / \mathrm{hr}$ and machining rates of $\$ 150 / \mathrm{hr}$, the total tool cost was approximately $\$ 1870$ (see Table 6). In terms of manufacturing time, from beginning to end, it took approximately 2 days to fully 
manufacture the mold. In comparison to SLS in the BAAM provides a more balanced distribution of costs; AM machine time is equivalent to material cost, and the cost of printing is close to the cost of finishing.

Table 6: BAAM Tool Cost Breakdown

\begin{tabular}{|l|c|c|c|}
\hline & Time/material & Cost & Percentage \\
\hline Pre-processing & 2 hours & $\$ 100$ & 5.3 \\
\hline Material & $65 \mathrm{lbs}$ & $\$ 520$ & 27.8 \\
\hline Processing & 2 hours & $\$ 400$ & 21.4 \\
\hline Post processing (labor) & & & 45.5 \\
\hline$-\quad$ Labor & 2 hours & $\$ 100$ & \\
\hline$-\quad$ machine & 5 hours & $\$ 750$ & \\
\hline Total & $\mathbf{9}$ hours & $\mathbf{\$ 1 8 7 0}$ & \\
\hline
\end{tabular}

ORNL provided a similar analysis for the same tool to be manufactured out of PPS on a Fortus 900 mc machine. First, material cost was roughly $\$ 650$ for $93 \mathrm{in}^{3}$ of material. The tool has $1725 \mathrm{in}^{3}$ of material. This brought the material cost to $\$ 12,018$. Production time with $0.020 "$ nozzle was 460 hours. An industrial FDM system capable of manufacturing this mold will cost approximately $\$ 350 \mathrm{~K}$ with $\$ 35 \mathrm{~K} /$ year service contracts. It was assumed that the system would be in service for 5 years with a $\$ 100 \mathrm{~K}$ trade in value and a $4 \%$ interest rate, the machine would cost $\$ 7800$ monthly. With a machine utilization of $50 \%$, the hourly cost of running the machine, excluding overhead associated with utilities and space charges, was $\$ 23 / \mathrm{hr}$. Therefore, conservatively assume the total hourly charge rate for an industrial FDM system is $\$ 40 / \mathrm{hr}$, this would bring the operating cost of the machine to $\$ 18,400$ and a total part production cost to $\$ 31,368$. This is still a very attractive cost for composite tooling but highlights how manufacturing time (460 hours for FDM vs 9 hours for BAAM) and low feedstock cost (\$8/lb vs $\$ 180 / 1 b)$ can result in a 17X reduction of AM costs $(\$ 31,368$ for FDM vs. $\$ 1,870$ for BAAM) and 50X increase in production rate. Figure 21 through Figure 23 show the cost distribution between three AM technologies: SLS, FDM, and BAAM.

Table 7: FDM Tool Cost Breakdown

\begin{tabular}{|l|c|c|c|}
\hline & Time/material & Cost & Percentage \\
\hline Pre-processing & 2 hours & $\$ 100$ & 3.2 \\
\hline Material & $65 \mathrm{lbs}$ & $\$ 12,018$ & 38.3 \\
\hline Processing & 460 hours & $\$ 18,400$ & 58.7 \\
\hline Post processing (labor) & & & 2.7 \\
\hline$-\quad$ Labor & 2 hours & $\$ 100$ & \\
\hline$-\quad$ Machine & 5 hours & $\$ 750$ & \\
\hline Total & $\mathbf{9}$ hours & $\mathbf{\$ 3 1 , 3 6 8}$ & \\
\hline
\end{tabular}




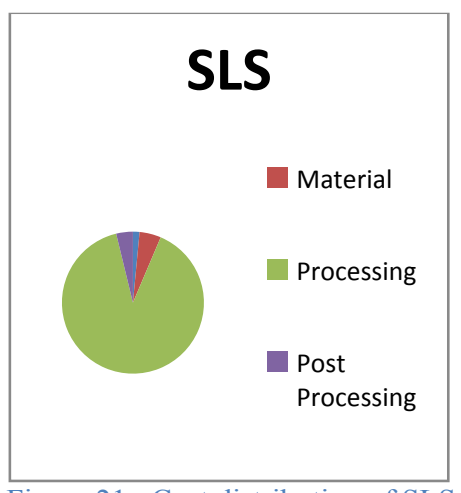

Figure 21: Cost distribution of SLS (selective laser sintering)

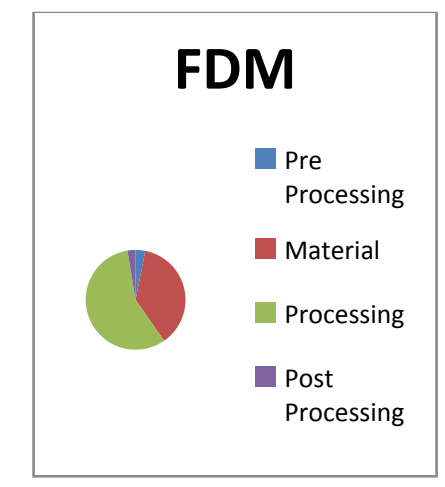

Figure 22: Cost distribution on FDM (fused deposition modeling)

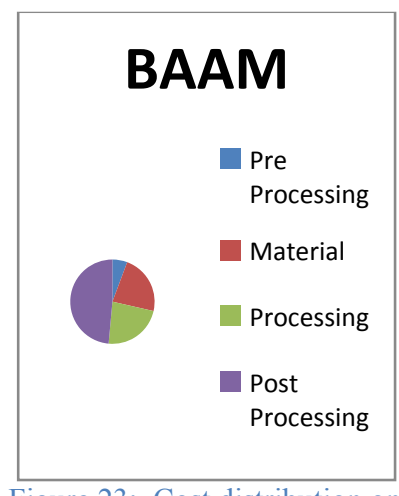

Figure 23: Cost distribution on BAAM (big area additive manufacturing)

\section{POTENTIAL APPLICATIONS OF CURRENT ADDITIVE MANUFACTURING SYSTEMS IN WIND POWER SYSTEMS}

Several application areas have been identified where technological advancements in AM processes are economically viable for small and large-scale wind energy tooling and component production. Furthermore, if wind applications were used as a target to drive the development of AM systems, more applications with significant economic benefits may become achievable.

\subsection{BLADE MOLDS}

The first identified application is in the manufacture of tooling, such as molds for wind turbine blades. Tooling is a primary target for the current state of AM technology because of its rapid prototyping capabilities. Molds of various sizes and shapes have been produced for a variety of industries. Large tooling however, remained out of reach until the development of large scale composite AM manufacturing processes like the Cincinnati BAAM. Figure 24 shows the ORNL/TPI AM blade mold demonstrator produced as a collaboration between ORNL and TPI and funded by DOE's Advanced Manufacturing and Wind Energy Technologies Office (WETO). 


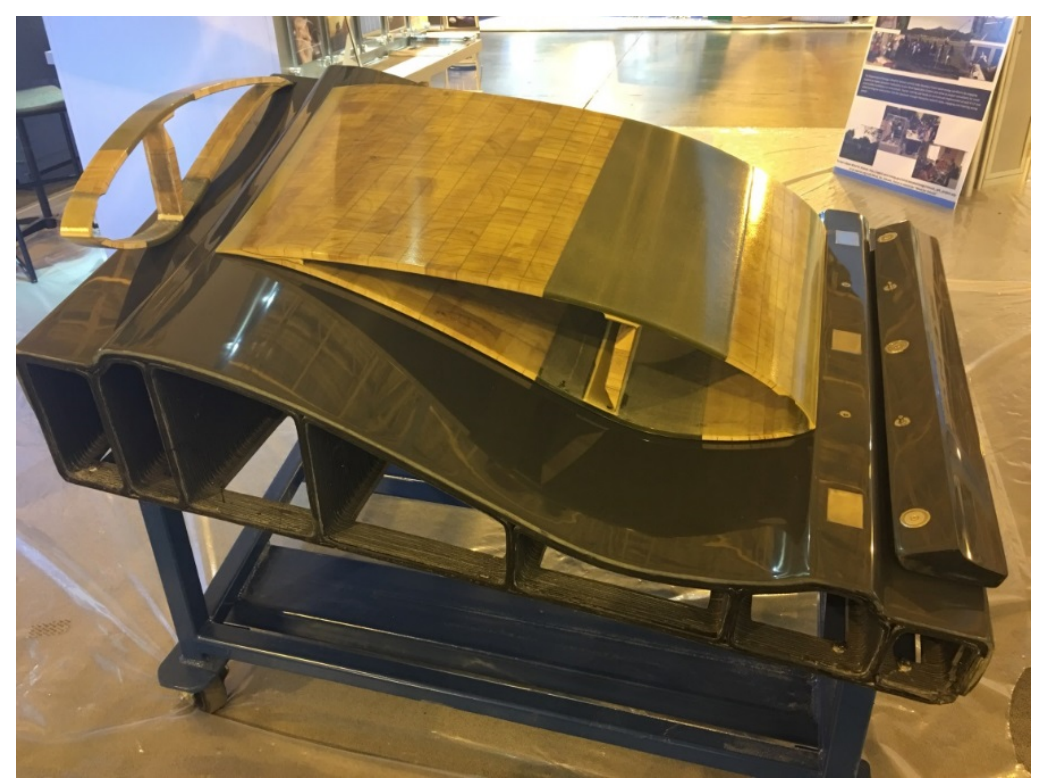

Figure 24: Additively manufactured blade mold and produced blade section.

The traditional blade mold manufacturing process is a multi-step, expensive operation. First, a plug is manufactured by subtractive machining of foam and tooling resin. This multi-piece assembly takes several weeks-to-months to produce from CAD drawings that generate computer numerical control (CNC) toolpaths. From there, the plug is shipped to the mold manufacturer where it is qualified and aligned. The mold manufacturer then applies a release agent and lays up fiberglass of sufficient thickness to support the molding operations. Miles of heating wire is manually embedded in the underside of the mold and arranged in zones of similar area. A steel frame then is manually erected and attached to the mold, prior to removal from the plug. From one plug set, up to eight molds can typically be produced amortizing the cost of the plug across multiple molds of the same design. For the production of one prototype mold, or a small set of molds, the cost, which can often reach into the millions of dollars, can be prohibitively expensive.

\subsubsection{ORNL- TPI Scaled Wind Farm Technology (SWiFT) Facility Mold}

The Sandia National Laboratories Scaled Wind Farm Technology (SWiFT) facility is a wind energy testing facility that uses multiple wind turbines to measure how wakes interact with one another. These turbines use custom-designed blades to simulate the dynamics of larger utility-scale wind turbines. As part of the R\&D, one set of blades will be produced using an AM mold fabricated in partnership between ORNL and TPI Composites, Inc. and funded by DOE's Advanced Manufacturing Office (AMO) and WETO. This research effort serves as a case study to examine not only the technological impacts of AM on wind blade tooling for the SWiFT site at the National Rotor Testbed (NRT), but also the economics of AM for utilityscale wind blade molds using the BAAM technology. 


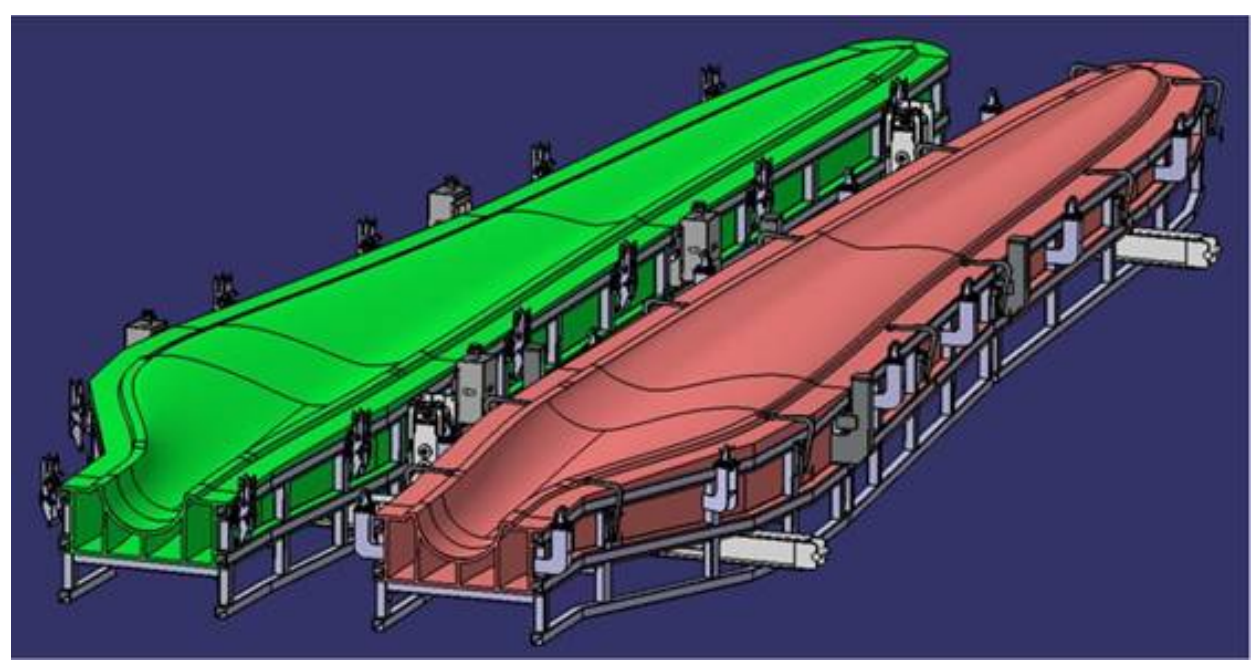

Figure 25: ORNL/TPI AM blade mold

By bypassing the plug step in the mold manufacturing process, a significant portion of the overall production cost can be reduced. As shown in Figure 25, the ORNL/TPI SWiFT blade mold uses AM in several sections and then is integrated into a steel frame used to align the halves of the mold and allow rotation of the high-pressure side on top of the low-pressure side. Produced in 16 additively manufactured sections, the design of the heating channels has been integrated into the mold sections themselves, reducing the manual labor cost associated with the emplacement of the heating wire to achieve the molding temperature of $50^{\circ} \mathrm{C}$.

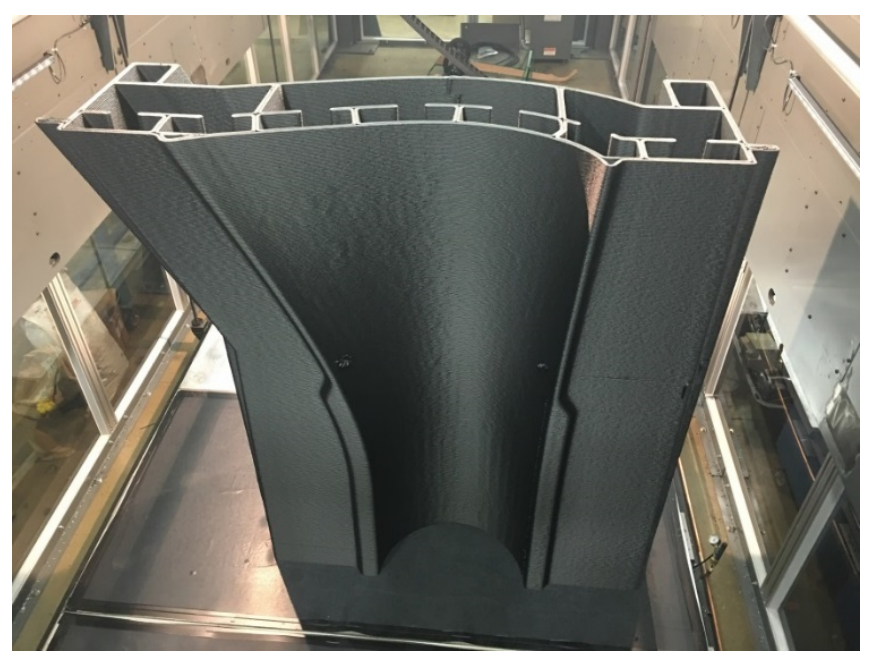

Figure 26: Printed low-pressure side section 1 in the BAAM CI printer 


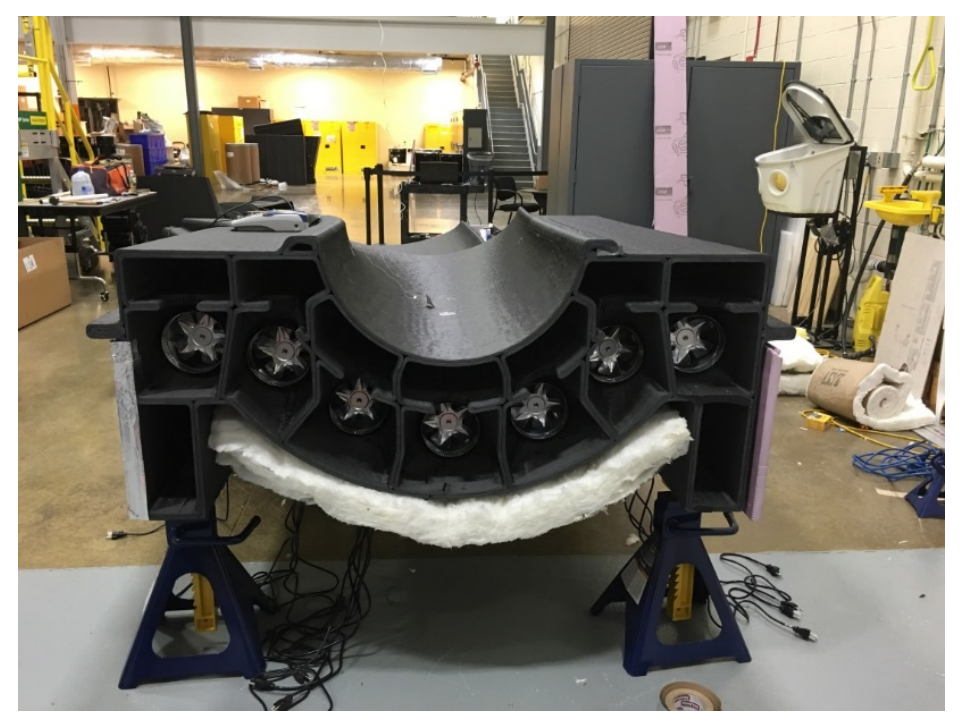

Figure 27: Integrated ORNL/TPI heater units in blade mold section

Each section of the mold is printed on end to maximize the resolution of the BAAM process and reduce the required support material as shown in Figure 26. Figure 27 demonstrates the arrangement of heater units in the SWiFT mold set for the uniform heating of the mold surface. Each channel has been designed to be of equal surface area to reduce non-uniformity of the temperature profile over the surface of the mold. Hot air is circulated through the mold until the surface temperature reaches the desired set point, at which point the set point is lowered to a maintenance level.

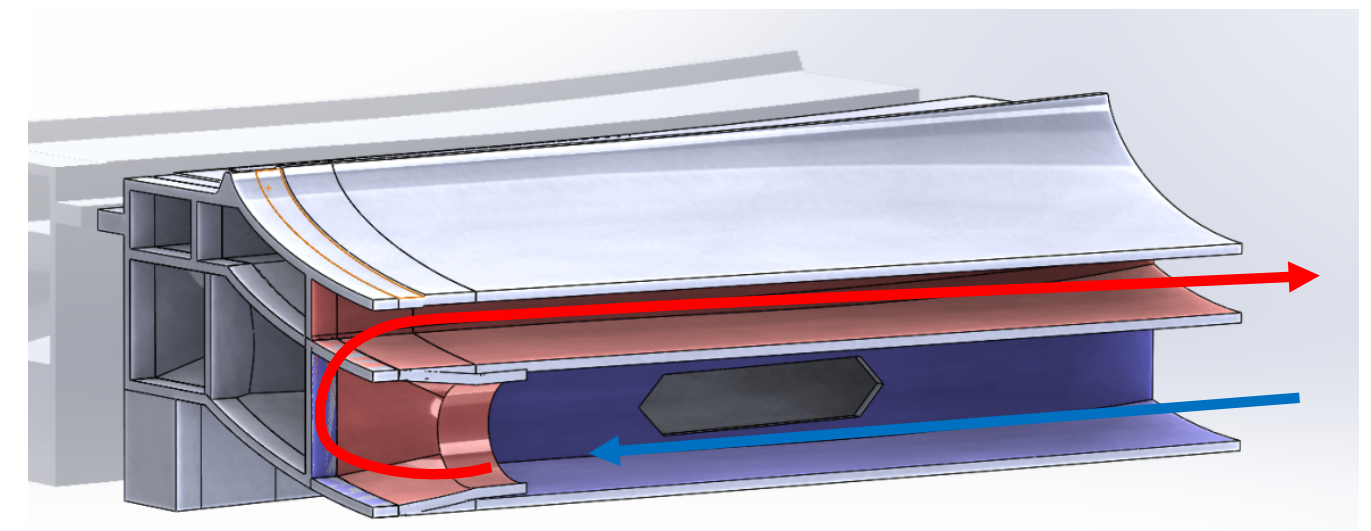

Figure 28: Airflow in a mold section

A cross-sectional view of the $2^{\text {nd }}$ mold section is shown in Figure 28. Arrows describe the heat flow. Hot air exits the heater unit and flows along the surface of the mold. It then loses energy and recirculates forming a closed loop. The functional structure of the AM component is used to achieve the desired surface geometry, to provide a housing for the heating unit, and to distribute the heat uniformly throughout the structure. AM enables a functional structure and eliminates the manual labor associated with the emplacement of the heating system. Furthermore, a failed heating unit is easily replaceable via a pocket on the underside of the return channel. 
Figure 29 shows the sections of the SWiFT AM blade mold produced in 2016. While many of the technical opportunities of AM in wind mold production are addressed in the production of the SWiFT mold, it also serves as a tool for the evaluation of economic incentives for similar molds on larger scales.

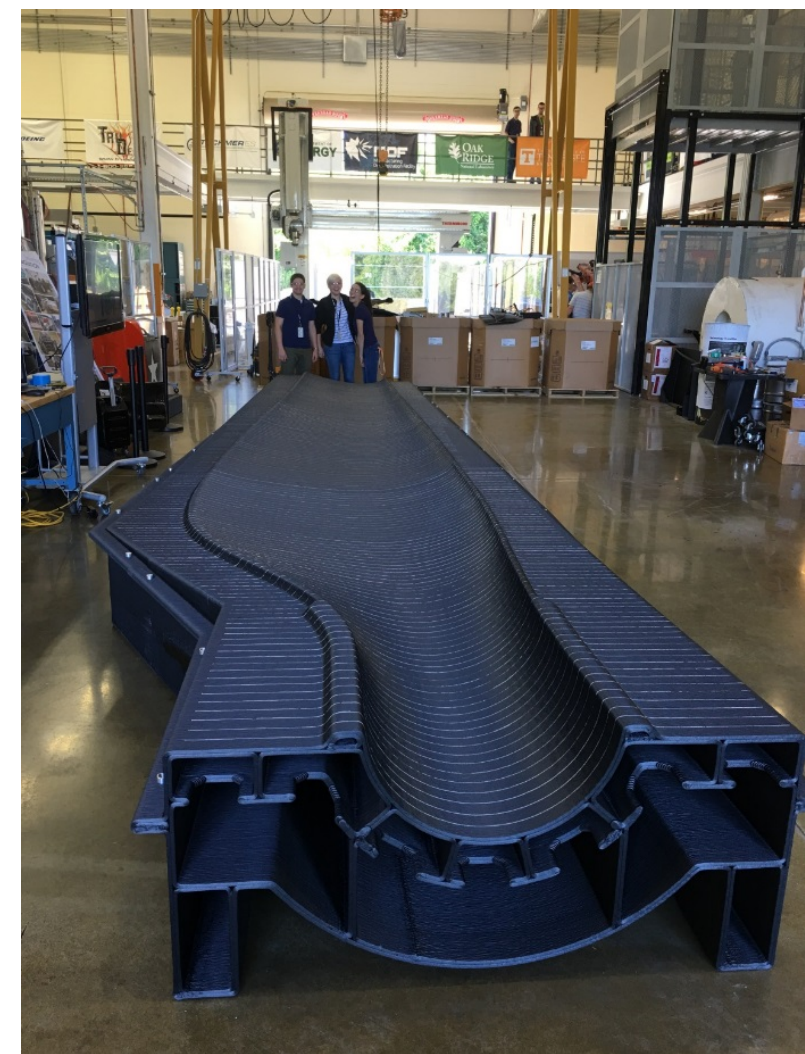

Figure 29: 5 of the 8 low-pressure side SWiFT mold sections

\subsubsection{Economics of Large-Scale AM Blade Mold Production}

To evaluate the economics of AM wind turbine blade molds in a production environment, an analytical model was created using the Clean Energy Manufacturing Analysis Center (CEMAC) methodology, which accounts for all steps in the manufacturing processes including equipment and materials as previously described. CEMAC has also compiled its own databases with information from publicly available sources including data about country specific labor rates, energy prices, corporate tax rates, interest rates, and shipping rates. This process flow was analyzed from design to end-use as previously presented in Figure 1. The model serves as a tool to gauge the relative impact of manufacturing factors on the overall cost of production for the AM molds. Specific information about AM and the wind energy industry were collected from subject matter experts. This includes interviews as well as data collected from market reports, press releases, news articles, and company websites.

Inputs to the model are broken down by several variables, including blade design parameters, material costs, labor factors, process parameters, and mold geometry. The model details output costs associated with materials, labor, energy, facilities, equipment, and maintenance costs with the toolset, and the selling, general, and administrative expenses or SG\&A. CEMAC models assume all materials and equipment are purchase at full market price. Expenses for facilities, maintenance, and equipment are based 
on standard depreciation schedules and charges. The CEMAC AM blade mold model assumptions and scenarios are listed in Table A, found in Appendix A.

Two sets of analyses have been performed. The first assumes the AM machine is dedicated to the production of the AM molds; the second case assumes the AM machine is fully utilized. These two cases portray different business models, where AM machines are dedicated to a particular process or are shared across manufacturers or end products. The two models represent near-term use of AM prior to the full establishment of AM technology throughout industry, or the models represent the choice businesses may make to invest in their own AM machines for additional $R \& D$ or intellectual property protection. The dedicated AM machine is modeled in a typical wind blade manufacturing facility that can produce 1,800 blades per year, with each blade being 50-meters long. It is assumed that this level of blade production requires a minimum of two molds per year, with each mold being used to produce approximately 1,000 blades, With the current SWiFT tool, i.e. the BAAM machine, processing speed, 4 molds (each at 50meters) would be the maximum manufacturing capacity per year. Based on this information, CEMAC chose the minimum requirement for production of two molds per year and the full utilization of each tool scenario. The variables for each scenario can be found in Table A, located in Appendix A. The second configuration assumes that the tool will be fully utilized by building blade molds as well as working on other projects.

First, the 13-meter SWiFT blade mold project was calculated using the construction values obtained from ORNL, and for two molds per year, the per mold cost is calculated to be approximately $\$ 284 \mathrm{k}$. These calculated values are displayed in Figure 30, which highlights material and equipment as the biggest contributors. The data shows that with the lower tool utilization factor, the cost breakdown for this project is highly dependent on the capital cost of the tool. The maintenance and SG\&A charges make up a significant portion of the overall cost. It is unlikely that in a full production facility an AM tool with this capability would operate with this low of a utilization factor. The AM tool could be used to facilitate more lean manufacturing processes into the assembly. For example, the nacelle is one component that could be manufactured using this AM technology.

TOTAL COSTS BY CATEGORY: \$/Mold United States

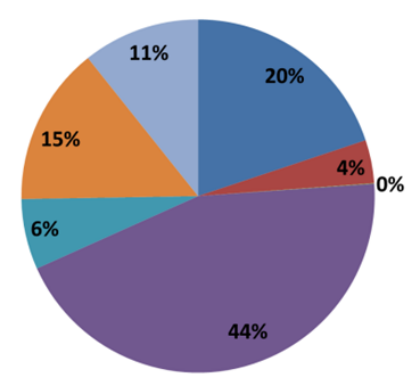

TOTAL COSTS BY CATEGORY: \$/Mold United States

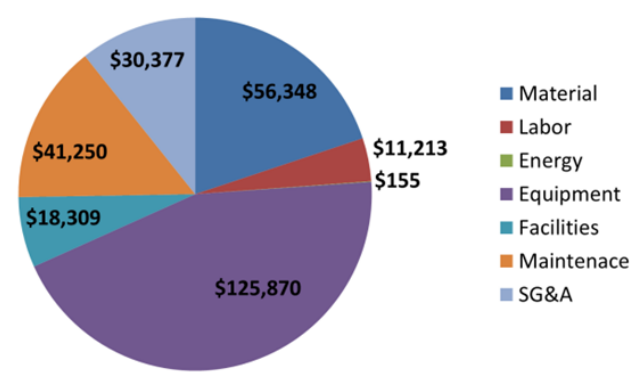

Figure 30: Mold cost breakdown (\$ and \% proportion) for $13 \mathrm{~m}$ AM molds made in the U.S. (2 per year)

The data was also used to calculate the cost of the SWiFT project with 50-meter blade molds, as shown in Figure 31. Overall, the total per mold cost could be approximately $\$ 641 \mathrm{k}$. Under this configuration a fully utilized tool is shown, where four 50-meter molds are produced per year. The modeled tool downtime was assumed to be $10 \%$ for maintenance and outages. The breakdown shows that the equipment tool costs become a significantly smaller factor. As expected, the material costs, including the mold material and to a lesser extent the consumable parts, become the most significant cost. The less intuitive change represented in the breakdown is the increase in labor costs. The build platform of the SWiFT tool is restricted to less than two meters. It is worth noting that the 13-meter blade molds need only 18 sections, compared to 60 
sections for the 50-meter mold. The labor required in moving, assembling, and configuring the sections increases three-fold.

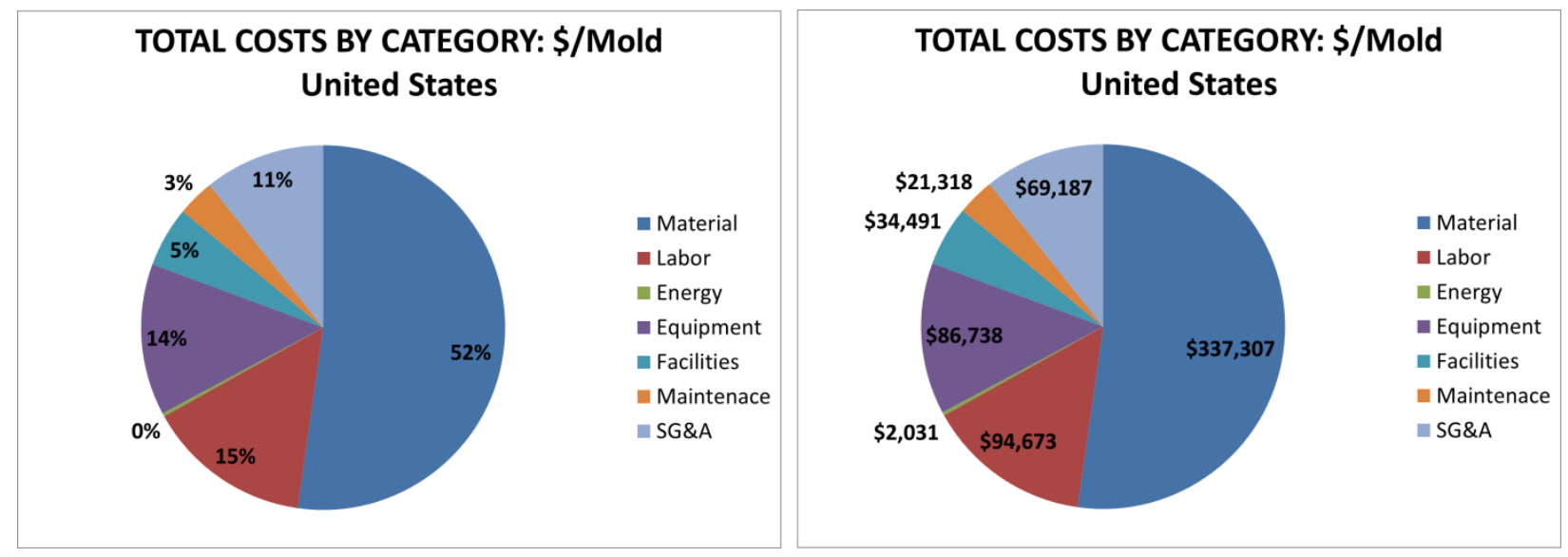

Figure 31: Mold cost breakdown (\$ and \% proportion) for $50 \mathrm{~m}$ AM molds made in the U.S. (4 per year)

Further analysis of the 50-meter AM blade mold scenario using both the current SWiFT tool and a next-gen AM tool known as Ingersoll 1, depicts the breakdown of cost categories across specific countries that are leaders in wind blade manufacturing and AM. Both the SWiFT AM tool and Ingersoll 1 were fully utilized, producing 4 and 48 molds per year respectively. This country breakdown can be seen in Figure 32 . Because of the relatively new nature of AM in this field, no discount of material costs was used in any country. Although in the future, it is conceivable that discounts in materials could be achieved similar to the discounts offered at current material refinement centers. The modular nature of this scenario does show that a $10 \%-20 \%$ price difference could be achieved by manufacturing overseas in countries with cheaper labor, using current generation AM tools like SWiFT. As highlighted, using the SWiFT tool would require 60 sections to build the 50-meter blade mold, and as such would require significant labor in the assembly.

Shipping for these components would account for less than $1 \%$ of the total cost. However, as cheaper multiple blade mold configurations could greatly enhance the R\&D of flexible manufacturing available from AM technologies, in-house design and fabrication is more likely. Additionally, shipping time and delays to R\&D progress could be significant. Further, cost improvements in AM manufacturing would shrink the benefit of overseas labor cost savings. A key benefit with these AM systems is the ability to manufacture at local system build sites. This allows for quick install and disassembles of the AM tool. As processing speeds and build size restrictions are reduced, labor requirements are reduced. The cost difference across locations becomes smaller and shipping becomes more cost prohibited with component size.

Looking forward, research in AM is resulting in the development of tools that are increasing in build size and deposition rate. A roadmap analysis of future AM tools was completed with the CEMAC model. ORNL's partnership with Ingersoll to build polymer AM machines capable of producing 50-meter AM blade molds in one, fully-built section, may significantly reduce labor costs associated with the current process that generates multiple sections. Currently, it has been estimated that a 50-meter mold would need 60 sections based on the current AM machine capability. As seen in Figure 32, producing the 50-meter blade molds using the Ingersoll 1 tool, could erode the labor savings from countries with cheaper labor, and thereby allow U.S. blade mold costs to be similar in per mold cost and increase cost competitiveness. 

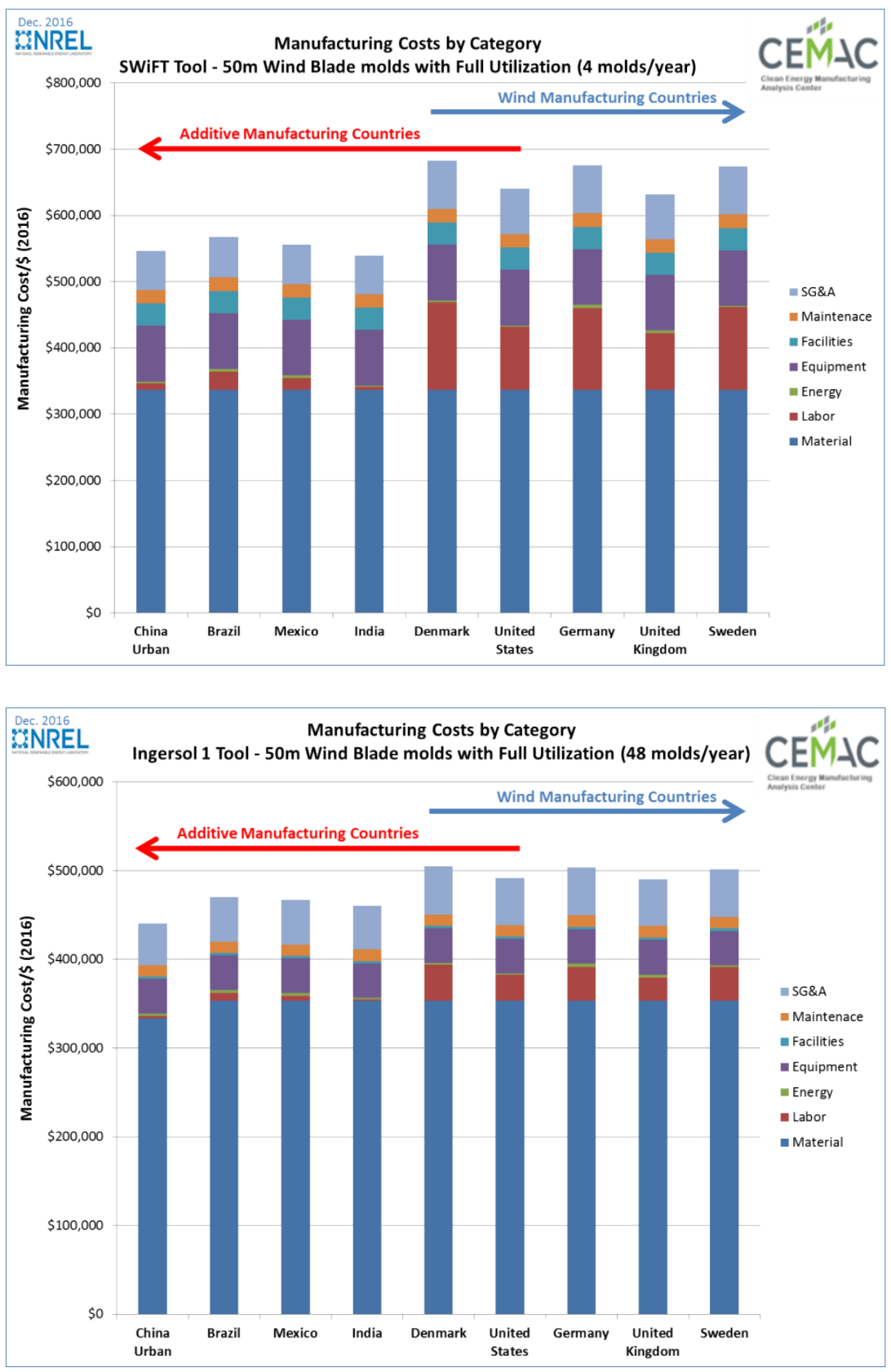

Figure 32: AM mold cost breakdown (\$) for $50 \mathrm{~m}$ AM molds modelled for Swift Project and Ingersoll I Project in 9 countries in the world

Figure 33 shows the dedicated yearly cost per AM mold for the current 13-meter blade molds using the SWiFT tool (i.e. BAAM machine). It also shows the cost of the 50-meter molds with the same AM tool, and then compares costs using the Ingersoll 1 and Ingersoll 2 AM machines. The Ingersoll machines can produce the 50-meter blade mold in a single build operation, but the size and build volumes are capital intensive. It is worth noting that the Figure 33 is based on producing two AM molds per year. The remainder of the time, it is assumed the machines are used for manufacturing other parts. However, depending on research, development, demonstration, and deployment (RDD\&D) goals for testing and manufacturing designs for different wind regimes, the machines could be used to produce more molds. 


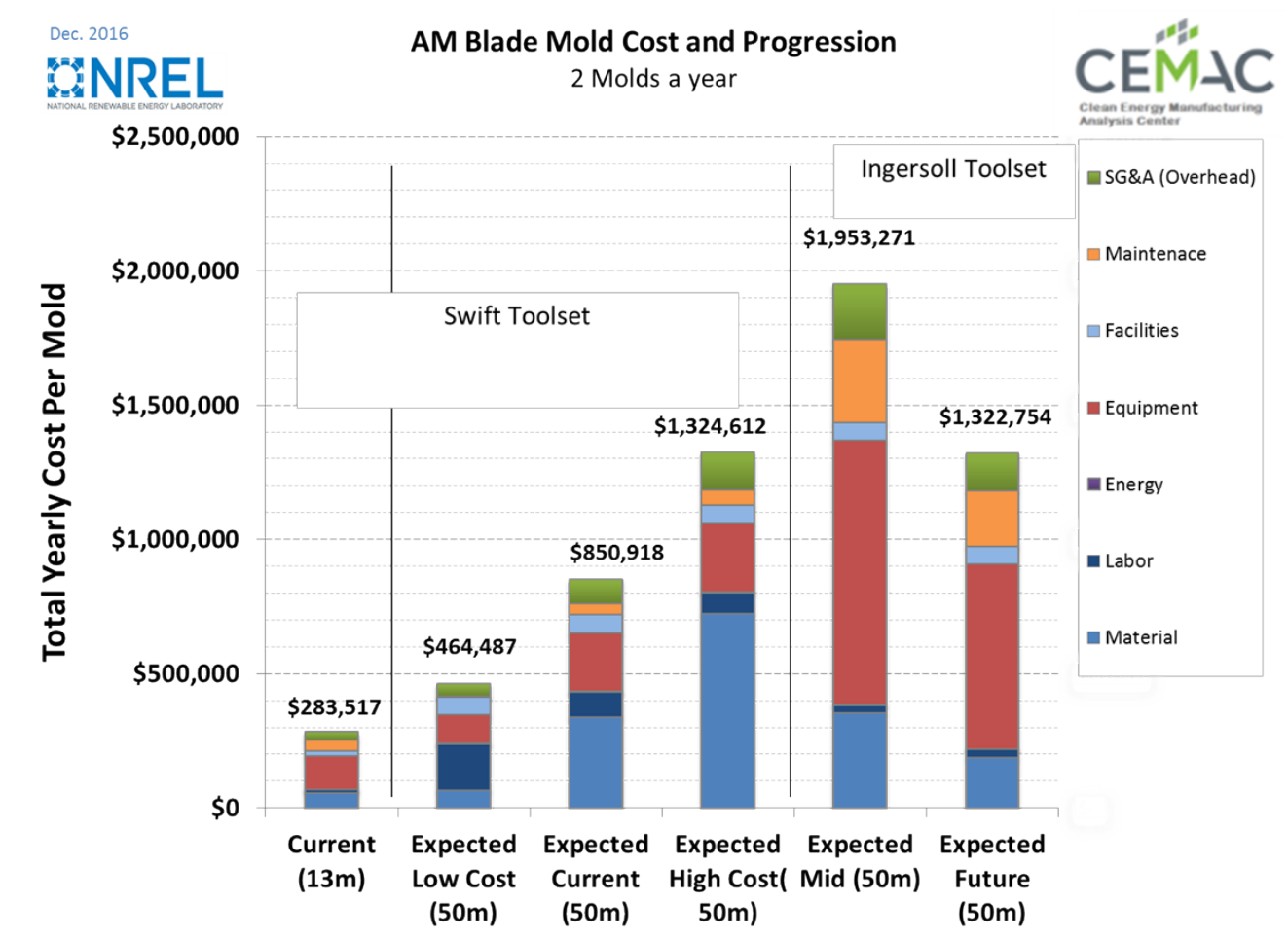

Figure 33: AM Blade Mold Cost and Potential Roadmap progressing to larger tools in the future

The current 13-meter AM blade molds that were made for the SWiFT project, based on the CEMAC modeling, cost approximately $\$ 284 \mathrm{k}$ per mold. Approximately $44 \%$ of that cost comes from the cost of the AM equipment. The current material cost to ORNL for the 13-meter blade molds is approximately $\$ 9.55 / 1 \mathrm{~b}$, and is considered a key variable both for the 50-meter blade mold and for future larger machines such as the Ingersoll 1 and 2.

The current AM machine used for the SWiFT project can also make the 50-meter blade molds. Therefore, three scenarios have been created for analysis: 1) Low Cost, 2) Expected Current, and 3) High Cost. The same AM machine that produced the 13-meter molds is used to make the calculations for the 50meter molds. The cost of two 50 -meter AM molds per year ranges from $\$ 464 \mathrm{k}$ to $\$ 1,325 \mathrm{k}$. A key difference between the 13-meter and 50-meter AM molds is the difference in required sections. The 13-meter mold requires 18 sections to be printed and assembled; the 50-meter mold requires 60 sections to be printed and assembled. This is immediately recognizable in the 50-meter scenarios because labor costs increase dramatically from assembly of the sections. In the Low Cost scenario, labor expenses make a significant impact on the per mold cost, reaching almost a third of the per mold cost. As the material cost per pound rises in the Expected and the High cost scenarios of the 50-meter molds, the proportion of total costs due to materials rises significantly. In the High Cost Current 50-meter mold scenario, the material cost is slightly higher than the current material cost for the 13 -meter molds $(\$ 9.83 / \mathrm{lb}$ compared to $\$ 9.55 / \mathrm{lb})$. For all three of the 50-meter AM mold scenarios, certain variables such as setup time per section and the energy requirement for heat per unit area was assumed to remain constant.

With the use of the next-gen Ingersoll 1 and 2 machines, there is a step change in the cost of some of the variables associated with the AM machine. The midterm Ingersoll 1 scenario could potentially occur in 3-5 years based on ORNL's estimates, while the Ingersoll 2 future scenario may be realized in 5 years or more. In the midterm, if only 2 molds were made per year with a dedicated Ingersoll 1 machine, it could be expected the per mold cost could be approximately $\$ 1,953 \mathrm{k}$ (compared to the current estimated $\$ 850 \mathrm{k}$ 
from building the 50-meter AM mold in sections). The most important variable for the Ingersoll 1 and 2 machines is the 10x increase in material deposition and build size relative to the current SWiFT AM machine. For example, ORNL has estimated that in using an Ingersoll 1 instead of the current SWiFT (BAAM) machine, the material deposition rate could increase to $1000 \mathrm{lb} / \mathrm{hr}$ instead of $100 \mathrm{lb} / \mathrm{hr}$, and the mold could be built a one piece. As production cycle time increases, labor costs decrease. The significant jump in the equipment costs associated with the molds from the Ingersoll 1 and 2 AM machines is caused by the high midterm and future cost scenarios of these very large AM machines. A conservative estimate puts the Ingersoll 1 and $2 \mathrm{AM}$ machine costs at nearly $\$ 11.25 \mathrm{M}$ in the midterm and $\$ 7.5 \mathrm{M}$ in the future. A large jump in the cost of the Ingersoll 1 machine relative to the SWiFT machine should be expected with such a large, untested, and currently developing AM machine.

If only two 50-meter AM molds are made per year on a dedicated Ingersoll 1 machine, the equipment costs for each mold could be as high as $\$ 983 \mathrm{k}$. It is important to note that the maintenance and SG\&A costs for such large AM machines are likely to impact the per mold cost. In the case of the Ingersoll 2 , the material and equipment costs decrease. Utilization of large AM machines like the Ingersoll 1 and 2 is key to recouping the capital invested and ensuring the machines are producing a quantity of AM parts and molds throughout the year. Considering that the Ingersoll 1 machine can produce two 50-meter blade molds in a week, the AM machine would be highly underutilized and would benefit from producing many other parts.

Figure 33 may be considered the "worst case" scenario. In Figure 33, the SWiFT, Ingersoll 1, and Ingersoll 2 AM machines are producing 50-meter blade molds according the blade requirements of a large wind blade facility, producing on the order of 1,800 blades per year. Even in this case, the cost per mold for the Ingersoll 1 and 2 molds is approximately $\$ 1,300 \mathrm{k}$ to $\$ 2,000 \mathrm{k}$. Considering that one blade mold can produce 1,000 blades, this amortizes to less than $\$ 2,000$ per blade for the mold cost. $\$ 2,000$ is a small amount per blade and has high potential for cost reduction. Getting access to blade mold costs for real wind blade facilities is very difficult and is considered proprietary, business sensitive information. Research by ORNL and discussions with industrial mold manufacturers, indicate that today's wind blade mold could be of the order of $\$ 2-3 \mathrm{M}$, which highlights that 50-meter AM blade molds today could be cost competitive to $\mathrm{CM}$ blade molds. Additionally, and more importantly, R\&D costs could be significantly reduced and greater customization of wind turbine blades could be realized through refined AM.

In Figure 34, the same cases are revisited with full utilization of the AM toolset. With full utilization of the AM toolset, the proportion of costs associated with capital expenses decreases significantly. With the Ingersoll 1 and $2 \mathrm{AM}$ machines (which can produce up to 50 blade molds per year), it is possible that the midterm per mold cost could be reduced to approximately $\$ 491 \mathrm{k}$. In the future 50 -meter scenario, the cost drops to approximately $\$ 284 \mathrm{k}$. Full utilization decreased equipment capital costs per mold, and smaller maintenance and SG\&A costs are also associated with full utilization. The cost decrease per mold for the midterm of the Ingersoll 1, when producing two molds per year, is estimated at more than $\$ 1,500 \mathrm{k}$. Material cost is still expected to be responsible for a significant portion of the associated costs. The equipment costs will significantly decrease as number of molds produced increases. As demonstrated at ORNL and by existing users of large AM machines, it is common for large AM machines to be used close to 24 hours per day because of the large initial capital cost and the desire to use the tool for multiple applications e.g. wind molds, ship and boat hulls, and defense items. In the future, AM tools for on-site wind manufacturing could be used for many components such as the blade molds, nacelle covers, generator magnets, and even heat exchangers. An AM tool's ability to use different materials would allow for higher utilization factors in different manufacturing processes. System design changes could be incorporated to use materials not traditionally considered in certain applications. Each AM manufactured component provides new opportunities and challenges for engineers and designers. While AM is not currently the answer for all manufacturing needs, it can provide quick, reasonably priced alternatives to $\mathrm{CM}$ when the tool is used at a high rate. 


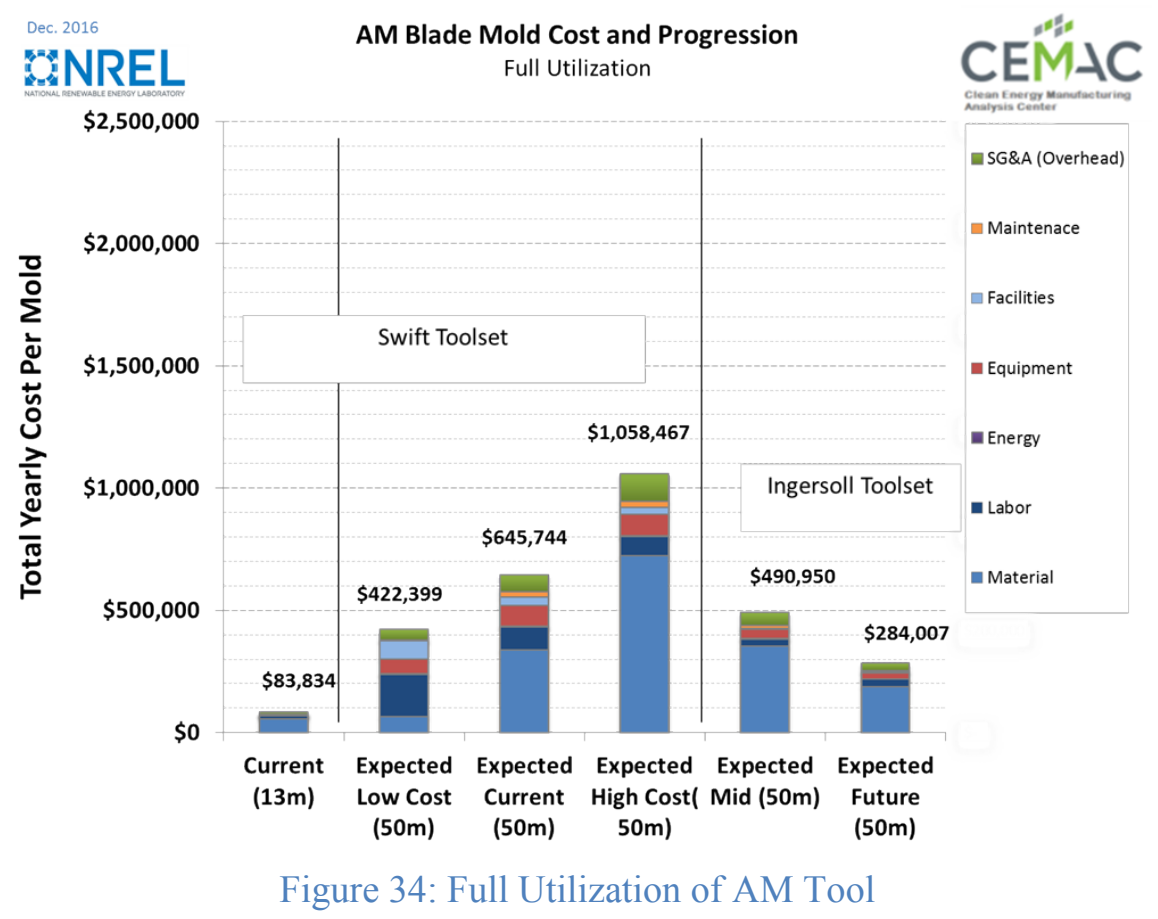

For wind, the key benefit from using AM lies in much more than the blade molds. The use of AM allows for a significant increase in design complexity, while saving material and assembly costs. The AM tools of the future are expected to have the ability to be used for multiple processing steps; this will drive down the unit cost for production. This flexibility allows for complete changes in design of wind components and structures, including the use of different materials. Such changes could result in the ability to customize wind turbines for the wind resource at specific locations, even resulting in on-site manufacturing of various designs within the same wind farm. Such customization could result in a more efficient operation of the entire installation

\subsubsection{Areas for Additional Economics and Supply Chain Analysis}

This cost analysis has been conducted for the production of blade molds using polymeric AM machines. As discussed above, AM encompasses many different deposition technologies for very specific manufacturing tasks. As these technologies mature, the AM machines will become tasked with multiple operations in manufacturing. Understanding the cost benefits of each technology in specific manufacturing processes will become critical to continued adoption. Industry-wide adoption will potentially unlock opportunities for lower manufacturing costs and more efficient operation of wind turbines.

Analyzing the Technology Readiness Level (TRL) level of the different AM technologies and their applications identifies specific areas of research that still need addressing. AM for metal materials follows some very similar building processes as the polymeric machines, but the pre- and post-processing steps can be quite different. Therefore, the cost and time structures of the builds may vary. Refinement of powder metal materials may also lead to more expensive raw metal material than conventional manufacturing materials. Analyzing the upstream manufacturing limitations costs for AM materials in metals and polymers identifies the largest cost drivers and opportunities for reduction. 
The comparison between AM and CM regarding complex parts could also be studied to identify how AM may increase the speed of manufacturing, which potentially reduces costs and LCOE. Designing components with more flexibly to meet operation requirements should be studied to determine if more complex designs affect manufacturing costs and onsite installation time and costs. For example, a quicklocking mechanism used for tower assembly or the replacement of components within the nacelle with a single additively manufactured part, should be studied in the context of the entire supply chain, including impacts on LCOE.

Identifying components where material changes could lower costs is another area to analyze in the future. Identifying the key wind components, including large blades, towers, and nacelles that can be manufacturing in current build areas with different polymer materials, coupled with design changes could affect AM's ability to compete with CM on cost alone. Newly developed AM polymers could also be designed to take advantage of reduced weight without sacrificing strength. Reduced weight saves on shipping costs as well. Understanding how changes costs of materials, labor, shipping, and capital equipment affect the economics of wind manufacturing helps determine situations where local manufacturing is the cheapest option. Along with the potential reduction in AM machine cost, the understanding of material costs, key supply chain constraints, and material behavior properties will be critical for accelerating industry adoption of AM.

Finally, to better understand the potential AM offers for extensive customization of wind turbine designs, an analysis could be conducted to couple engineering design models and LCOE models. With AM, components such as blades and towers could be customized to take full advantage of the wind resources, topography, and grid requirements at specific locations. The impact of such customization is currently unknown, but it could provide additional insight into the opportunities and limitations of AM technologies.

\subsection{NACELLE COVERS}

Nacelle covers provide an aerodynamic shell around the wind turbine components and a safety barrier for service personnel. Opportunities for improvement to nacelle covers through AM include improved technical and economic incentives in producing molds for their fiberglass construction and a paradigm shift in their manufacture through direct AM.

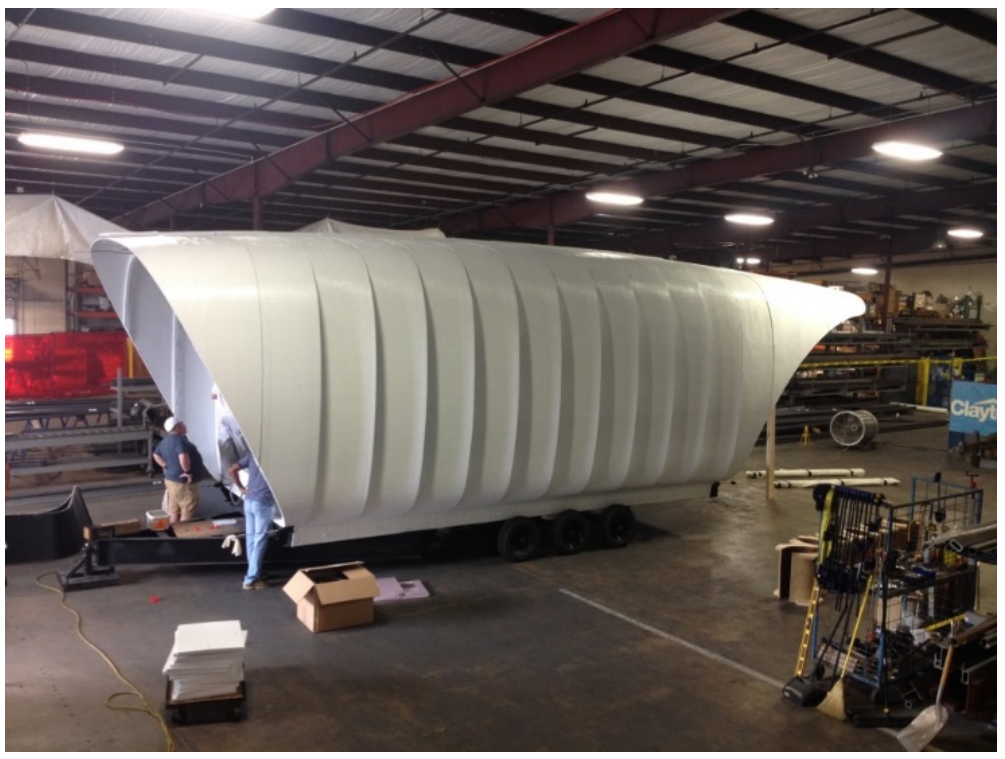

Figure 35: ORNL AMIE structure 
Challenges in traditional nacelle design include high part count, passive cooling, weather protection, and ergonomics. While the geometry of a nacelle is replicable, as demonstrated by the shell of the ORNL Additive Manufacturing Integrated Energy (AMIE) structure shown in Figure 35, the opportunities in direct AM of the nacelle are found in the functionalization of the structure to include passive airflow systems, which are integrated wire ways and structural bases for housing the components of the nacelle.

Some of these features were already demonstrated in the AMIE project. Shown in Figure 36, are the integrated wire ways and printed housings for components like windows.

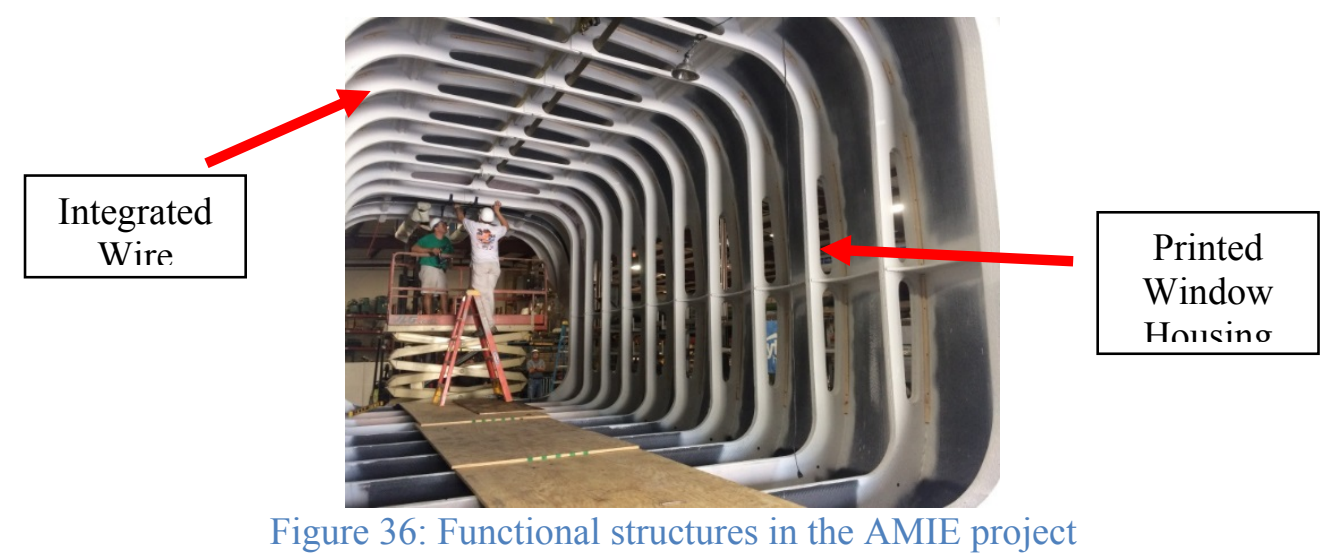

\subsection{MAGNETS}

Rare earth materials represent a significant supply chain problem for the wind industry, and high strength magnets, which rely on rare earth materials, are used throughout wind systems. Large permanent magnets are required for direct drive turbines, which are an emerging technology. Magnets are often used to secure ladders and platforms in wind turbine towers to reduce stress caused by welding the tubular structure.

Technology for 3D printing bonded magnets is emerging (Figure 37). Microstructural control, or the ability to selectively control where and when the rare earth materials are deposited, offers promise to reduce the amount of rare earth materials used without sacrificing the bulk properties of the magnet.

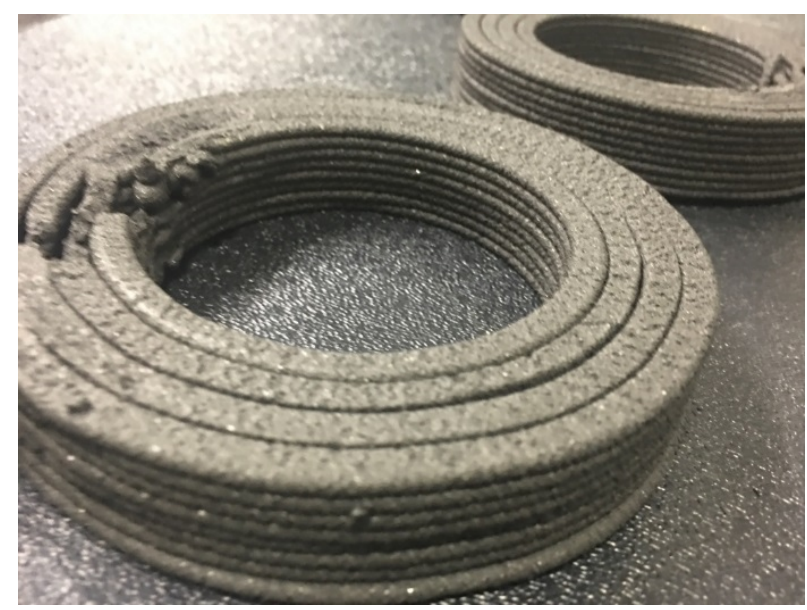

Figure 37: ORNL large scale printed magnets 


\subsection{HEAT EXCHANGERS}

Many of the benefits of AM stem from the ability to manufacture complex geometries. This ability lends itself very well to the manufacture and design of heat exchangers. Developments in AM-produced heat exchangers are accelerating. For example, Figure 38 displays some AM-produced or possible heat exchanger designs.
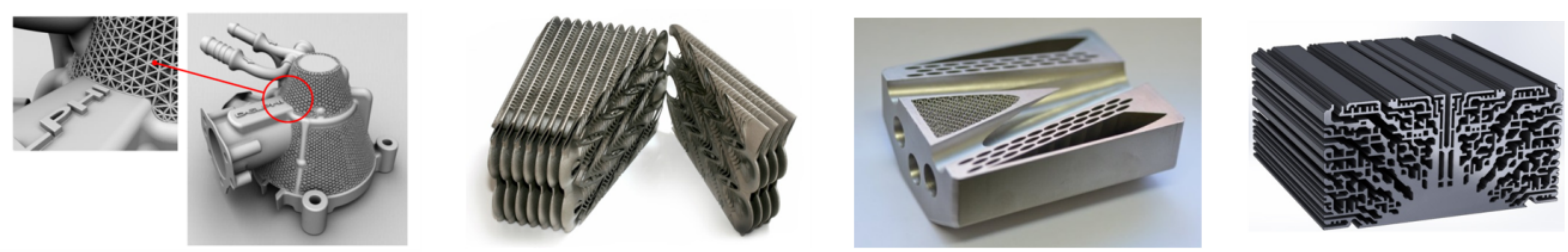

Figure 38; Examples of existing or potential AM-produced heat exchanger designs ${ }^{10}$

Recently a startup company based in Australia called Conflux developed an AM automotive heat exchanger that, Conflux claims, is half the weight of a conventional heat exchanger. Therefore, it is significantly more efficient and has a better operating performance. Conflux also claims that the design avoids flow restrictions with far more complex geometries than can be produced with subtractive manufacturing techniques of etching, bending/pressing, brazing, and welding. A prototype of the conflux design is illustrated in Figure 39.

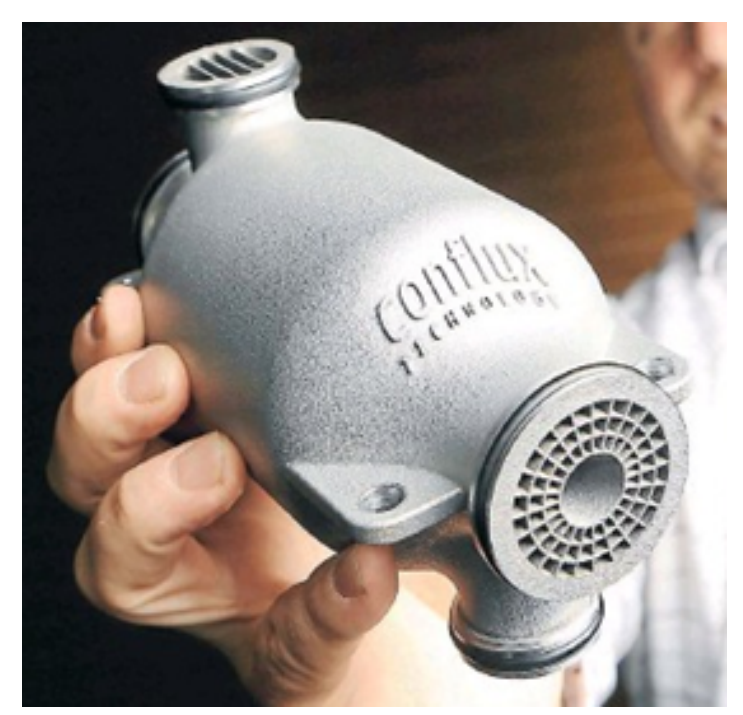

Figure 39: Compact heat exchanger design enabled by AM and produced by Conflux. [74]

Conflux says its heat exchanger design exhibits high area density with low pressure drop, resulting in a high rate of thermal exchange. The design also reduces the presence of unnecessary material that could not be removed using conventional techniques. Although this product is currently in the concept testing phase, the manufacturer claims that the design already exceeds current best performances despite the $50 \%$ weight reduction.

${ }^{10}$ Sources, left to right: [108],[109],[110],[111] 


\subsubsection{Micro Channels}

ORNL's research is also expanding the possibilities of AM heat exchangers. Recently, Patrick Geoghegan used AM to make microchannels in refrigerant heat exchangers [76]. The small-hole-diameter channels were possible only with AM, as the length/diameter ratio of the channels produced was not feasible in conventional manufacturing processes. The small-diameter design is compact and reduces the need for additional material and refrigerant, presenting a cost-effective and more environmentally friendly solution. The design consists of microchannel passages that reduce surface tension effects at small droplet sizes and cause the refrigerant to coat all sides of the microchannels, increasing the effective area for heat transfer. As a result, heat transfer rates are dramatically increased. Although this approach is being investigated for refrigeration, the fundamentals are applicable to wind turbine manufacturing. Another benefit of improved heat transfer is that the heat exchanger can be downsized to reduce weight and space requirements.

\subsection{REPAIR AND REMANUFACTURING}

While manufacturing new components garners the most interest, an immediate application of AM for turbine machinery may improve parts exposed to wear that eventually fail. Directed energy depositions systems are paired with subtractive machining to form hybrid systems. These systems are capable of growing material on a conventionally manufactured part and then subtractively machine the part to tolerance. This process affords opportunities for repair and remanufacturing of CM parts including, but not limited to, low-speed shafts and yaw components.

\subsection{FUTURE APPLICATIONS}

When discussing future applications of AM, it's prudent to understand the hype curve associated with a new technology (see

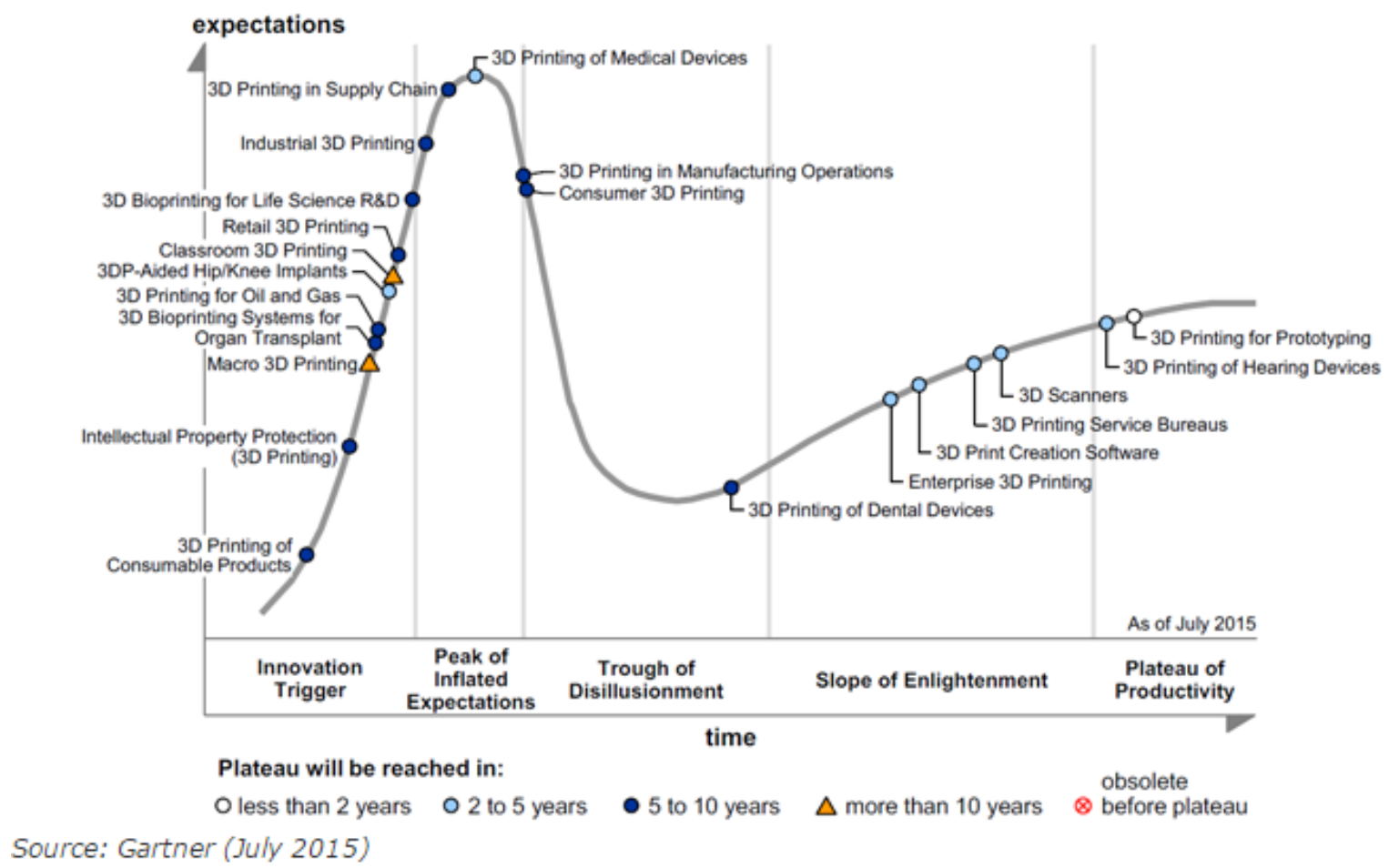


Figure 40). The curve provides a projection of the hype or excitement associated with a technology over time. With most technologies, there is the initial innovation trigger where a technology is rapidly evolving, and there is wide-spread projection of potential applications and impacts. After a few years, the hype peaks with irrational projections based on poor information about the true maturity of the technology. This transforms into a period of disillusionment because the reality of the limitations of the technology causes many of the overly optimistic projections to fall off. The final slope of enlightenment is where the true impact of the technology matches with rational applications. The AM hype curve shows that the primary mature applications of additive manufacturing are in the prototyping and biomedical industries. Another application that may be considered for the plateau of productivity is the tooling industry. AM is finding more and more industrial applications in the area of molds, jigs, and fixtures. The automotive, aerospace, and appliance industries are rapidly transitioning to printed tools because of the complexity, high cost, and long lead times associated with these parts.

Another area of particular interest to the wind industry is Macro 3D printing, which is shown in the curve. Macro 3D printing is large-scale 3D printing. It is still in its infancy - ten years from full maturity. However, this is the technology that has the greatest potential to impact the wind industry. This combination of immaturity and potential impact means that the wind industry can influence the technology in terms of requirements.

In terms of scale, there are new equipment manufacturers developing systems that are one to two orders of magnitude larger and faster than the current abilities of the Cincinnati BAAM. Ingersoll Machine Tool company announced the development of Wide High Additive Manufacturing (WHAM), see Figure 41 and Figure 42. The system will have a build volume that is approximately 25 feet wide, 20 feet tall, and in excess of 100 feet long and is scalable to much larger dimension. The production rate will start at 1,000 $\mathrm{lb} / \mathrm{hr}$ but is scalable to higher rates. This scale system enables the direct manufacture of parts (molds, blades, nacelles, etc.) that are competitive with current wind manufacturing needs.

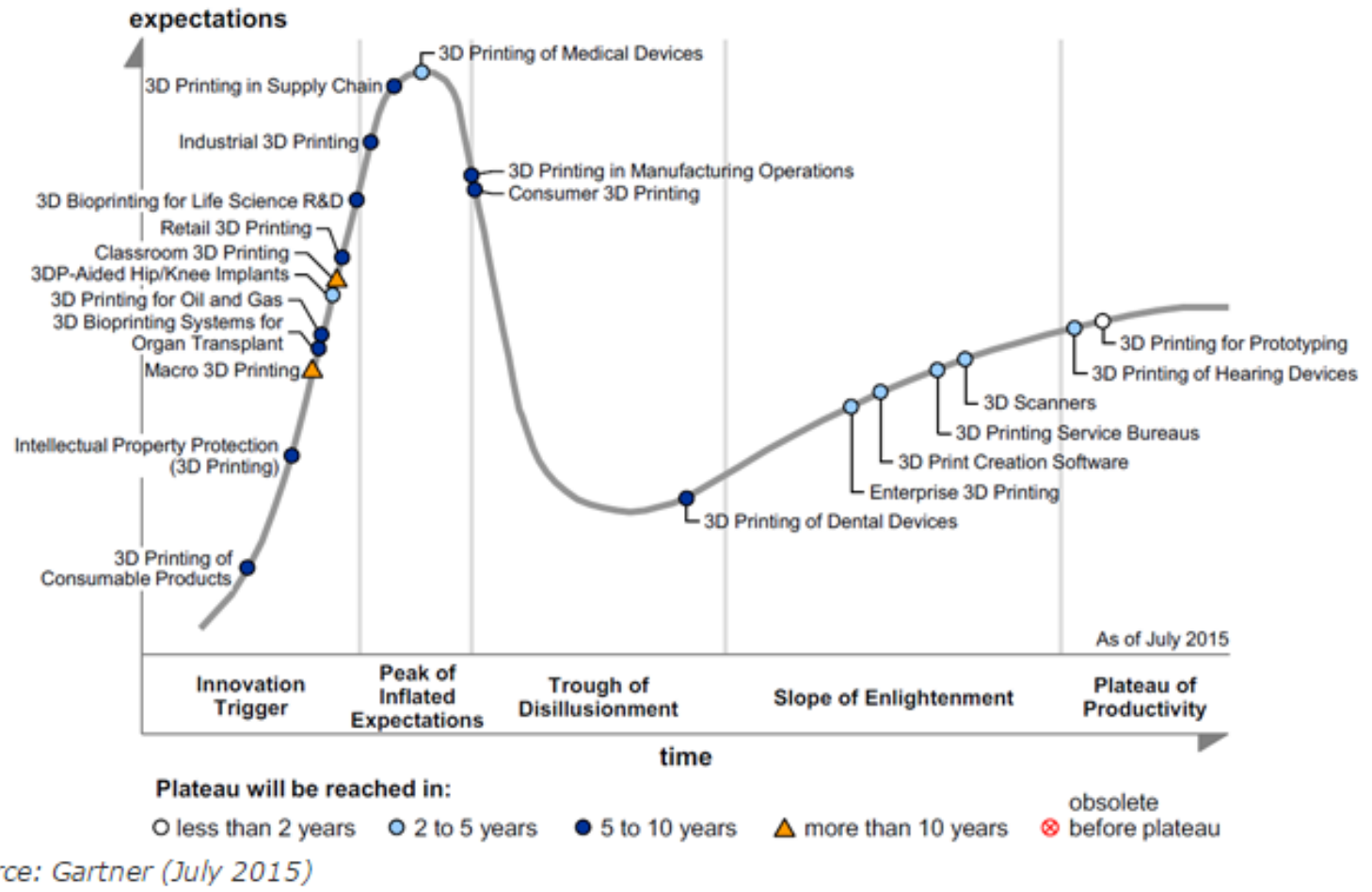

Figure 40: Additive Manufacturing Hype Curve 


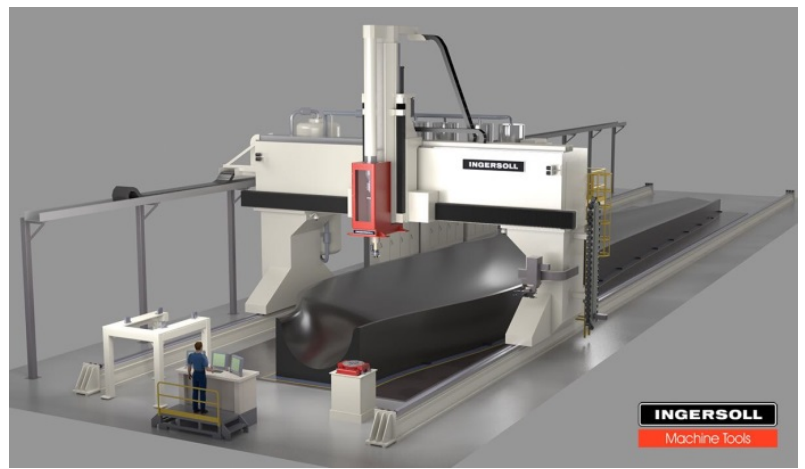

Figure 41: Front view WHAM

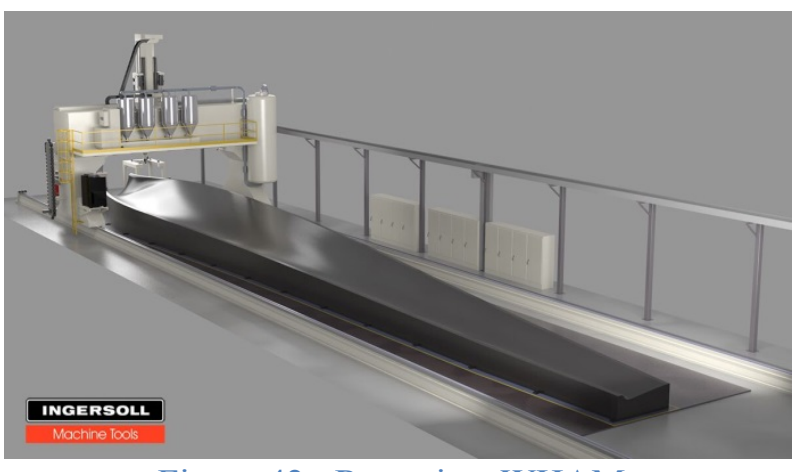

Figure 42: Rear view WHAM

In terms of applications, there is potential to directly manufacture wind turbine blades (see Figure 43). However, to do so will require innovations in the material and process. First, from the materials perspective, everything used to date is based on short chopped carbon fiber. These materials are ideal for tooling because of their high stiffness, but they do not have the strength needed for structures. There will be a need for long or continuous fiber reinforcement in order to directly manufacture wind turbine blades. In addition, to keep part weight down, there is a need to print core structures (such as foam) to achieve nearnet shape. Systems such as the WHAM will have the ability to print, machine, and coat all within one machining center. At rates of $1,000 \mathrm{lb} / \mathrm{hr}$ and greater, it is feasible to envision rapid automated manufacturing of customized wind turbine blades with multi-material (carbon fiber, glass fiber, foam, etc.) solutions.

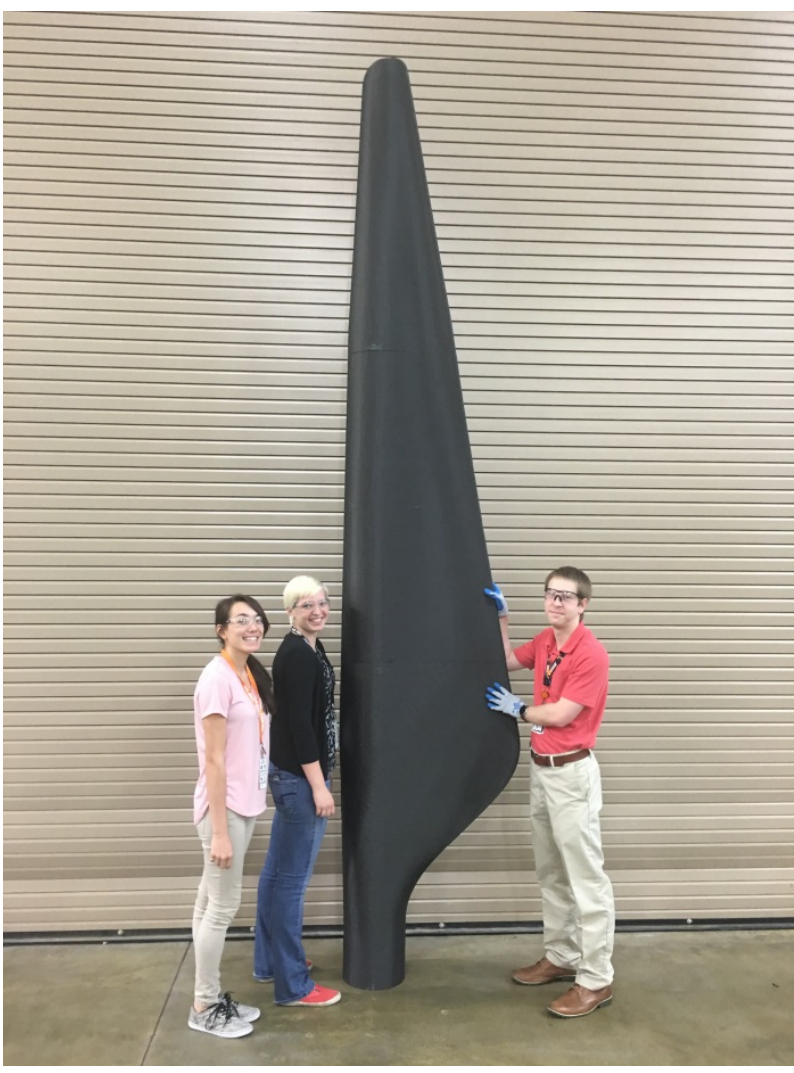

Figure 43: 3D printed wind turbine blade 
Another emerging technology is large-scale metal AM. Cranfield University has developed largescale wire and arc AM. This enables robotic welding of large structures. Large-scale metal AM could provide tremendous opportunities for the nacelle. The rotor and hub are generally very complex structures that need to be strong yet lightweight. Traditional manufacturing approaches require castings. The size of these structures severely limits the companies (and countries) that can produce large parts like this. Development of large-scale metal AM technologies will remove the manufacturing limitations and open up competition as well as enable the potential for local manufacturing.

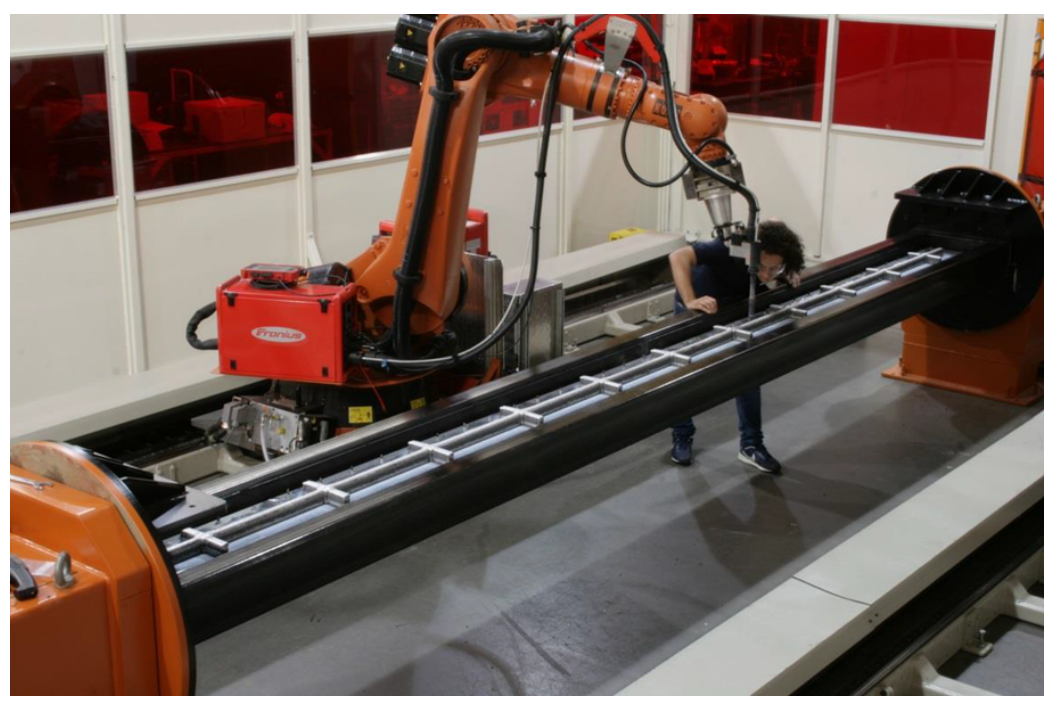

Figure 44: Cranfield University Large Scale Metal AM

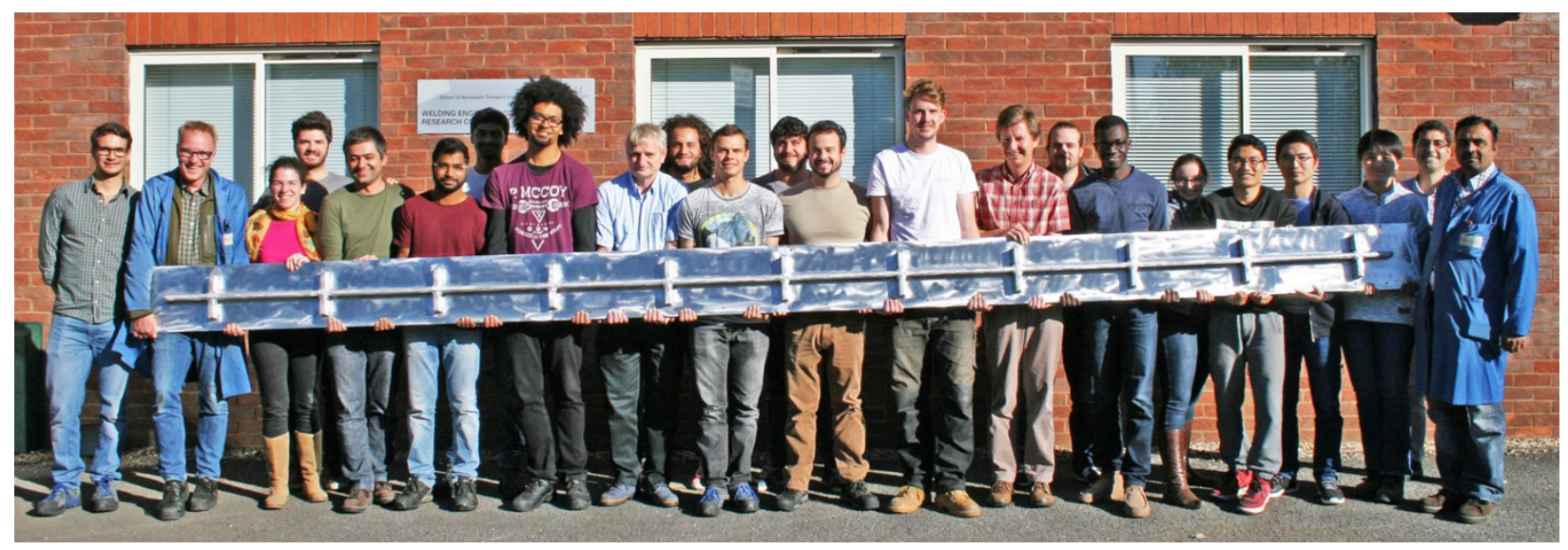

Figure 45: Cranfield University Large Scale Metal AM part 


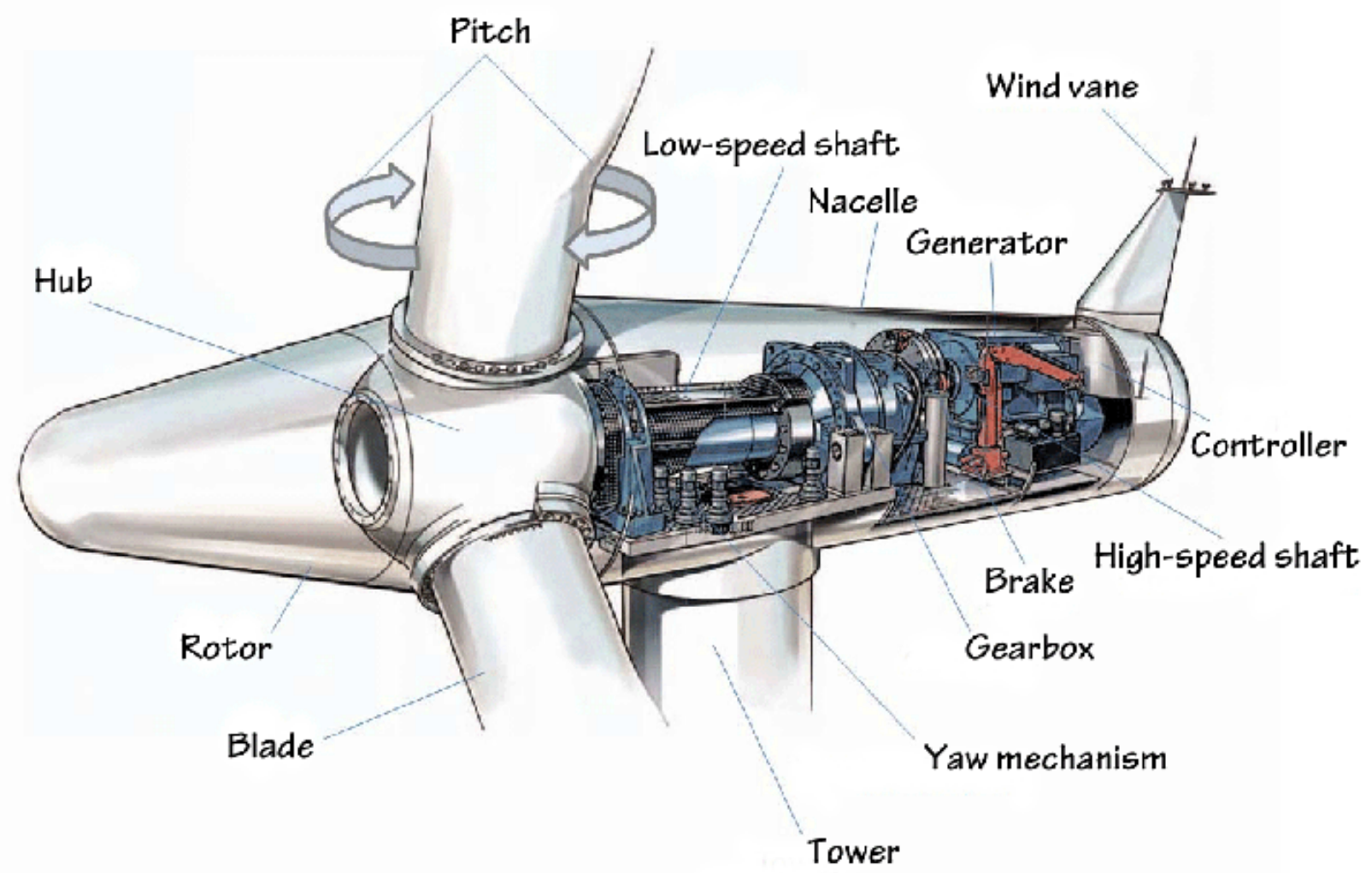

Figure 46: Wind turbine nacelle

(source: Center on Globalization, Governance and Competiveness, Duke University)

One final component that could be manufactured with new technologies is the tower. Figure 47 shows the construction of the St. Louis arch using cranes that moved with the structure. There is no reason to believe that the construction of the tower cannot be automated with additive systems that move 
with the structure. There are current research efforts focused on large-scale construction (see

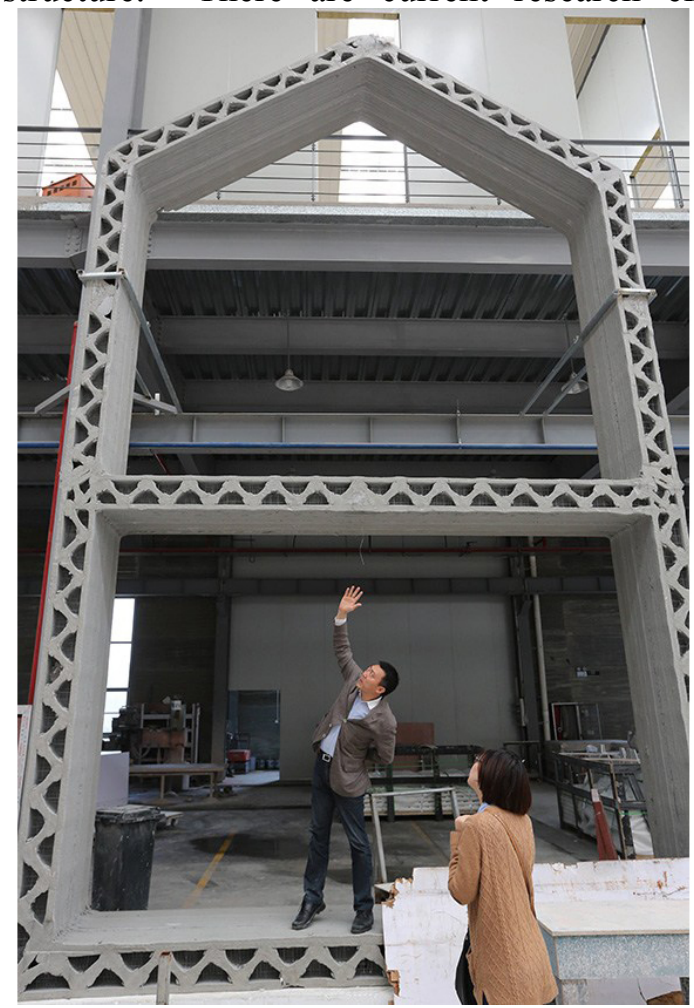

Figure48). This could open up new material options such as, fiber reinforced concrete that can be strong, durable, and inexpensive.

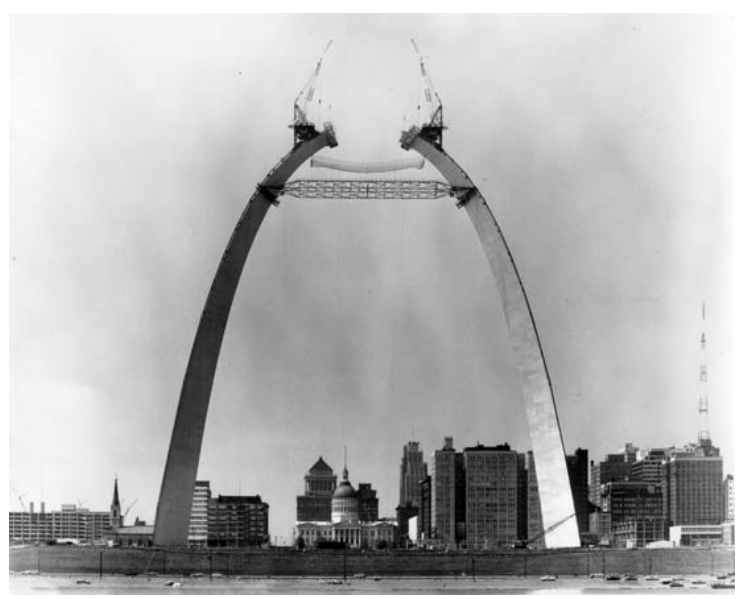

Figure 47: Construction of the St. Louis Arch 


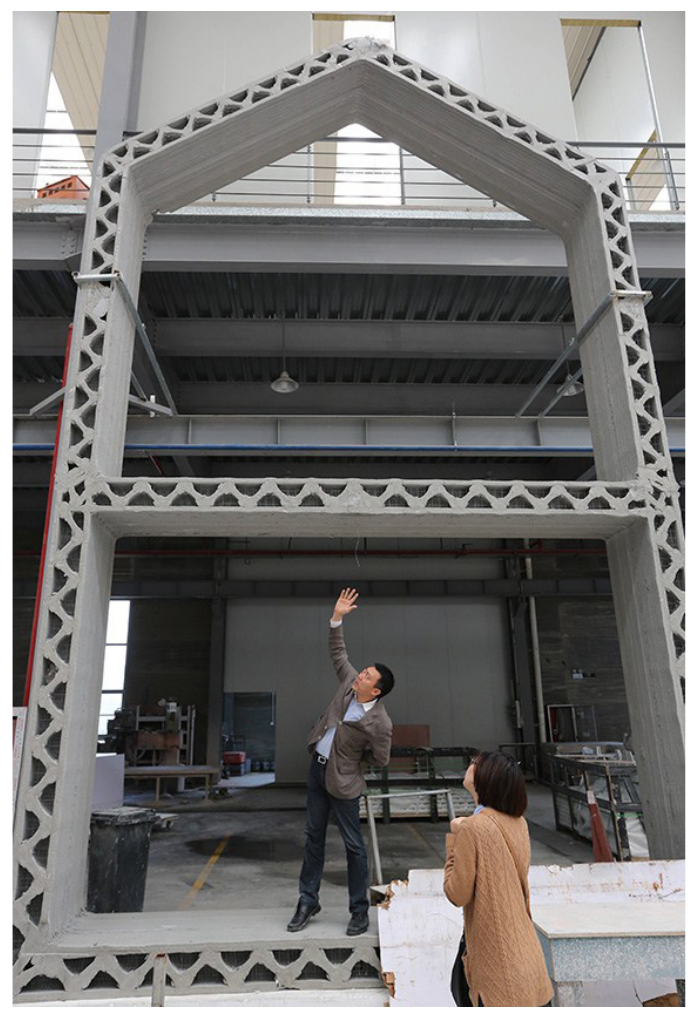

Figure48: 3D printed concrete house

Advancements in large-scale AM have the potential to revolutionize the wind industry. There needs to be advancements in materials and processes to optimize the opportunities of AM, but the technology is rapidly moving toward a scale, cost, and speed that matches the needs of the industry. However, one of the greatest changes could be the ability to manufacture on site. A typical wind turbine field has anywhere from 50 to 200 generators. Therefore, anywhere from 150 to 600 wind turbine blades, 50 to 200 nacelles, and towers must be transported from a factory to the field for assembly. A large portion of the cost of a wind turbine generator is transportation. This could be radically changed if it becomes possible to have local, on-site manufacturing. Consider Local Motor's microfactory (see Figure49). The future of large-scale AM could enable the development of mobile microfactories. The idea is that it will cost less to relocate the microfactories than it costs to move all the components across the country. 


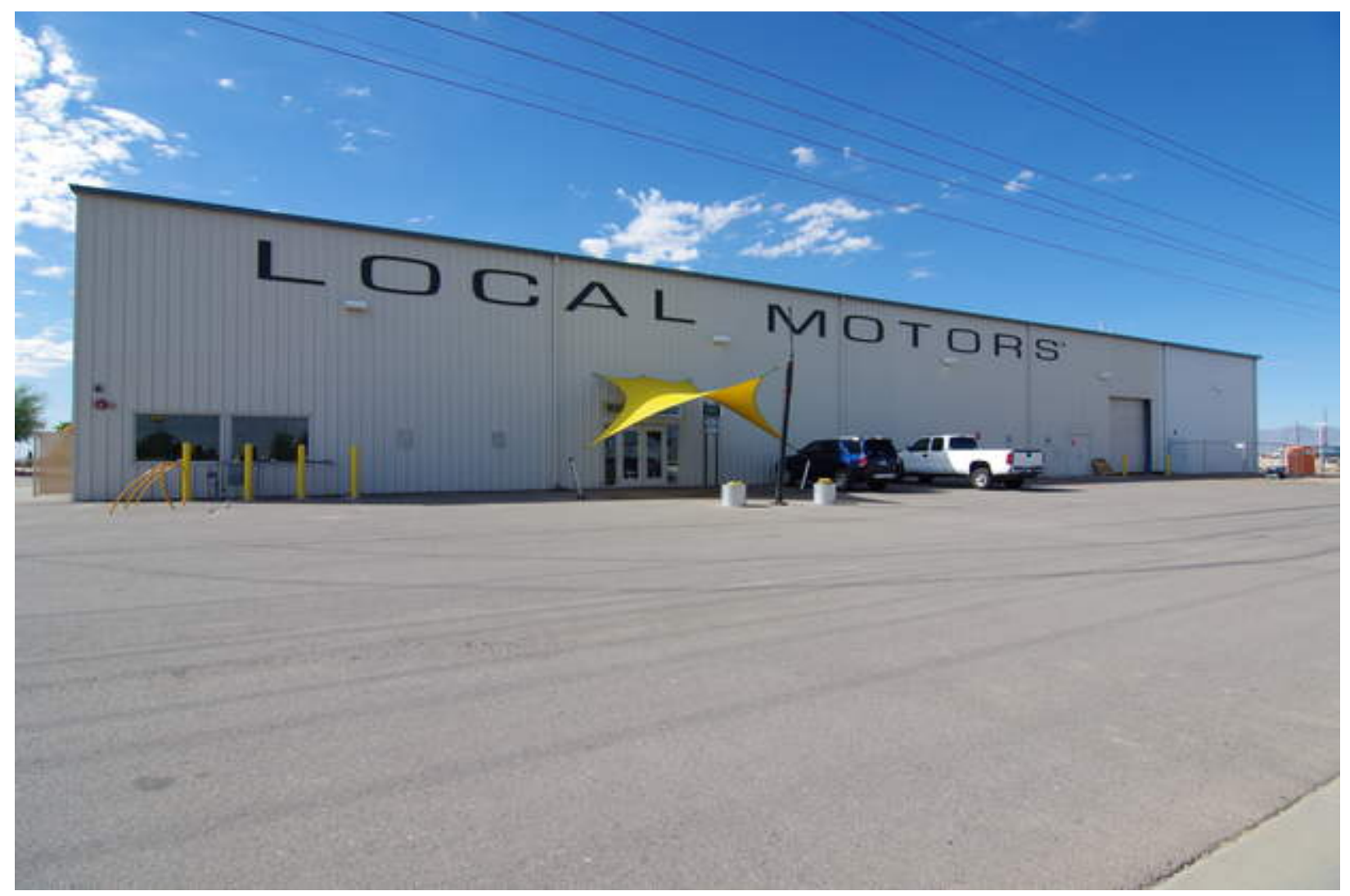

Figure 49: Local Motors microfactory

\section{SYNERGY WITH OTHER WIND OFFICE PROJECTS}

AM has the potential to enable a completely new type of wind plant where each wind turbine is optimally designed to fit highly-localized wind resource conditions as well as a performance profile optimized as part of a larger system-level wind plant optimization. DOE is currently funding a multi-year research initiative called Atmosphere to Electrons (A2e) [120,121] that could use AM processes and technologies. A2e is intended to understand the complex physics of wind plants and their interaction with the atmosphere. The program is working to quantify the opportunities of wind power plants and the use of innovative ways to maintain system reliability while enabling a low-cost grid. A main objective of A2e is to develop new strategies and technologies to limit wind farm losses and lower annual operating costs. The key to lowering the current levelized cost of wind energy (LCOE) could be improving the wind farm system configuration to take advantage of AM's design complexities for wind turbines components through customized installations and total part count reduction. Advances in science will allow us to design a virtual optimized wind plant for any given site that has variable turbines throughout the plant with different sized blades, generators, and hub heights. The implementation of this highly-customized SMART Wind Plant with active control of wind flow and precise assessment of energy production will reduce the cost of energy for wind plants to less than half of current costs. Current wind turbines operate independently. In the wind plant of the future, turbines will work collectively to maximize the energy produced by the entire system. 
Unfortunately, realization of this future SMART Wind Plant will not be possible with today's approaches to manufacturing, transportation, and installation of wind plants. Current approaches rely on manufacturing standardized components that are transported to a large-number of sites. Envisioned future wind plants will have very large turbine blades that could not be transported cost-efficiently and extremely tall towers that would be too large for transport over land. To overcome large transportation costs associated with future blade and tower technology and to enable the levels of customization envisioned with sitespecific turbine design, on-site manufacturing will be necessary and will likely require AM as well. For example, a highly optimized plant may have turbines with five or more different rotor sizes. Amortizing the cost of five different blade molds across the project (or perhaps several projects) would be prohibitively high. However, if pieces of the mold were interchangeable (i.e. only the outer span of the blade varied across the designs), then the costs could be spread more evenly and blades could be manufactured on-site - eliminating large transport costs and reducing amortization costs across the fleet.

While wind turbine OEM's continue to push the limits of conventional manufacturing, a future is envisioned for wind plant performance and cost that likely cannot be realized without on-site customized manufacturing processes. The A2e future SMART plant may not be possible without advances in manufacturing promised by AM.

Another key tool for modeling these wind plants of the future is the Wind-Plant Integrated System Design and Engineering Model (WISDEM). This is a tool designed by NREL to assess the LCOE for a wind plant. The software combines individual turbine costs and plant system installation costs with the energy production and financial modeling to understand the total cost of energy for the wind site.

The learnings from the A2e program and the CEMAC bottom up cost modeling for additively manufactured parts will be key inputs for the WISDEM tool to generate a detailed understanding of the critical cost variables and design improvement requirements of the wind farms of the future. Together these projects will help to identify the technological barriers of manufacturing, cost, and design for the future of wind energy generation. 


\section{REFERENCES}

[1] T. Wohlers, Terry; Gornett, in:, Wohlers Rep. 2014, Wohlers Associates, 2014, pp. 1-34.

[2] Smartech Marketing Publishing, Additive Manufacturing Opportunities in the Automotive Industry: A Ten-Year Forecast, Charlottesville, Va, 2014.

[3] Wohlers Associates, Wohlers Report 2015, Wohlers Associates, 2015.

[4] A.B. Spierings, N. Herres, G. Levy, Rapid Prototyp. J. 17 (2011) 195-202.

[5] X. Gong, T. Anderson, K. Chou, in:, ASME/ISCIE 2012 Int. Symp. Flex. Autom., ASME, St Louis, 2012, pp. 507-515.

[6] A. Butscher, M. Bohner, S. Hofmann, L. Gauckler, R. Milller, Acta Biomater. 7 (2011) 907-920.

[7] I. Gibson, D. Rosen, B. Stucker, Additive Manufacturing Technologies, Springer New York, New York, NY, 2015.

[8] ExOne, (2015).

[9] S.M. Gaytan, M.A. Cadena, H. Karim, D. Delfin, Y. Lin, D. Espalin, E. MacDonald, R.B. Wicker, Ceram. Int. 41 (2015) 6610-6619.

[10] M.P. Paranthaman, C.S. Shafer, A.M. Elliott, D.H. Siddel, M.A. McGuire, R.M. Springfield, J. Martin, R. Fredette, J. Ormerod, J. Miner. Met. Mater. Soc. (2016) 1-5.

[11] G. Manogharan, M. Kioko, C. Linkous, JOM 67 (2015) 660-667.

[12] D. Stevenson, in:, AM-Dagen 2013, Kistamässan, 2013, p. 44.

[13] MCE-5, Variable Compression Ratio Intelligent, Lyon, 2009.

[14] C. a. Brice, W.H. Hofmeister, Metall. Mater. Trans. A Phys. Metall. Mater. Sci. 44 (2013) $5147-$ 5153.

[15] M. Daymond, M. Johnson, J. Appl. Crystallogr. 34 (2001) 263-270.

[16] A.S. Wu, D.W. Brown, M. Kumar, G.F. Gallegos, W.E. King, Metall. Mater. Trans. A 45 (2014) 6260-6270.

[17] S.L.N. Ford, J. Int. Commer. Econ. (2014) 1-35.

[18] P.F. Jacobs, D.T. Reid, Computer, A.S.A. of SME., Rapid Prototyping \& Manufacturing: Fundamentals of Stereolithography, Society of Manufacturing Engineers, 1992.

[19] R.G. Zorrilla, 3D Print. (2013) 1-5.

[20] F. Catalano, GeekWire (2015) 1-2.

[21] G. Morris, (2015) 22.

[22] D.S. Thomas, Economics of the U.S. Additive Manufacturing Industry, 2013.

[23] Z. Simkin, A. Wang, in:, Wohlers Rep. 2014, 2014, pp. 1-6.

[24] J. Vanian, Fortune (2015) 1-5.

[25] T. Alexander, K. Hartley, IMTS Partn. Press Release (2014) 2.

[26] S. Curran, P. Chambon, R. Lind, L. Love, R. Wagner, S. Whitted, D. Smith, B. Post, R. Graves, C. Blue, J. Green, M. Keller, in:, SAE Tech. Pap., SAE International, 2016.

[27] W.D.C. Emmett J. Horton, Science (80-. ). 225 (1984) 587-593.

[28] H. Helms, U. Lambrecht, Int. J. Life Cycle Assess. 12 (2007) 58-64.

[29] C. Woodyard, USA Today (2015) 2.

[30] E. Chhabra, Forbes (2015) 5.

[31] B.B. Millsaps, 3DPrint.com (2016) 3-7.

[32] M. Mcleod, Des. Eng. (2014) 2-3.

[33] Oak Ridge National Laboratory, Flickr (2015) 1.

[34] A. George, Wired (2014) 2.

[35] N. Carlson, B.L. Stoner, Thermal Barrier Coating on High Temperature Industrial Gas Turbine Engines, Cleveland, OH, 1977.

[36] K.L. Hoag, M.C. Brands, W. Bryzik, in:, SAE Tech. Pap., SAE International, 1985.

[37] T.M. Yonushonis, Barrier For Diesel Components Coatings Energy Conservation and Renewable Office of Propulsion Systems, Cleveland, OH, 1991. 
[38] D.R. Clarke, and C.G. Levi, Annu. Rev. Mater. Res. 33 (2003) 383-417.

[39] R.J. Primus, K.L. Hoag, P.F. Flynn, M.C. Brands, in:, SAE Tech. Pap., SAE International, 1984.

[40] T.M. Yonushonis, J. Therm. Spray Technol. 6 (n.d.) 50-56.

[41] TACOM, (1984).

[42] TACOM, (1991).

[43] P.C. Becker, Heavy Vehicle Propulsion Materials FY 2004 Progress Report, Oak Ridge, TN, 2004.

[44] I. Automation Creations, MatWeb (2016).

[45] D.C. Hofmann, S. Roberts, R. Otis, J. Kolodziejska, R.P. Dillon, J. Suh, A. a Shapiro, Z.-K. Liu, J.-P. Borgonia, Sci. Rep. 4 (2014) 5357.

[46] J. Benatmane, Environment Report for Delphi Pump Housing, London, 2010.

[47] D.E. Cooper, M. Stanford, K.A. Kibble, G.J. Gibbons, Mater. Des. 41 (2012) 226-230.

[48] E. Atzeni, A. Salmi, Int. J. Adv. Manuf. Technol. 62 (2012) 1147-1155.

[49] F. Coenen, Vraagenaanbod.nl (2016) 6416.

[50] B. Ozpineci, in:, IEEE Transp. Electrif. Conf., Dearborn, MI, 2015, p. 28.

[51] M. Millikin, Green Car Congr. (2014) 3.

[52] Vehicle Technologies Office, Electric Drive Technologies 2015 Annual Report, Washington, DC, 2016.

[53] T.L. Bergman, A.S. Lavine, F.P. Incropera, Fundamentals of Heat and Mass Transfer, 7th Edition, John Wiley \& Sons, Incorporated, 2011.

[54] S.K. Waye, in:, 2014 DOE Hydrog. Fuel Cells Progr. Veh. Technol. Off. Annu. Merit Rev. Peer Eval. Meet., NREL, Arlington, VA, 2014, p. 32.

[55] R.R. Dehoff, M.M. Kirka, W.J. Sames, H. Bilheux, A.S. Tremsin, L.E. Lowe, S.S. Babu, Mater. Sci. Technol. 31 (2015) 931-938.

[56] Y. Zhou, X. Zhou, Q. Teng, in:, Solid Free. Fabr. Symp., 2015, pp. 81-87.

[57] Y. Li, D. Gu, Mater. Des. 63 (2014) 856-867.

[58] G.P. Dinda, a. K. Dasgupta, J. Mazumder, Mater. Sci. Eng. A 509 (2009) 98-104.

[59] H.L. Wei, J. Mazumder, T. DebRoy, Sci. Rep. 5 (2015) 16446.

[60] J.A. Bennett, J.G. Weinberg, J. Res. Natl. Bur. Stand. (1934). 52 (1954) 235-245.

[61] a. Maiti, G.D. Mahan, S.T. Pantelides, Solid State Commun. 102 (1997) 517-521.

[62] C.-W. Nan, R. Birringer, Phys. Rev. B 57 (1998) 8264-8268.

[63] F.J. DiSalvo, Science 285 (1999) 703-706.

[64] A.I. Gridnev, V.S. Rastegaev, I.P. Stadnik, in:, IEEE Trans. Magn., Valdimir, Russia, 1989, pp. 3896-3898.

[65] S. Lopez, B. Cassoret, J.F. Brudny, L. Lefebvre, J.N. Vincent, IEEE Trans. Magn. 45 (2009) 4161-4164.

[66] Y. El-Ibiary, IEEE Trans. Ind. Appl. 39 (2003) 1205-1210.

[67] T. Mukherjee, J.S. Zuback, A. De, T. DebRoy, Sci. Rep. 6 (2016) 19717.

[68] M. Nakada, Tribol. Int. 27 (1994) 3-8.

[69] O. Cansizoglu, O. Harrysson, D. Cormier, H. West, T. Mahale, Mater. Sci. Eng. A 492 (2008) 468-474.

[70] M. Angel, R. Belmonte, C.D. Copeland, D. Hislop, G. Hopkins, A. Schmieder, S. Bredda, S. Akehurst, (2015).

[71] M. Hoshi, Tribol. Int. 17 (1984) 185-189.

[72] Fit Production, CASE STUDY Futuristic Design Now: CYLINDER HEAD, Lupburg, Germany, 2015.

[73] S. Shih, E. Itano, J. Xin, M. Kawamoto, Y. Maeda, in:, SAE Tech. Pap., SAE International, 2003.

[74] J. Elder, Sydney Morning Her. (2015) 2.

[75] Navistar, Navistar MaxxForce 13 Engine Update, 2013.

[76] C. Samoray, ORNL News (2015) 2.

[77] E. Samei, (2012) 52. 
[78] T.J. Toops, C.E.A. Finney, E.J. Nafziger, D. Splitter, M. DeBusk, A. Pawlowski, in:, 2015 DOE Hydrog. Fuel Cells Progr. Veh. Technol. Off. Annu. Merit Rev. Peer Eval. Meet., Arlington, VA, 2015, p. 30.

[79] A. Heinrich, Gizmag (2016) 1-2.

[80] N. Savage, IEEE Spectr. (2016) 2-3.

[81] H. Jääskeläinen, DieselNet Technol. Guid. (2007).

[82] A.E. Jakus, S.L. Taylor, N.R. Geisendorfer, D.C. Dunand, R.N. Shah, Adv. Funct. Mater. (2015) 6985-6995.

[83] M. Millikin, Green Car Congr. (2013) 6.

[84] /Drive, The 3D Printed Variable Turbo - /INSIDE KOENIGSEGG, Youtube, United States, 2014.

[85] C. V. Koenigsegg, Turbine Housing for a Supercharger, 8,807,929 B2, 2014.

[86] A.B. Kair, K. Sofos, (2014) 1-123.

[87] J. Kech, R. Hegner, T. Männle, Turbocharging : Key Technology for High-Performance Engines, 2011.

[88] A. Pawlowski, D. Splitter, SAE Tech. Pap. (2015).

[89] X. Wu, Intermetallics 14 (2006) 1114-1122.

[90] T. Tetsui, Y. Miura, Mitsubishi Heavy Ind. Ltd. Tech. Rev. 39 (2002) 1-5.

[91] K. Maki, A. Ehira, M. Sayashi, T. Sasaki, T. Noda, M. Okabe, S. Isobe, in:, Society of Automotive Engineers, Inc., Warrendale, PA (United States), 1996.

[92] D. Cormier, H. West, O. Harrysson, K. Knowlson, in:, Solid Free. Fabr. Symp., Austin, TX, 2004, pp. 440-447.

[93] S. Biamino, B. Kloden, T. Weibgarber, B. Kieback, U. Ackelid, in:, Fraunhofer Direct Digit. Manuf. Conf., 2014, pp. 27-34.

[94] M. Burkinshaw, Cummins Technol. News (2016) 3.

[95] D. Splitter, A. Pawlowski, R. Wagner, Front. Mech. Eng. 1 (2016).

[96] U.S. Department of Energy (DOE), (2013).

[97] J.O. Andersson, T. Helander, L. Höglund, P.F. Shi, B. Sundman, Thermo-Calc and DICTRA, Computational Tools for Materials Science, Calphad, 2002.

[98] G.E. Moore, Underst. Moore's Law Four Decad. Innov. (2006) 67-84.

[99] D. Johnston, Lawerence Livermore Natl. Lab. (2015) 1-3.

[100] LPW Technology, (2015) 1.

[101] D. Koeberlein, in:, 2015 DOE Hydrog. Fuel Cells Progr. Veh. Technol. Off. Annu. Merit Rev. Peer Eval. Meet., Arlington, VA, 2015, p. 30.

[102] O. Delgado, N. Lutsey, The U.S. SuperTruck Program, Washington, DC, 2014.

[103] P. Reeves, in:, Insid. 3D Print. New York, New York, 2013.

[104] Vehicle Technologies Office, Electric Drive Technologies 2014 Annual Report, Washington, DC, 2015.

[105] A. Kaya, M. Lazova, S. Lecompte, M. De Paepe, in:, ICR2015, Proc., 2015.

[106] M.A. Reyes Belmonte, C.D. Copeland, D. Hislop, G. Hopkins, A. Schmieder, S. Bredda, S. Akehurst, SAE Tech. Pap. (2015).

[107] H.B. Larsen, Silicon Val. Tech Talk (2016) 4-7.

[108] C.A. Giffi, B. Gangula, P. Illinda, 3D Opportunity for the Automotive Industry, 2014.

[109] Autodesk Within, Autodesk Within (2011) 2.

[110] TCT Magazine, TCT Mag. (2014) 2.

[111] R. Bornoff, J. Parry, Annu. IEEE Semicond. Therm. Meas. Manag. Symp. 2015-April (2015) 303308.

[112] Exothermia, (2014) 1.

[113] Holshouser, C., C. Newell, S. Palas, L. J. Love, V. Kunc, R. F. Lind, P. D. Lloyd, J. C. Rowe, C. A. Blue and C. E. Duty (2013). "Out of bounds additive manufacturing." Advanced Materials and Processes 171(3). 
[114] Love, L. J., V. Kunc, O. Rios, C. E. Duty, A. M. Elliott, B. K. Post, R. J. Smith and C. A. Blue (2014). "The importance of carbon fiber to polymer additive manufacturing." Journal of Materials Research 29(17): 1893-1898.

[115] Monzon, M., , Gibson, I., Benitez, A., Lorenzo, L., Hernandez, P., Marrero, M. (2013). "Process and material behavoir modeling for a new desig of micro-additive fused deposition." International Journal of Manufacturing Technology 67: 2217-2726.

[116] Salmi, E. A. a. A. (2012). "Economics of Additive Manufacturing for End-Use Metal Parts." International Journal of Advanced Manufacturing Technology: 1147-1155.

[117] Tekinalp, H. L., V. Kunc, G. M. Velez-Garcia, C. E. Duty, L. J. Love, A. K. Naskar, C. A. [118] Blue and S. Ozcan (2014). "Highly oriented carbon fiber-polymer composites via additive manufacturing." Composites Science and Technology 105: 144-150.

[119] Wohlers, T. (2015). Wohlers Report 2015. Fort Collins, Wohlers Associates, Inc.

[120] Hammond, S.W., M. A. Sprague, D. Womble, M. Barone (2015). A2e High Fidelity Modeling: Strategic Planning Meetings. SNL Report SAND2015-9499.

[121] Keller J. and C. Westergaard (2015). Atmosphere to Electrons: Update on Strategic Plan for Wind Plant Reliability. NREL Report NREL/PR-5000-63872. 
APPENDIX A. DATA AND ASSUMPTIONS FOR AM MOLD COST ANALYSIS

Source: Brian Post, ORNL

\begin{tabular}{|c|c|c|c|c|c|c|c|}
\hline \multirow[b]{2}{*}{ Material Parameters } & \multirow[t]{2}{*}{ Units } & \multirow[t]{2}{*}{13 meter Current } & \multicolumn{3}{|c|}{ Swift machine used for 50 meter mold } & \multirow{2}{*}{$\begin{array}{c}\text { Ingersoll I } \\
\text { Midterm }\end{array}$} & \multirow{2}{*}{$\begin{array}{c}\text { Ingersoll II } \\
\text { Future } \\
\end{array}$} \\
\hline & & & Low Cost & Average Scenario & High Cost & & \\
\hline Material Cost & $(\$ / \mathrm{kg})$ & $\$ 9.55$ & $\$ 0.99$ & $\$ 4.43$ & $\$ 9.83$ & $\$ 4.41$ & $\$ 2.20$ \\
\hline Material Density & $(\mathrm{kg} / \mathrm{m} 3)$ & 1,140 & 1,000 & 1,200 & 1,140 & 1,200 & 1,200 \\
\hline Length & $\mathrm{m}$ & 13 & 50 & 50 & 50 & 50 & 50 \\
\hline Max Build Size & $\mathrm{m}$ & 1.83 & 1.83 & 1.83 & 1.83 & 55 & 55 \\
\hline Molds Manufactured Per Year (Min/Full Utilization) & unit & $2 / 50$ & $2 / 4$ & $2 / 4$ & $2 / 4$ & $2 / 48$ & $2 / 52$ \\
\hline \multicolumn{8}{|l|}{ Labor } \\
\hline Set up time & hr/build & 2 & 2 & 2 & 2 & 10 & 10 \\
\hline Finishing Time/ section & $\mathrm{m} 2 / \mathrm{hr}$ & 0.493 & 0.493 & 0.493 & 0.493 & 0.493 & 0.493 \\
\hline Finishing Time & $\mathrm{hr} / \mathrm{m} 2$ & 10 & 10 & 10 & 10 & 10 & 10 \\
\hline Assembly Time & hr/section & 4 & 4 & 4 & 4 & 4 & 4 \\
\hline Design Time & $\mathrm{hr}$ & 40 & 40 & 40 & 40 & 40 & 40 \\
\hline Cutting rate & $\mathrm{m} 2 / \mathrm{hr}$ & 0.2 & 0.2 & 0.2 & 0.2 & 0.2 & 0.2 \\
\hline \multicolumn{8}{|l|}{ Energy } \\
\hline Energy Requirement to Heat & $\mathrm{W} / \mathrm{m} 2$ & 3255 & 3255 & 3255 & 3255 & 3255 & 3255 \\
\hline Pre-processing energy requirement & $\mathrm{hr}$ & 2 & 2 & 2 & 2 & 2 & 2 \\
\hline \multicolumn{8}{|l|}{ Facilities } \\
\hline Production Floor Space & $\mathrm{m} 2$ & 488 & 1780 & 1780 & 1780 & 1780 & 1780 \\
\hline Production Floor Price & $\$ / \mathrm{m} 2$ & 1500 & 1500 & 1500 & 1500 & 1500 & 1500 \\
\hline \multicolumn{8}{|l|}{ Tool } \\
\hline Machine Cost & $\$$ & $1,500,000$ & $\$ 75,000$ & $1,500,000$ & $\$ 2,000,000$ & $\$ 11,250,000$ & $\$ 7,500,000$ \\
\hline Heater Cost & $\$$ & 2,217 & $\$ 1,194$ & 2,217 & 3,410 & 22,166 & 22,166 \\
\hline Production Speed & $\mathrm{kg} / \mathrm{hr}$ & 36.4 & 13.6 & 36.4 & 45.5 & 453.6 & 453.6 \\
\hline Downtime & $\%$ & $10 \%$ & $5 \%$ & $10 \%$ & $20 \%$ & $10 \%$ & $1 \%$ \\
\hline
\end{tabular}




\begin{tabular}{|l|c|c|c|c|c|c|}
\hline Typical Manufactured Part Yield & $\%$ & $90 \%$ & $99 \%$ & $90 \%$ & $50 \%$ & $80 \%$ \\
\hline Number of build sections & units & 18 & 60 & 60 & $60 \%$ & 1 \\
\hline
\end{tabular}

Modeling Assumptions Units

Tool Installation

\begin{tabular}{|l|r|}
\hline$\%$ & $10 \%$ \\
\hline$\%$ & $5 \%$ \\
\hline years & 7 \\
\hline years & 20 \\
\hline$\%$ & $12 \%$ \\
\hline
\end{tabular}

\begin{tabular}{|l|l|r|}
\hline Building Deprecations & years & 20 \\
\hline SG\&A Expense & $\%$ & $12 \%$ \\
\hline
\end{tabular}

